University of Louisville

ThinkIR: The University of Louisville's Institutional Repository

Electronic Theses and Dissertations

$5-2021$

\title{
Saving butterflies in the city: gardens as conservation spaces in urban landscapes.
}

Lindsay D. Nason

University of Louisville

Follow this and additional works at: https://ir.library.louisville.edu/etd

Part of the Other Ecology and Evolutionary Biology Commons

\section{Recommended Citation}

Nason, Lindsay D., "Saving butterflies in the city: gardens as conservation spaces in urban landscapes." (2021). Electronic Theses and Dissertations. Paper 3643.

https://doi.org/10.18297/etd/3643

This Doctoral Dissertation is brought to you for free and open access by ThinkIR: The University of Louisville's Institutional Repository. It has been accepted for inclusion in Electronic Theses and Dissertations by an authorized administrator of ThinkIR: The University of Louisville's Institutional Repository. This title appears here courtesy of the author, who has retained all other copyrights. For more information, please contact thinkir@louisville.edu. 
SAVING BUTTERFLIES IN THE CITY: GARDENS AS CONSERVATION SPACES

IN URBAN LANDSCAPES

\author{
By \\ Lindsay D. Nason \\ B.S., University of Louisville, 2015
}

\begin{abstract}
A Dissertation
Submitted to the Faculty of the

in Partial Fulfillment of the Requirements

for the Degree of

Doctor of Philosophy in

Biology

Department of Biology

University of Louisville

Louisville, Kentucky
\end{abstract}

College of Arts and Sciences of the University of Louisville

May 2021 

SAVING BUTTERFLIES IN THE CITY: GARDENS AS CONSERVATION SPACES

IN URBAN LANDSCAPES

\author{
By \\ Lindsay D. Nason \\ B.S., University of Louisville, 2015
}

A Dissertation Approved on

April 15, 2021

By the Following Dissertation Committee:

\begin{tabular}{c}
\hline Dr. Perri Eason \\
\hline Dr. Margaret Carreiro \\
\hline Dr. James Alexander \\
\hline Dr. Gary Cobbs \\
\hline
\end{tabular}

Dr. Lynne Rieske-Kinney 


\section{ABSTRACT \\ SAVING BUTTERFLIES IN THE CITY: GARDENS AS CONSERVATION SPACES IN URBAN LANDSCAPES}

Lindsay D. Nason

April 15, 2021

Butterfly populations are declining, and habitat degradation due to urbanization is a major contributing factor. Gardens represent a large proportion of land area in many cities, and thus may be important for conserving butterflies in urban environments. In this dissertation, I examine how garden features (ex: size, level of urbanization, plant diversity) affect adult butterfly diversity/abundance, behavior, and the predation risk faced by caterpillars. My study sites were native plant gardens in Jefferson, Bullitt, and Hardin Cos.,KY. In Chapter One, I used clay caterpillars to assess differences in predation pressure in gardens along a gradient of percent impervious surface (\%IS). I glued clay caterpillars to plant leaves at 24 gardens in both July and October 2017, then assessed them for damage. $97 \%$ of damage was attributable to parasitoid wasps, spiders, ants, vertebrates, and predatory wasps. Overall attack rate declined significantly with increasing \% IS and plant species richness (plantR). The attack rate by each predator type responded differently to \%IS and plant biovolume density (BVD). 
In Chapter Two, I surveyed adult butterflies at 26 gardens from May-October 2018, to evaluate how garden characteristics influence butterfly diversity and abundance. Butterfly species richness (BSR) significantly increased as garden size increased. BSR was also affected by an interaction between \%IS and plantR. BSR increased with increasing plantR, and this effect was stronger when \%IS was high. Butterfly abundance was affected by multiple interactions, including \%IS with garden area, and \%IS with BVD. Butterfly abundance increased with increasing garden size and BVD, particularly when \%IS was high. The proportion of larval host-specialist species I recorded declined as \%IS, but increased when both garden size and plantR increased together.

In Chapter Three, I recorded the flight/feeding behaviors of cabbage white butterflies (Pieris rapae) to determine if urbanization affects butterfly behavior. I conducted behavioral trials at 6 urban and 6 rural gardens in July-October 2019. Butterflies released in urban gardens spent more time actively flying and/or feeding from flowers than butterflies in rural gardens. They also flew more tight turns, even when they did not feed from flowers, indicating more intensive searching behavior in urban gardens. 


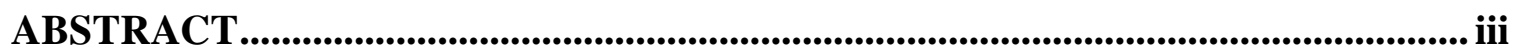

LIST OF TABLES ............................................................................................................. vii

LIST OF FIGURES ....................................................................................................................... viii

INTRODUCTION

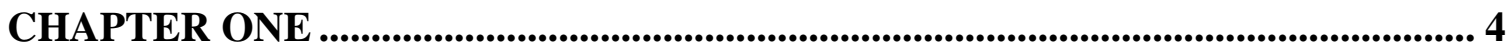

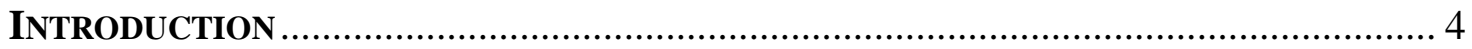

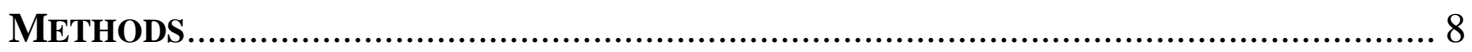

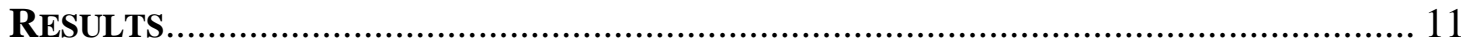

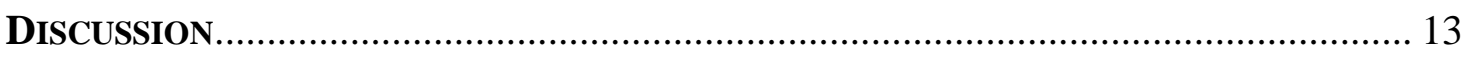

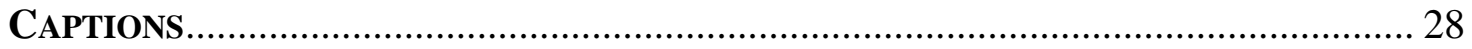

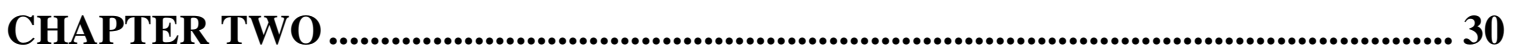

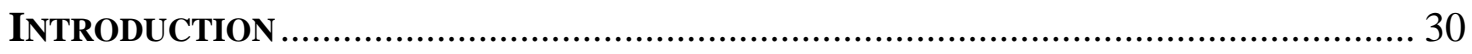

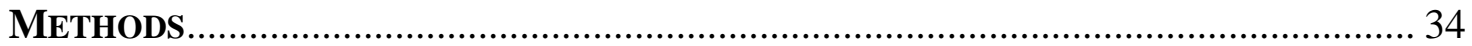

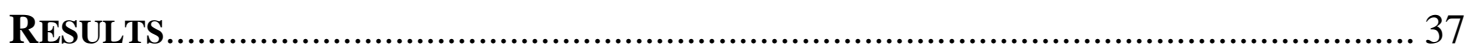

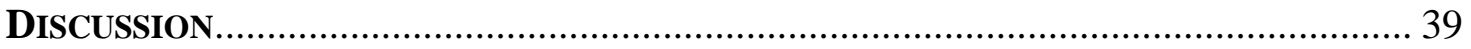

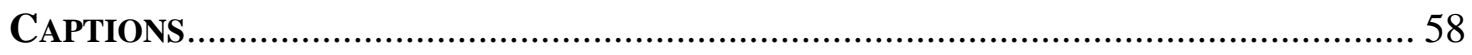

CHAPTER THREE .......................................................................................................... 60 


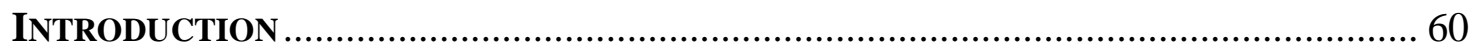

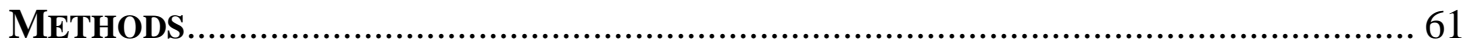

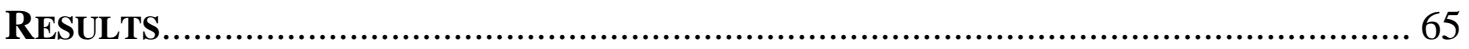

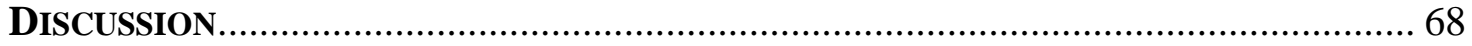

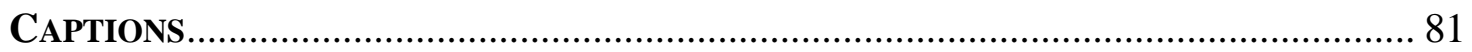

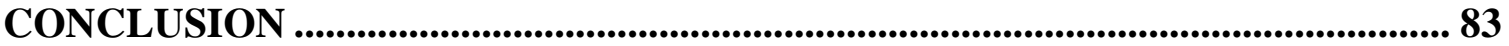

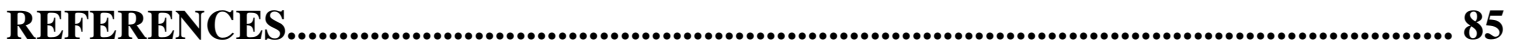

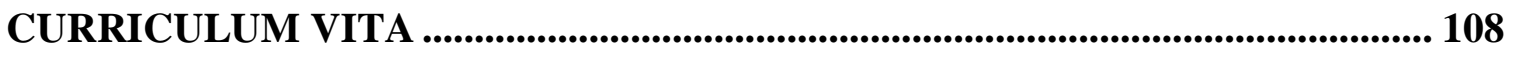




\section{LIST OF TABLES}

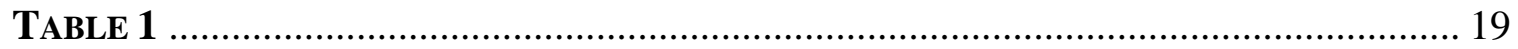

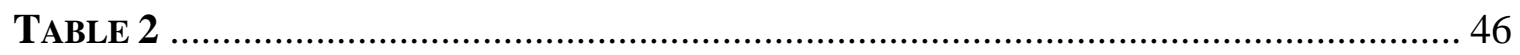

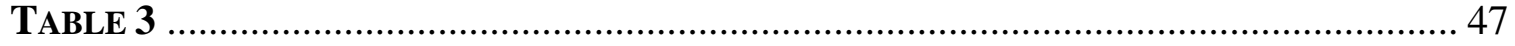

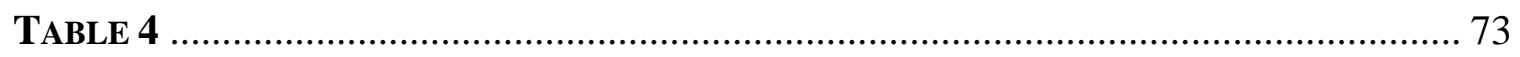

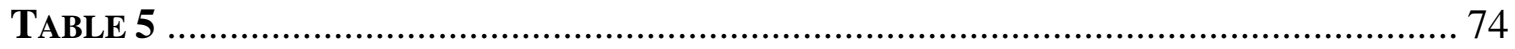




\section{LIST OF FIGURES}

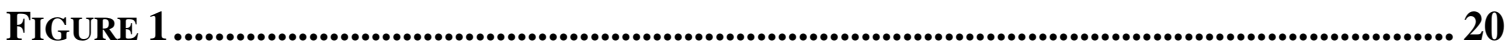

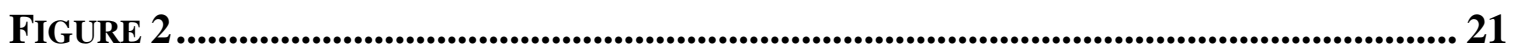

FIGURE 3 .......................................................................................................................... 22

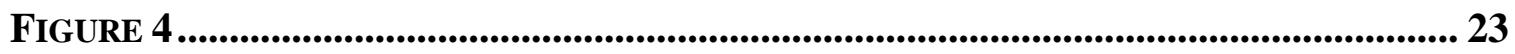

FIGURE 5 ................................................................................................................................ 24

FIGURE 6

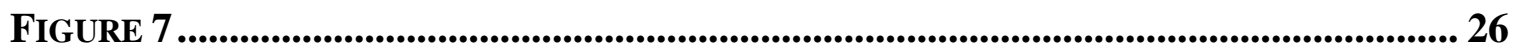

FIGURE 8

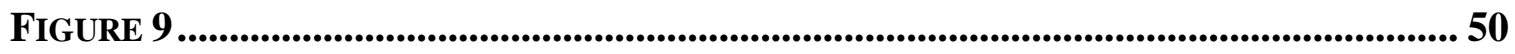

FIGURE 10 ........................................................................................................................ 51

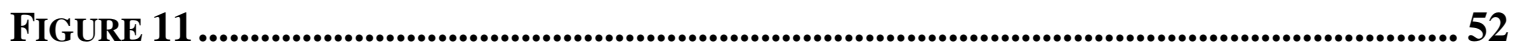

FIGURE 12 .................................................................................................................. 53

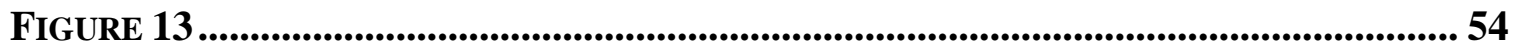

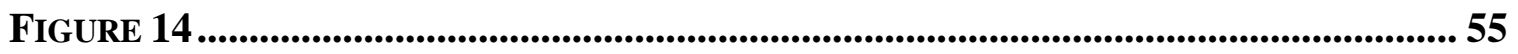

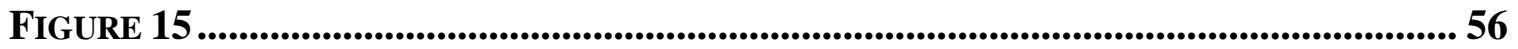

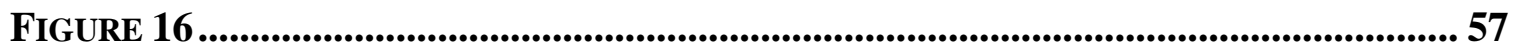

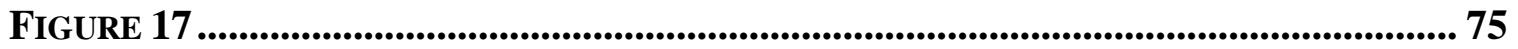

FIGURE 18 ................................................................................................................... 76

FIGURE 19............................................................................................................................... 77 


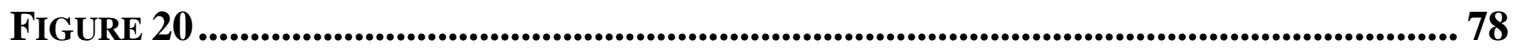

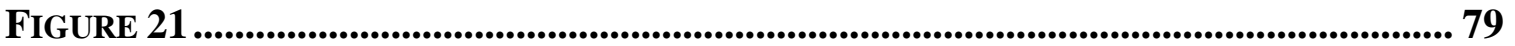

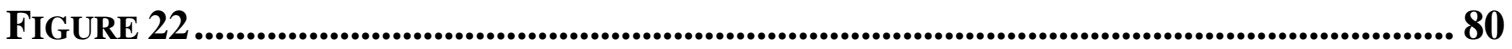




\section{INTRODUCTION}

Urban landscapes are the fastest growing type of habitat across the world. In the United States alone, urban land use has increased substantially over the last four decades. Urban habitats have been found to be highly detrimental to the great majority of species, and urban communities are almost always found to be less diverse than corresponding rural or natural communities. Therefore, it is imperative to reduce current rates of urbanization, particularly the spread of low-density sprawl, if we are to retain local and native species. However, urban habitats cannot be ignored by ecologists and conservationists. Even if urbanization rates slow dramatically, current reserve and restoration projects alone will not be able to maintain local biodiversity. To prevent continued species losses at local and regional scales, we must substantially improve human-dominated landscapes (like cities) to reduce their environmental impact and support greater levels of biodiversity.

Gardens are potentially a major resource for conservation in urban environments. Collectively they comprise a large portion of the available plantable space in cities, and often represent a greater land area than public greenspace. Since they are managed by private citizens, private gardens would not face the budgetary concerns of park systems). Given their small size, gardens are likely not effective habitat for certain animals (e.g., species that require core habitat or have large home ranges), but they could support 
relatively small species that are adaptable to patchy habitat. Lepidopterans are a particularly good target for conservation in urban gardens. They are small, mobile animals that utilize resources (host and nectar plants) that are fairly simple to add to most gardens. This type of conservation requires public interest and participation, so it is also helpful that lepidopterans (specifically butterflies) are highly charismatic.

For my dissertation research, I evaluated the potential of urban native plant gardens to act as conservation spaces for butterflies. First, I conducted a study using clay caterpillar models to assess predator attack rates on lepidopteran larvae across a gradient of percent impervious surface. The primary purpose of this research was to determine if caterpillars in urban gardens faced a greater predation threat than caterpillars in more rural gardens, and therefore establish whether planting host plants in urban gardens is likely to be a beneficial strategy or one that could cause ecological traps (i.e., whether butterflies can reproduce effectively in urban gardens, or if their reproductive efforts are wasted because caterpillars are too likely to be eaten).

In my second study, I recorded butterfly species richness and abundance data at most of the same native plant gardens as the clay caterpillar study. The focus of this research was measuring the effect of different local characteristics of the gardens (garden area, plant species richness, planting density), and evaluating their ability to offset the expected negative effects of increasing urbanization on butterfly diversity and abundance. The ultimate goal of this research was to identify ways to improve urban gardens so that they can attract and support large, diverse communities of butterflies.

In my final study, I monitored the flight and foraging behaviors of the cabbage white butterfly (Pieris rapae) in a subset of the gardens I used in my previous research. 
The goal of this study was to determine if (and how) urbanization affected the foraging and associated movement behaviors of butterflies. Foraging and movement behaviors are influenced by landscape structure and connectivity, so this data provides insights into butterflies' perceptions of the urban matrix and how it influences their decisions. This, in turn, can inform conservation planners about the best way to distribute resources for butterflies throughout a city (i.e., should resources be concentrated in very high-quality hotspots, or are stepping-stone improvements needed widely across the matrix to facilitate better connectivity). 


\section{CHAPTER ONE}

\section{Introduction}

Urban landscapes are the fastest-growing type of habitat across the world. In the United States alone, urban land use increased from $289,904 \mathrm{~km}^{2}$ in 1950 to 1.48 million $\mathrm{km}^{2}$ in 2000 (Brown et al. 2005). Urban land, including both urban centers and suburban areas, has increased by an average of 5\% globally between 1970-2010 (Güneralp et al. 2020). In North America, the rate of urban land conversion consistently outpaced increases in urban population density, indicating high levels of low-density urban sprawl, and more than half of the land that was converted to urban use had been forested (Güneralp et al. 2020). Globally, the conversion of natural habitat to urbanized habitat will continue to increase, and urban sprawl is projected to consume another 5.87 million $\mathrm{km}^{2}$ of land by 2030 (Seto et al. 2012). This rapid urban expansion has destroyed, fragmented and isolated natural habitats and has led to the decline of numerous plant and animal taxa across the globe.

Urban habitats are highly detrimental to the great majority of animal taxa (McKinney 2002) including insects (Hill and Wood 2014, Verboven et al. 2014, Prescott and Eason 2018). Lepidopterans are no exception to the common pattern; many butterfly (Swengel et al. 2011) and moth (van Langevelde et al. 2018) species have been in drastic population decline over the last several decades, and increased urbanization is associated 
with declines in abundance and species richness of both butterflies (Blair and Launer 1995, Olivier et al. 2016) and moths (Bates et al. 2014, Merckx and Van Dyck 2019). These declines are likely due in part to reduced floral resources and loss of larval host plants (Potts et al. 2010), and in the case of moths, increased light pollution (van Langevelde et al. 2018).

To address this problem, new conservation strategies that do not rely solely on set-asides of protected natural areas are being developed (Rosenzweig 2003). One of these strategies, known as "reconciliation ecology" seeks to improve degraded habitats such as urbanized areas by including species habitat amid residential, commercial and other land-use types to promote increases in biodiversity (Rosenzweig 2003). For butterflies and other flower-visiting insects, conservation organizations such as National Wildlife Federation have encouraged members of the public to create native plant gardens as a conservation tactic, thus providing at least small patches of natural habitats in residential landscapes (Oder 2015). Gardens typically comprise $16 \%$ to $36 \%$ of land area in cities and towns (Goddard et al. 2010), and the majority of privately owned plantable space in cities that could potentially be converted into gardens or meadows often far exceeds the available plantable space in public park systems (Johnston et al. 2019, Marshall et al. 2019). Collectively, gardens and other urban plantings have considerable conservation potential. A recent study by Johnston et al. (2019) found that potential milkweed plantings in eastern U.S. cities could provide up to $1 / 3$ of what is needed to stabilize the eastern monarch population.

However, the efficacy of gardens as conservation spaces for pollinators and overall animal diversity has not been fully explored. Research has shown high variability 
in the animal diversity that urban environments are able to support. Some studies have found that urban environments act purely as population sinks, or even "ecological traps" that draw animals away from more undisturbed habitat to the detriment of their population (Levy and Connor 2004, Sumasgutner et al. 2014, Suárez-Rodríguez et al. 2017). Others have found more positive results, finding that urban habitats can provide some pollinators with crucial food resources, (Samnegård et al. 2011, Pereira-Peixoto et al. 2014, Hülsmann et al. 2015, Hausmann et al. 2016), and that some urban populations of insects, can even be self-sustaining (bumblebees: Gunnarsson and Federsel 2014; Diptera, Coleoptera, Hemiptera, and Hymenoptera: Smith and Fellowes 2014). Multiple studies have also recognized the potential of urban habitats to increase biodiversity if management practices are changed (Shwartz et al. 2013, Hill and Wood 2014, Pardee and Philpott 2014, Philpott et al. 2014, Smith and Fellowes 2014, Otoshi et al. 2015, Tam and Bonebrake 2016, Callaghan et al. 2019). Typically, "best management practices" associated with butterfly gardens involve planting caterpillar host plants to make gardens breeding habitats rather than just providing nectar sources; the best-known campaign is to plant milkweed for monarchs. It is usually assumed that planting host plants must be a net positive, despite some evidence indicating that caterpillar survival in urban gardens can be very poor and thus that such gardens may be acting as ecological traps within a larger district that includes natural areas (Levy and Connor 2004).

Lepidopteran species vary widely in their ability to adapt to an urban environment (Blair and Launer 1995, New and Sands 2002, Konvicka and Kadlec 2011, Merckx and Van Dyck 2019, Franzén et al. 2020), and very few studies have evaluated how caterpillar abundances change across an urbanization gradient. A handful of studies have 
compared caterpillar abundances between urban and forested areas as a measure of food availability for insectivorous birds, but their results have been mixed. Two studies found reduced caterpillar abundance (Marciniak et al. 2007) or biomass (Seress et al. 2018) in urban areas, one study found no significant change in abundance (Solonen 2001), and another found higher caterpillar abundance in urban areas (Isaksson and Andersson 2007).

One factor that might contribute to such disparities in caterpillar abundance is predation pressure. Two studies have directly evaluated how predation pressure on caterpillars changes across disturbance gradients. In a tropical forest in the Philippines, predator attack rate increased with increasing habitat degradation (Posa et al. 2007). In contrast, in temperate Denmark, predator attack rate declined as the level of urbanization increased (Ferrante et al. 2014). These and many other studies have used clay caterpillar models, an established method for estimating predator attack rate (e.g., Koh and Menge 2006, Posa et al. 2007, Tvardikova and Novotny 2012, Ferrante et al. 2014, Roslin et al. 2017). Because marks left on the models are attributable to different predator taxa (e.g., birds, wasps, spiders), they can also be used as an indicator of how predator communities vary in different environments (Ferrante et al. 2014, Seifert et al. 2015, Roslin et al. 2017).

In this study, we assessed whether caterpillar survival differs in native plant gardens in urban versus more rural areas by measuring predator attack rates on clay caterpillar models. To determine whether local factors affect caterpillar predation, we also examined the effects of garden attributes - specifically plant species richness and plant biovolume density - on predator attacks on the models. Finally, we tested whether 
season and model size affected predation. Previous studies have suggested that the effects of caterpillar size on predation rates may not be consistent (Stamp and Bowers 1988, Hooks et al. 2003), and we also wanted to learn whether caterpillar size affected the predator types that attacked caterpillars.

\section{Methods}

Study sites

We conducted this study in two adjacent counties in Kentucky, USA, Jefferson and Bullitt. Jefferson County includes the entire city of Louisville $\left(38^{\circ} 15^{\prime} \mathrm{N}, 85^{\circ} 46^{\prime}\right.$ W), which had a population just above 760,000 in 2019 (U.S. Census Data 2019). Jefferson and Bullitt counties are located in north-central Kentucky and are a part of the Interior Low Plateau, Bluegrass Section and in the Eastern Broadleaf Forest (Continental)Province biome (USDA Forest Service 2018). Annual mean temperature for Louisville is $14.6 \mathrm{C}$ with a mean minimum in January of $-2.8 \mathrm{C}$ and a mean maximum in July of 31.7 C. Annual precipitation averages $114 \mathrm{~cm}$ and ranges from 7.6 to $13.4 \mathrm{~cm}$ monthly (US Climate Data 2018).

We conducted trials in July and October 2017 at 24 native plant garden sites (Fig. 1). These gardens included seven residential gardens, eight gardens at schools, eight gardens in urban and rural parks, and one corporate garden. They ranged from $21 \mathrm{~m}^{2}-$ $2,165 \mathrm{~m}^{2}$ in size, and all gardens had high sun exposure, with little to no tree cover.

\section{Garden Characteristics}


We measured the following variables for each site: $\%$ impervious surface surrounding the garden, garden area $\left(\mathrm{m}^{2}\right)$, plant species richness, and plant biovolume density $\left(\mathrm{m}^{3} / \mathrm{m}^{2}\right.$ ) (Table 1). We used ArcGIS ${ }^{\circledR}$ (version 10.6) to calculate the percent impervious surface surrounding each garden, using circles with a $0.5-\mathrm{km}, 1-\mathrm{km}$, and 1.5 $\mathrm{km}$ radii. Model comparison using AIC showed that the 1-km scale explained most variation in model attack rate, and using that scale, percent impervious surface ranged from $6.1 \%-84.2 \%$. Plant species richness in the gardens ranged from 13-65 species. Plant biovolume density $\left(\mathrm{m}^{3} / \mathrm{m}^{2}\right)$ was calculated using two different methods depending on plant density. At high-density sites, plant height was recorded every $2 \mathrm{~m}$ along a transect; transects were $3 \mathrm{~m}$ apart for small sites (less than $500 \mathrm{~m}^{2}$ ) and $5 \mathrm{~m}$ apart for large meadows (over $1000 \mathrm{~m}^{2}$ ). At high-density sites plant biovolume density is equivalent to mean plant height. At low-density sites, each plant's volume was calculated individually, and the sum of all plant volumes was divided by area to calculate plant biovolume density. Plant biovolume density ranged from $0.02-0.69 \mathrm{~m}^{3} / \mathrm{m}^{2}$.

\section{Caterpillar models and placement in gardens}

We created green clay caterpillar models by mixing 2 parts green plasticine clay with 1 part yellow (clay brand: Sargent $\left.\mathrm{Art}^{\circledR}\right)$. We made models in two sizes, large $(5 \mathrm{~cm}$ long, $6 \mathrm{~mm}$ diameter) and small ( $3 \mathrm{~cm}$ long, $3 \mathrm{~mm}$ diameter), and we affixed them to plant leaves with Loctite ${ }^{\circledR}$ superglue. In each garden, we placed one large and one small caterpillar on each of 20 plants for a total of 40 caterpillars/site/trial and an overall total of 1920 clay caterpillars, with 960 set out in July and 960 in October. The selected plants belonged to various species of herbaceous perennials that were representative of the 
range of plant species at the garden. The plants were at least $0.5 \mathrm{~m}$ in height and at least $1.0 \mathrm{~m}$ distant from any other plant with model caterpillars. Caterpillar placement on the plant was randomized with respect to vertical spacing (top, middle or bottom third of the plant) and horizontal spacing (models were either on opposite sides of the plant main stem or on the same side of the stem and separated by vertical space only). We checked caterpillars for damage after 24 and 48 hours; caterpillars damaged after 24 hours were removed without replacement. All remaining caterpillars were removed after 48 hours and assessed to determine predator type using Low et. al (2014) as a guide (Fig. 2). To further verify marks made by hymenopterans versus orthopterans, we captured multiple grasshopper and katydid species of different sizes, directly recorded their bite marks on clay caterpillar models, and compared those marks to those on the experimental caterpillars. We considered all caterpillars that were damaged to have been predated and thus the predation rate was the proportion of caterpillar models that showed damage. Each damaged model was assigned a single predator; in the relatively few cases where multiple predators attacked the same model, the predator that did the most extensive damage was used for our analyses.

\section{Statistical Analyses}

We analyzed which factors influenced total predation rate across gardens using logistic regression models with GLM in R, and we determined which factors influenced predation rates of different predator types using multinomial logistic regression with the mlogit package in $\mathrm{R}$ ( $\mathrm{R}$ Core Team 2016). Two factors, garden area and percent 
impervious surface, were highly correlated; accordingly we used a model comparison (AIC) approach to determine which variable better explained the data. We found that percent impervious surface was a much better predictor of both total predation rate and of predation by predator type; we therefore dropped garden size from both models. The explanatory variables included in the two models were season (July or October), model size (small or large), percent impervious surface, plant species richness, and plant biovolume density.

\section{Results}

We recovered $1883(98.1 \%)$ of the 1920 caterpillar models we placed in the gardens; this included $98.4 \%$ of the large models and $97.7 \%$ of the small ones. The models we did not recover were not included in statistical analyses. Of the 1883 recovered models, 981 (i.e., $52.1 \%$ of the models), were attacked by a predator. Overall, 97.3\% of the attacks could be attributed to 5 predator types (Fig. 3): parasitoid wasps (47.1\%), spiders $(16.2 \%)$, ants (13.5\%) vertebrates $(13.3 \%)$, and predatory wasps $(7.2 \%)$. In the analysis of overall probability of predation, impervious surface, plant species richness, model size, and season all have significant main effects, but plant biovolume did not. The probability of a clay caterpillar being attacked after 48 hours declined from approximately $62 \%$ to $39 \%$ as percent impervious surface increased from 6 to $84 \%$ (p < 0.001, Fig. 4a), and declined from approximately $58 \%$ to $43 \%$ as plant species richness increased ( $p=0.047$, Fig. $4 b)$. Large model caterpillars were attacked more frequently than small models ( $\mathrm{p}<0.001$ ); $58 \%$ of all large models were attacked and $46 \%$ of all small models were attacked. Models were also attacked more frequently in October than 
July ( $<<0.001) ; 45.7 \%$ of the July models were attacked and $58.7 \%$ of the October models were attacked. There were no significant interaction effects.

In contrast, in the model of the proportions of caterpillars damaged by particular predator types, season, caterpillar size, and plant species richness did not have any significant effects. The final model included percent impervious surface (1-km radius), plant biovolume density $\left(\mathrm{m}^{3} / \mathrm{m}^{2}\right)$, and the interaction between them; further, the effects of these factors varied across predator taxa. The probability of a caterpillar model being attacked by parasitoid wasps was significantly affected by an interaction between percent impervious surface and plant biovolume density ( $\mathrm{p}<0.001$, Fig. 5). Below approximately $35 \%$ impervious surface, the probability of attack by parasitoid wasps increased as plant biovolume density increased. Above 35\% impervious surface this trend reversed, and the probability of attack by parasitoid wasps decreased as plant biovolume density increased. The probability of attack by vertebrates was also affected by both percent impervious surface and plant biovolume density, but as separate main effects rather than via an interaction. The probability of attack by vertebrates decreased approximately $20 \%$ as percent impervious surface increased from 6 to $84 \%(p=0.01$, Fig. 6a) and increased approximately $13 \%$ as plant biovolume density increased ( $p=0.002$, Fig. $6 b)$. The probability of attack by predatory wasps decreased approximately $14 \%$ as percent impervious surface increased from 6 to $84 \%(p=0.002$, Fig. $7 \mathrm{a})$ and slightly increased (approximately 6\%) as plant biovolume density increased ( $p=0.06$, Fig. $7 b$ ). The probability of attack by spiders was not affected by percent impervious surface $(p=0.79)$ but marginally increased (approximately 3\%) as plant biovolume density increased ( $\mathrm{p}=$ 0.02 , Fig. 8). The probability of a model being attacked by ants was not significantly 
affected by either percent impervious surface $(\mathrm{p}=0.79)$ or plant biovolume density $(\mathrm{p}=$ $0.79)$.

\section{Discussion}

Overall, our caterpillar models were attacked by predators significantly less frequently in urban areas than rural areas. In gardens surrounded by very low percent impervious surface $(\sim 5 \%)$, our model predicted that a caterpillar had a $62 \%$ probability of being predated within 48 hours. In gardens with very high percent impervious surface ( $\sim 5 \%$ ), the probability of being predated within 48 hours dropped to $39 \%$. The likelihood of being attacked within 48 hours was also affected by variation in caterpillar model size, season, and garden plant species richness. These factors did not affect the likelihood of attack by any particular predator, but some garden characteristics did affect different predator taxa differently. For example, the likelihood of attack by two of our predator taxa, ants and spiders, was not significantly influenced by percent impervious surface at all, but attacks by predatory wasps and vertebrates strongly declined as percent impervious surface increased. Plant biovolume density, which was not a significant factor in the total predation model, significantly affected all of our predator taxa (except ants) in some way.

Parasitoid wasps were the dominant predator of our clay models. They accounted for $47.1 \%$ of all attacks, and the probability of a model being attacked by a parasitoid was high across all sites. The variation in the rate of attack was influenced by an interaction between percent impervious surface and plant biovolume density. In more rural areas, parasitoid attack rates were highest when plant cover was very dense. Conversely, in 
urban areas parasitoid attack rates were highest when plant cover was sparse. This is possibly due to a change in the parasitoid community across the urban gradient. A study by Burks and Philpott found that parasitoid wasp diversity decreased with increasing urbanization, but parasitoid abundance increased with increasing urbanization. The parasitoid wasp species able to persist in urban areas may not necessarily need much vegetative cover to survive in an urban environment, and can take advantage of the fact that the caterpillar models are easier to see in low-density gardens. However, if that is the case, it is likely specific to the local or regional parasitoid wasp community, as a prior study in Brazil found that predation on lepidopteran pupae by parasitoid wasps in an urban area increased significantly as vegetative cover increased (Ruszczyk 1996). The predation pattern found by Ruszczyk may also be more reflective of the general predator response. Although plant biovolume density did not have a significant main effect in our overall attack rate model, this model was highly affected by the complex response of parasitoids. Attacks by vertebrates, spiders, and predatory wasps all increased as plant biovolume density increased, regardless of the level of urbanization. This is likely due to the ability of denser plant cover to support the presence of these predators, as several studies have shown that diversity and abundance of each of these groups increases when ground or shrub cover is more dense (Lancaster and Rees 1979, Beissinger and Osborne 1982, Costello and Daane 1998, Lassau and Hochuli 2005, Silva et al. 2010, Melin et al. 2018, Sáenz-Romo et al. 2019).

The decrease in total predation rate in urban areas is likely attributable to decreases or functional changes in predator diversity and abundance (excepting parasitoid wasps). Our analysis of attack frequency by predator type showed that attacks by 
predatory wasps and vertebrates declined with increasing percent impervious surface. The majority of attacks by vertebrates in our study were bird attacks, and increasing urbanization often causes bird diversity to decline (Lancaster and Rees 1979, Blair 1996, Chace and Walsh 2006, Aronson et al. 2014). Furthermore, the highly abundant bird species in urban environments are predominantly granivorous or omnivorous rather than insectivorous (Lancaster and Rees 1979, Beissinger and Osborne 1982, Crooks et. al 2003, Chace and Walsh 2006), so the decline in vertebrate attacks that we found may be more reflective of reduced numbers of insectivorous birds than a decline in absolute bird abundance. In general, the effects of urbanization on predatory wasps are less clear, in part because of the scarcity of studies on this topic. Our data show that predatory wasp attacks on caterpillars decline with increasing urbanization, and a recent study in Rome, Italy (Corcos et al. 2019) similarly found a decline in sphecid wasp abundance with increasing urbanization; however, a study in Sydney, Australia (Christie and Hochuli 2009) found no significant effects of urbanization on any wasp taxa. The variation in predatory wasps' responses to urbanization may depend at least in part on the degree of dissimilarity between the habitat surrounding the urban area and the urban habitats themselves. However, it is unclear whether the difference we observed was driven by a reduction in the numbers of predatory wasps or a change in their community composition that results in the absence of species that specialize on caterpillars.

We also found that late-instar caterpillars and caterpillars of larger-bodied species may be at higher overall risk of predation than early instar caterpillars and caterpillars of small-bodied species, as the large caterpillar models were predated more frequently than the small caterpillar models. Hooks et al. (2003) found that bird and spider predation 
significantly reduced the amount of large caterpillars on individual plants but did not affect the amount of small caterpillars on the plants. However, clay models cannot exhibit the defenses of real caterpillars, and Stamp and Bowers (1988) found that late-instar caterpillars were much more successful at evading wasp predation than early-instar caterpillars. Late-season caterpillars may be more at risk of predation, as the likelihood of a model being attacked was much higher in October than July. This result is likely due to diminishing alternative resources for predators in all taxa we studied. Finally, we found that the attack rate on the models declined by about $15 \%$ when plant species richness was very high. This effect is opposite to what has been found in most other studies, which have found increases in predation when plant species richness is increased (Sobek et al. 2009, Hertzog et al. 2017, Leles et al. 2017). There are a few studies that have shown different effects of plant species richness on predators. Fabian et al. (2014) found no significant relationship between the abundance of herbivore-predating wasps and plant species richness, and the direction of the trend (although not statistically significant) was negative, with fewer wasps where plant species richness was high. Yang et al. (2018) found that insectivorous bird predation declined with increasing tree species richness in a tropical forest, and Sperber et al. (2004) found no effect of herbaceous plant species richness on parasitoid wasp richness. It is also possible that our highly plant-diverse sites are in some way associated with another variable that we weren't able to measure and that influenced predator presence (e.g., garden management techniques, microhabitats, plant species attributes).

Our models were damaged at a rate (52.1\%) comparable to rates in other caterpillar predation studies in temperate regions that used either clay models (50\%, 
Ferrante et al. 2014) or live caterpillar larvae (56\%, Grenis et al. 2015), suggesting that our results were not unduly influenced by using clay models instead of live caterpillars. Our results, which correspond with the trend found by Ferrante et al. (2014), suggest that if there is a reduction in caterpillar survival in some urban caterpillar populations, that reduction may not be due to increased predation, although of course this should be studied in more cities at a greater diversity of latitudes, in varied habitats, and of different sizes. To fully determine whether caterpillar survival is similar between urban and rural gardens, there also need to be more studies addressing caterpillar survival directly and other factors that may affect it, such as food quality and availability. Furthermore, if there is greater survival of caterpillars in urban habitats, then there could be increased herbivory that significantly affects both damage to and success of plants in urban gardens. Future studies should investigate plant-caterpillar interactions in urban gardens, and determine what degree of plant damage alters gardeners' responses to the caterpillars' presence. Additionally, a broader range of lepidopteran species should be studied, as current research shows some species-specific responses. For example, a study on the Apollo butterfly (Parnassius apollo) showed poor caterpillar survival in urban gardens (Levy and Connor 2004), but a few studies on the monarch (Danaus plexippus) have found no significant differences in caterpillar survival between urban and rural areas (Cutting and Tallamy 2015, Geest et al. 2019). Such research can inform more targeted conservation strategies for different lepidopteran species in residential areas.

In conclusion, we found that urban gardens are not necessarily "ecological traps" for lepidopterans. Caterpillars that hatch in urban areas may face a lower predation threat than caterpillars in rural areas. However, this potentially higher survival may come at the 
expense of losses to biodiversity in other taxa, namely predatory wasps and insectivorous birds, which showed a sharp decline in attack rate as impervious surface increased. Given the importance of preserving biodiversity in general, we recommend that urban gardeners increase the plant density in their gardens to facilitate the presence of more bird, spider, and predatory wasp activity. While this and other strategies to improve gardens, such as greater use of native plants, will likely increase attacks on caterpillars, our data suggest that the predation pressure may not be substantially different to what is occurring in more natural environments. Our findings suggest that we should continue to encourage urban gardeners to continue planting host plants, as their efforts will help conserve lepidopteran species rather than contributing to their demise. 
Table 1

\begin{tabular}{|c|c|c|c|c|c|}
\hline Site & Site Type & $\begin{array}{l}\% \text { Impervious } \\
\text { Surface (1 km } \\
\text { radius) }\end{array}$ & $\begin{array}{l}\text { Garden Area } \\
\qquad\left(\mathrm{m}^{2}\right)\end{array}$ & $\begin{array}{l}\text { Plant Species } \\
\text { Richness }\end{array}$ & $\begin{array}{c}\text { Plant } \\
\text { Biovolume } \\
\text { Density } \\
\left(\mathrm{m}^{3} / \mathrm{m}^{2}\right) \\
\end{array}$ \\
\hline Bernheim & Park & 6.1 & 2574 & 21 & 0.41 \\
\hline Beckley I & Park & 7.5 & 2165 & 31 & 0.44 \\
\hline Beckley II & Park & 7.5 & 2000 & 29 & 0.50 \\
\hline Iroquois I & Park & 14.0 & 1238 & 29 & 0.61 \\
\hline Iroquois II & Park & 14.0 & 200 & 21 & 0.49 \\
\hline Private Garden I & Residential & 18.3 & 20.8 & 23 & 0.40 \\
\hline Cherokee I & Park & 21.9 & 1024 & 25 & 0.40 \\
\hline Cherokee II & Park & 21.9 & 1024 & 24 & 0.38 \\
\hline Moore & School & 26.7 & 384.1 & 22 & 0.55 \\
\hline $\begin{array}{l}\text { Louisville Nature } \\
\text { Center }\end{array}$ & Park & 30.2 & 448.7 & 34 & 0.69 \\
\hline Private Garden II & Residential & 30.5 & 453.4 & 33 & N/A \\
\hline Chenoweth & School & 32.7 & 125.8 & 39 & 0.03 \\
\hline St. Agnes & School & 33.0 & 82.3 & 26 & 0.05 \\
\hline Portland & School & 38.9 & 44.4 & 33 & 0.04 \\
\hline Private Garden III & Residential & 40.2 & 96.8 & 49 & 0.30 \\
\hline John Paul II & School & 42.2 & 82.3 & 24 & 0.65 \\
\hline Holy Spirit & School & 42.9 & 59.5 & 20 & 0.04 \\
\hline Private Garden IV & Residential & 43.5 & 102.1 & 46 & 0.48 \\
\hline Private Garden V & Residential & 44.0 & 91.6 & 59 & 0.41 \\
\hline Private Garden VI & Residential & 44.3 & 35.4 & 40 & 0.12 \\
\hline $\begin{array}{c}\text { Old Louisville } \\
\text { Community Garden }\end{array}$ & Residential & 62.2 & 34.2 & 29 & 0.47 \\
\hline Copper and Kings & Business & 66.8 & 341.9 & 38 & 0.41 \\
\hline $\begin{array}{l}\text { U of L Korfhage } \\
\text { Garden }\end{array}$ & School & 68.9 & 372.4 & 65 & 0.02 \\
\hline St. Francis & School & 84.2 & 184.5 & 13 & 0.24 \\
\hline
\end{tabular}


Figure 1

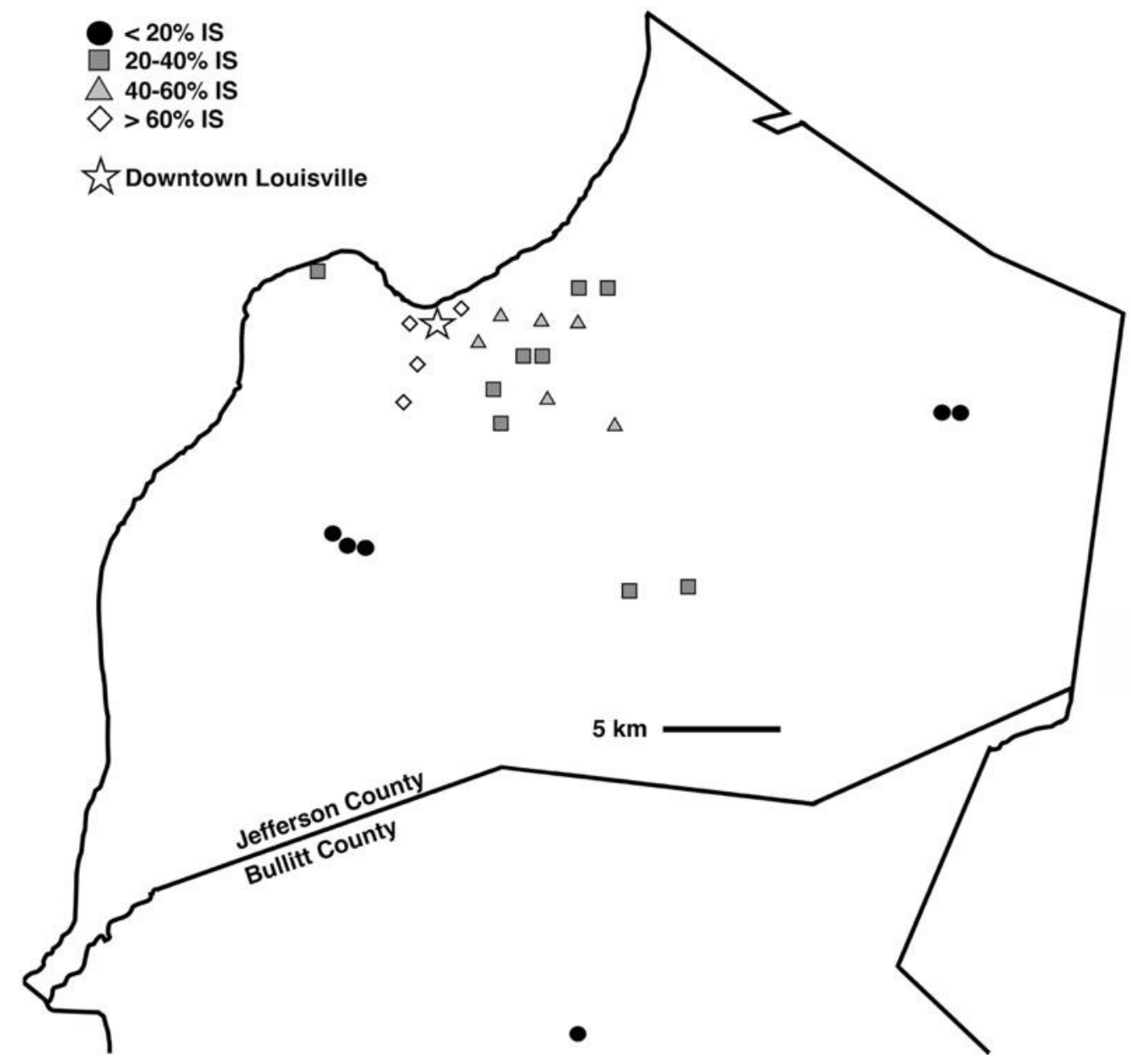


Figure 2

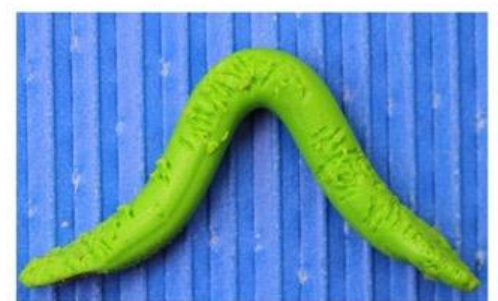

(a)

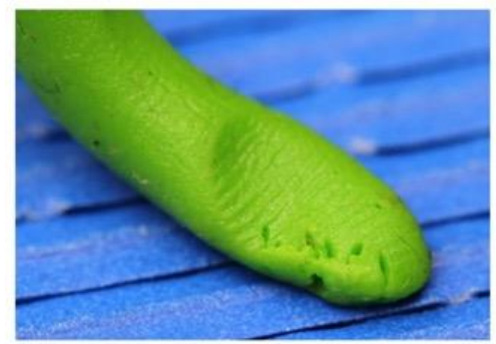

(d)

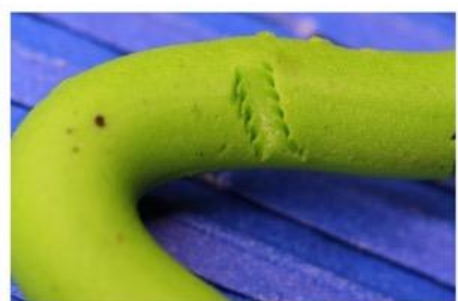

(b)

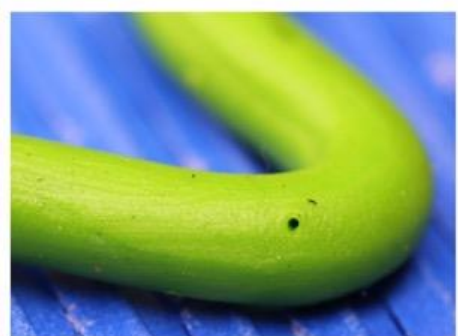

(e)

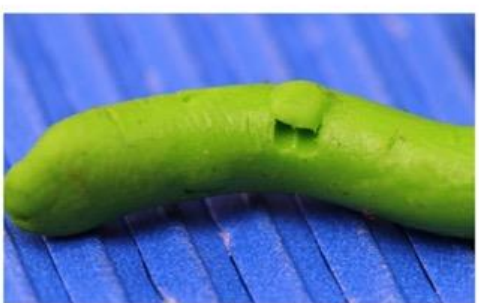

(c)

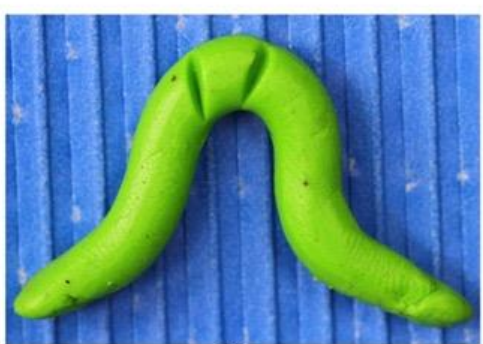

(f) 
Figure 3

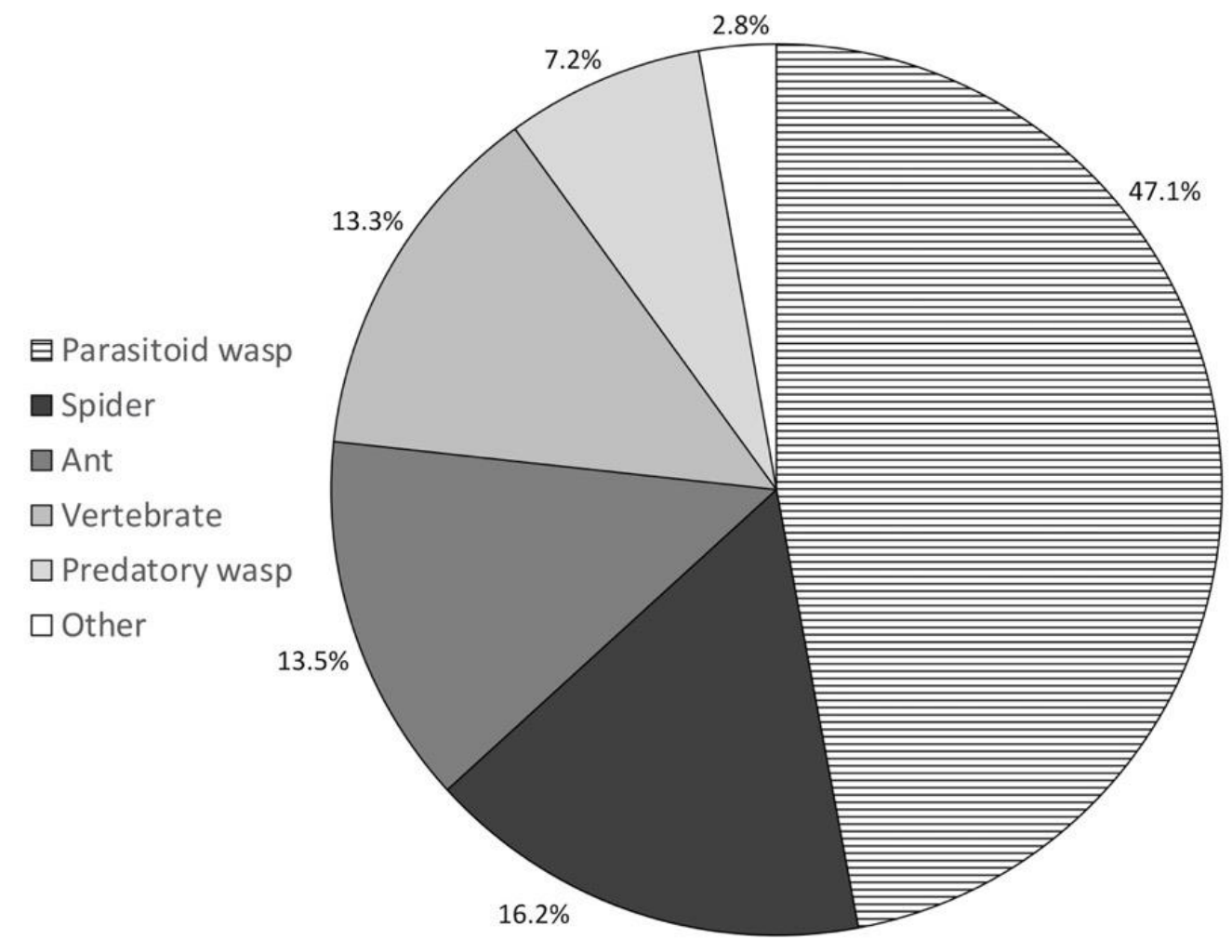


Figure 4
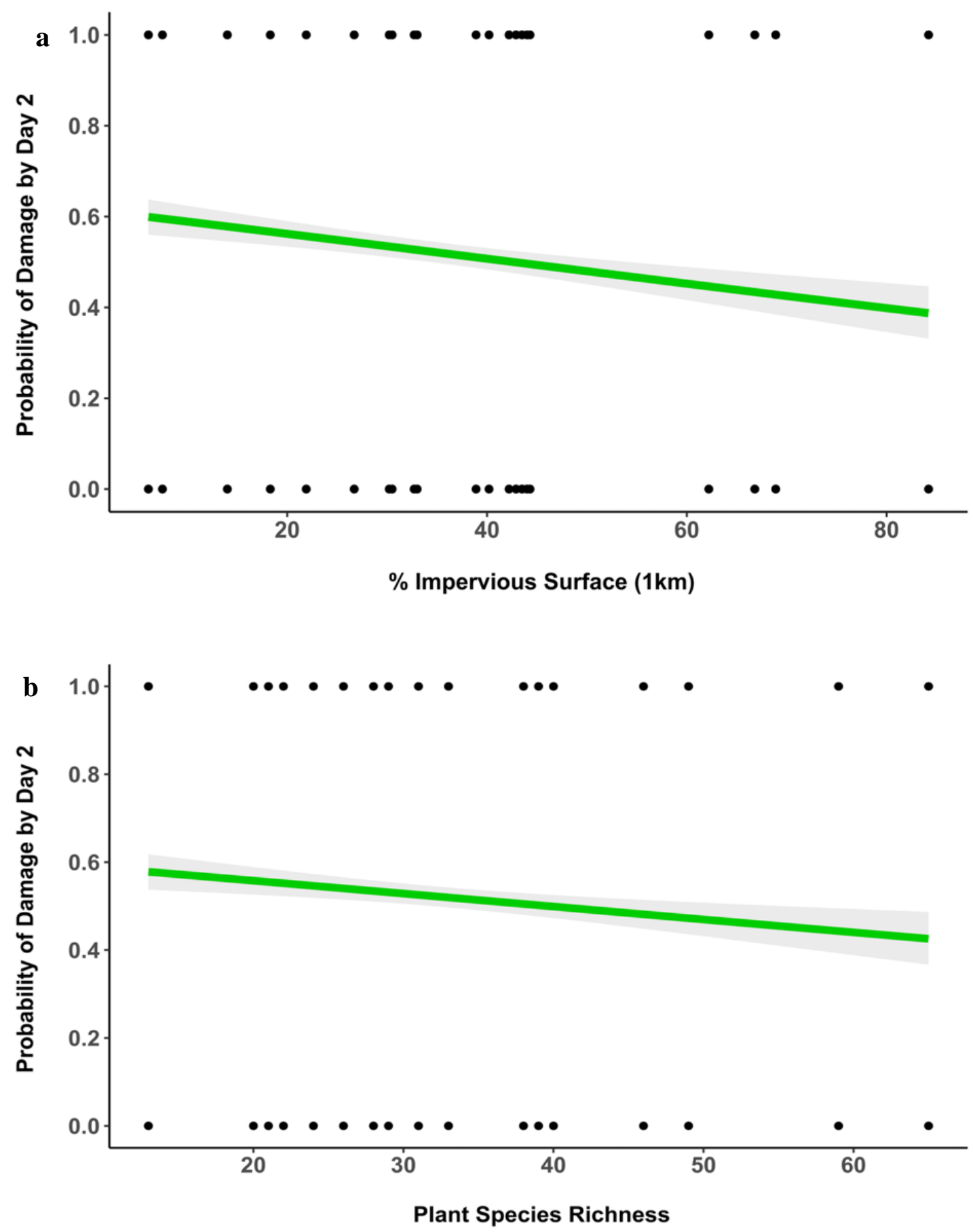
Figure 5

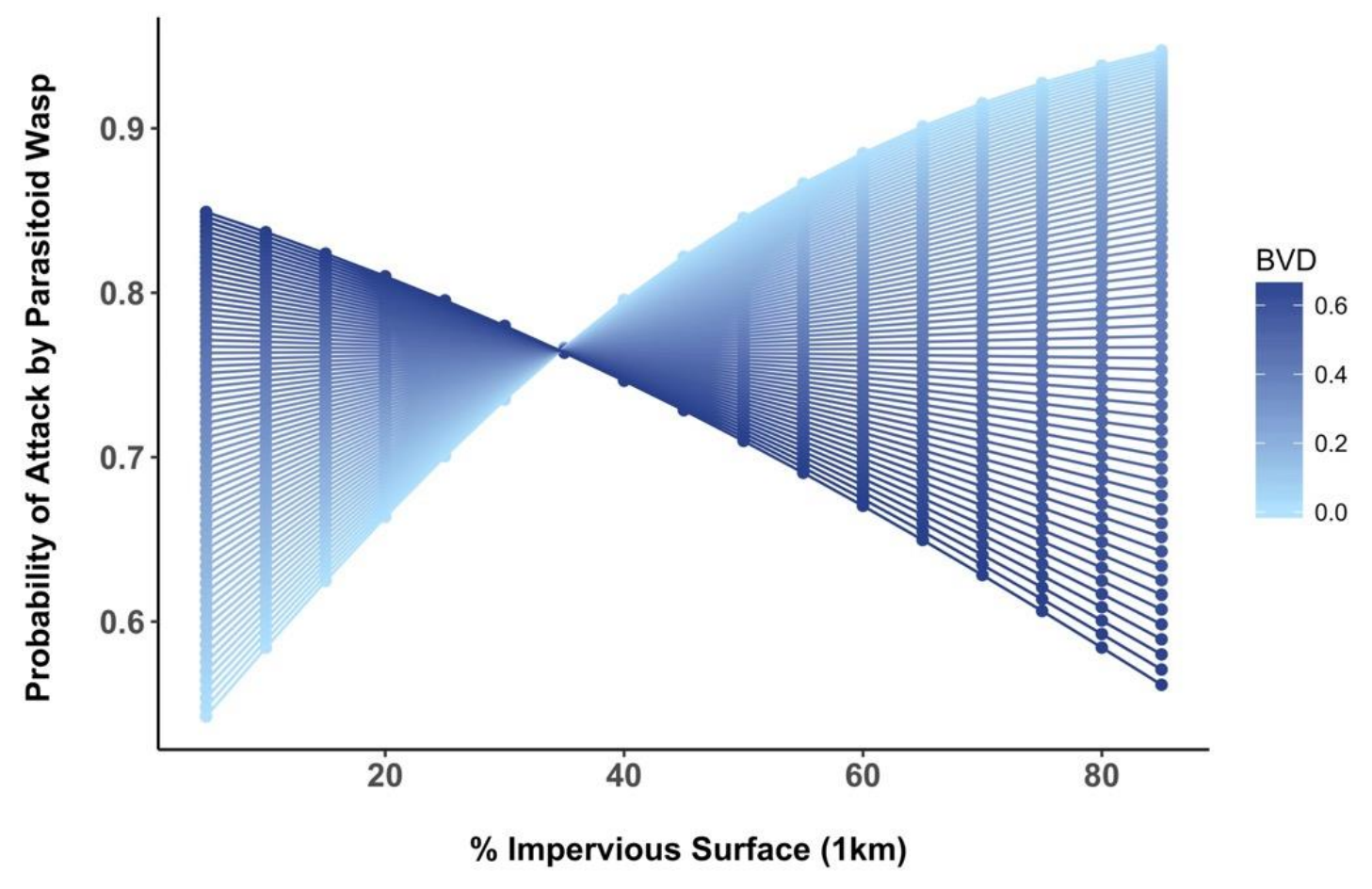


Figure 6
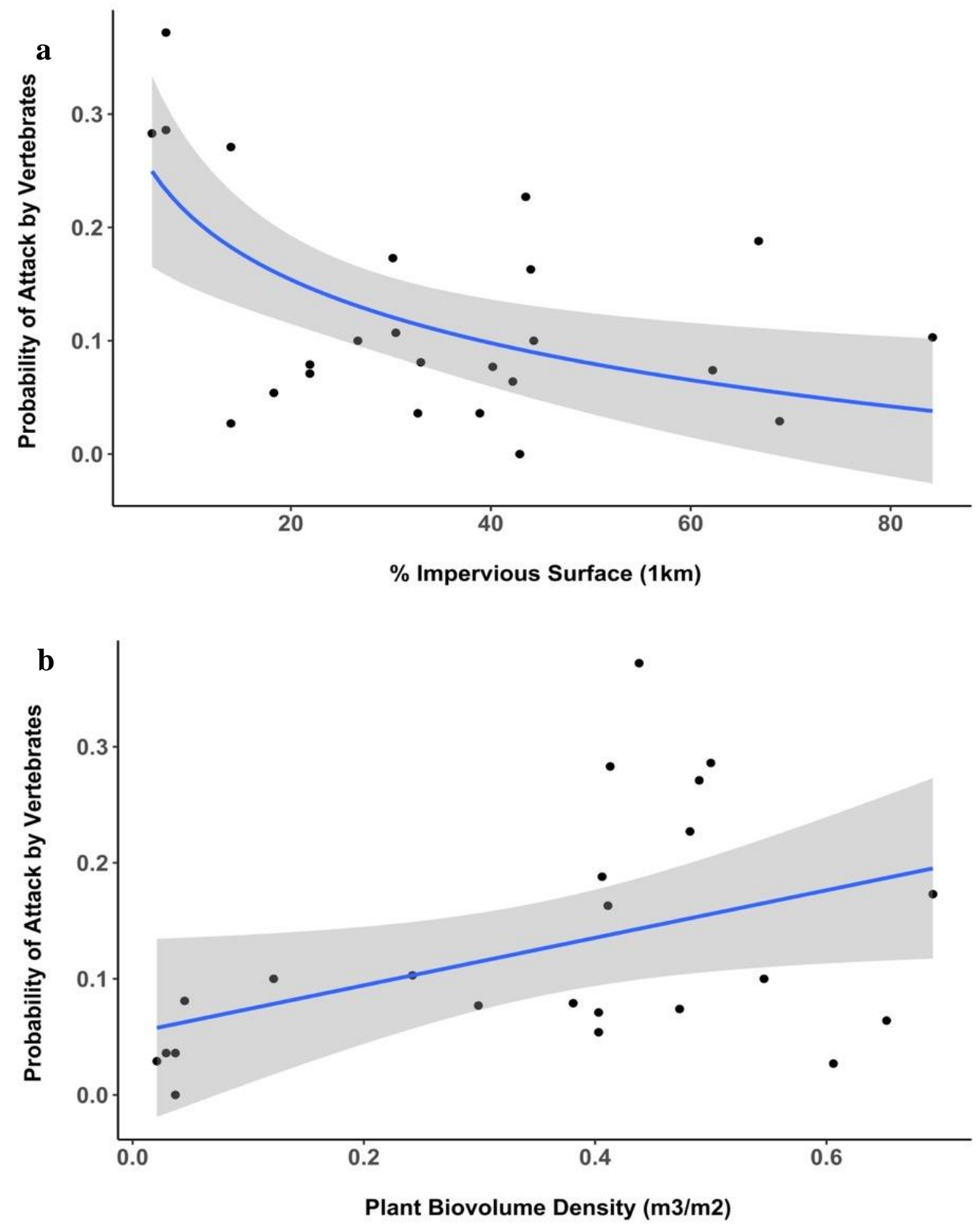
Figure 7
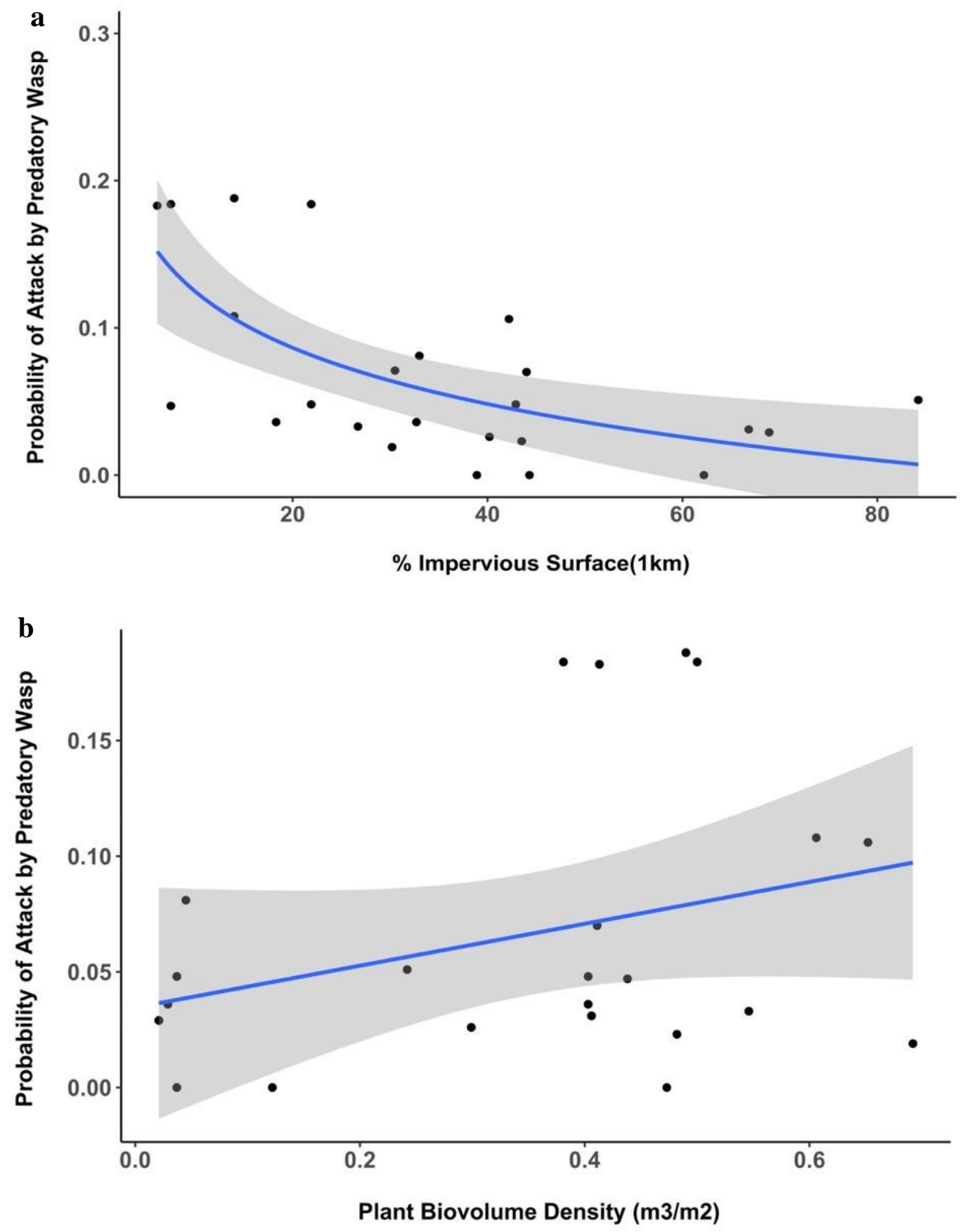
Figure 8

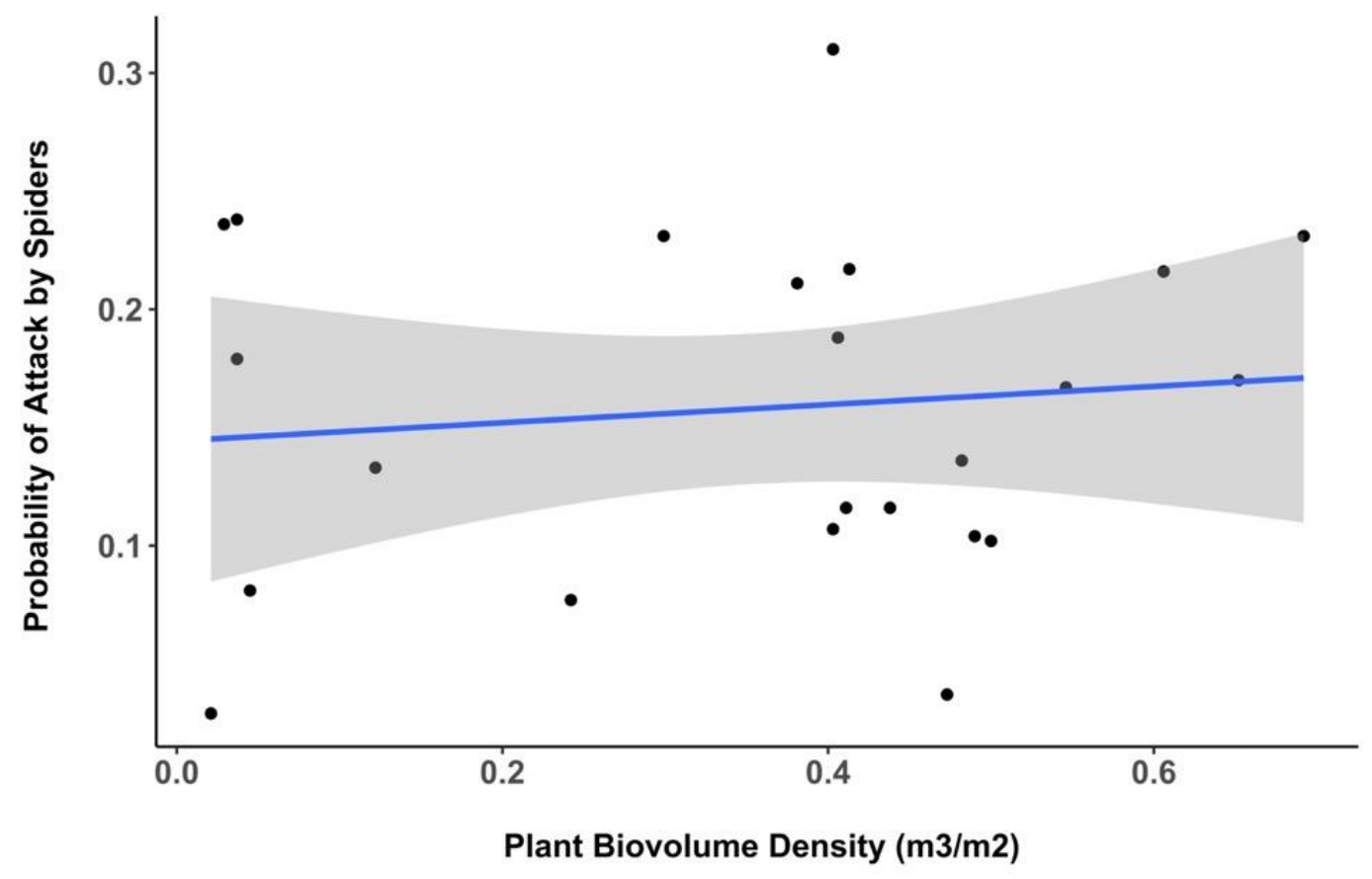




\section{Captions}

Table 1 A table showing each garden site and its characteristics. U of L refers to the University of Louisville

Fig. 1 A map showing the relative locations of the 24 garden sites, with the symbol for each site indicating the level of impervious surface (IS) surrounding each site

Fig. 2 Caterpillar models showing damage by different predator taxa: a) Predatory wasp b) Reptile c) Mammal d) Spider e) Parasitoid wasp f) Bird

Fig. 3 The percentage of attacks on caterpillar models made by each predator type across all sites

Fig. 4a The probability of a caterpillar model being attacked after 48 hours decreased as percent impervious surface increased (logistic regression, $\mathrm{p}<0.001$ )

Fig. 4b The probability of a caterpillar model being attacked after 48 hours decreased as plant species richness increased (logistic regression, $\mathrm{p}=0.047$ )

Fig. 5 Predicted probabilities of parasitoid wasp attacks versus impervious surface at different values of plant biovolume density (BVD). Below approximately $35 \%$ impervious surface, increasing plant biovolume density increased the probability of attack by parasitoid wasps. Above 35\% impervious surface this trend reversed, and 
decreasing plant biovolume density increased the probability of attack by parasitoid wasps. (logistic regression, $\mathrm{p}<0.001$ )

Fig. 6a The probability of attack by vertebrates decreased as percent impervious surface increased (logistic regression, $\mathrm{p}=0.01$ )

Fig. 6b The probability of attack by vertebrates increased as plant biovolume density increased (logistic regression, $\mathrm{p}=0.002$ )

Fig. 7a The probability of attack by predatory wasps decreased as percent impervious surface increased (logistic regression, $\mathrm{p}=0.002$ )

Fig. 7b The probability of attack by predatory wasps slightly increased as plant biovolume density increased (logistic regression, $\mathrm{p}=0.06$ )

Fig. 8 The probability of attack by spiders marginally increased as plant biovolume density increased (logistic regression, $\mathrm{p}=0.02$ ) 


\section{CHAPTER TWO}

\section{Introduction}

Many pollinator species have experienced severe population declines and local extinction events over the last several decades, and the conversion of naturalized and rural lands to urban and suburban developments is a key contributor to this decline (Potts et al. 2016, Vanbergen 2013). Urbanization results in the destruction and fragmentation of core habitat and the loss of crucial nectar and nesting resources, frequently resulting in lower pollinator species richness and abundance. Such negative effects are particularly strong when natural areas are lost (as opposed to the loss of farmlands). Urbanization also causes changes in community composition that favor generalists over specialists (Wenzel et al. 2020). Unfortunately, urban landscapes are the fastest-growing habitat type across the world. In the United States alone urban land cover has increased from 60,703 $\mathrm{km}^{2}$ in 1945 to $469,435 \mathrm{~km}^{2}$ in 2017 , a seven-fold increase in just over 70 years (USDA 2020, Bigelow and Borchers 2012). Globally, there was an average 5\% increase in urban and suburban land from 1970-2010 (Güneralp et al. 2020), and urban sprawl is projected to consume another 5.87 million $\mathrm{km}^{2}$ of land by 2030 (Seto et al. 2012).

Lepidopterans mirror these overall trends in pollinator declines as lands become increasingly urbanized (Casner et al. 2014), as evidenced by several surveys of butterfly species richness and abundance across urban-rural gradients (Blair 1999, Ramírez- 
Restrepo and MacGregor-Fors 2016, Merckx and Van Dyck 2019, Tzortzakaki et al. 2019, Kurylo et al. 2020, Kuussaari et al. 2020). The loss of butterflies from urbanized habitats is often attributed to the destruction of certain specialized habitats (core forest and wetland, particularly) and reductions in larval host plant (Bonebrake and Cooper 2014) and nectar plant availability (Abrahamczyk et al. 2020). Specialist butterfly species are particularly hard-hit by urban land conversion, and they disappear from the landscape quickly as urban intensity increases, whether they are specialized in terms of larval host plant (Kitahara and Fujii 1994, Clark et al. 2007), floral preference (Bergerot et al. 2010) or habitat (Blair and Launer 1995, Blair 1999, Koh and Sodhi 2004). One possible means of increasing butterfly populations is through the creation of residential butterfly gardens, a conservation tactic often promoted by conservation organizations like National Wildlife Federation (Oder 2015). Gardens are a good target for modifying urban green space because they typically comprise $16 \%$ to $36 \%$ of land area in cities and towns (Goddard et al. 2010), and the majority of privately owned plantable space in cities that could potentially be converted into gardens or meadows often far exceeds the available plantable space in public park systems (Johnston et al. 2019, Marshall et al. 2019). Various lines of evidence suggest that urban gardens may have potential as conservation space for at least some pollinator taxa. Urban bees (Gunnarsson and Federsel 2014, Baldock et al. 2019) and hoverflies (Baldock et al. 2019) often are found in higher concentrations in urban gardens and allotments than in other areas of cities, suggesting that gardens may be resource patches for these groups. This conclusion is also supported by research showing that urban honeybees preferentially forage in gardens or other nearby high-quality floral patches (Garbuzov et al. 2015, Young et al. 2021). Bee 
diversity in urban areas can be the same as (Banaszak-Cibicka and Żmihorski 2020) or greater than (Baldock et al. 2015) the bee diversity in surrounding rural areas.

Furthermore, garden characteristics often have stronger impacts on pollinator abundance and diversity than do landscape-scale effects (reviewed by Majewska and Altizer 2020). In urban bees, garden size (Quistberg et al. 2016, Egerer et al. 2020), floral abundance (Ahrné et al. 2009, Matteson and Langellotto 2010, Pardee and Philpott 2014, Quistberg et al. 2016, Simao et al. 2018), plant diversity (Hülsmann et al. 2015, Wilson and Jamieson 2019), and plant species composition (Hülsmann et al. 2015, Threlfall et al. 2015) may be particularly important factors. These studies suggest that high-quality urban gardens may be able to compensate for some of the negative impacts of urbanization on some pollinators, and that we can improve urban green spaces that are currently poor habitat for pollinators.

Because the majority of urban pollinator research has focused on bees, we currently have a poor understanding of the factors that promote greater butterfly diversity and abundance in urban gardens. Most studies of butterflies in urban areas have focused on land-use changes and the negative impact of urbanization, but there is some evidence that local factors can also influence urban butterfly diversity and abundance. For example, garden size is positively correlated with European butterfly (Knapp et al. 2008, Fontaine et al. 2016, Shwartz et al. 2013) and moth diversity (Bates et al. 2014), and high plant species richness has been linked to greater butterfly diversity in urban rights-of-way in Canada (Leston and Koper 2016) and rooftop gardens in Singapore (Wang et al. 2017).

The presence of native plants may also affect the conservation potential of urban gardens, given that the replacement of native species with exotics has been linked to the 
decline of insect herbivores (reviewed by Tallamy et al. 2020). Urban gardens are generally associated with high proportions of exotic plant species (Concepción et al. 2015), so it may be possible to substantially improve their quality by increasing the prevalence of native plant use by gardeners. The presence of native plants is associated with greater bee species richness (McIntyre and Hostetler 2001, Egerer et al. 2020) and abundance (Pardee and Philpott 2014, Threlfall et al. 2017, Egerer et al. 2020), as well as the presence of more native (Pardee and Philpott 2014), rare (McIntyre and Hostetler 2001) and specialist (Threlfall et al. 2015) species. There is some evidence that native plants may be associated with higher diversity and abundance of butterflies as well. Butterfly species richness is higher in grasslands (Collinge et al. 2003) and montane habitats (Simonson et al. 2001) that have a higher proportion of native species and butterfly abundance slightly increased with native floral abundance in urban transects of Melbourne, Australia (Kurylo et al. 2020). In suburban yards, a higher species diversity of moth and butterfly caterpillars occurred in native plant gardens than in yards with nonnative ground cover and shrubs (Burghardt et al. 2009). Regardless, the effectiveness of urban native plant gardens as possible refuges for butterflies is still not well understood.

In this study, we evaluated the potential of gardens to ameliorate the expected negative effects of increasing urbanization on butterflies. We assessed several local characteristics of native plant gardens (garden area, flowering plant species richness, and planting density) situated on an urban-rural gradient, and determined their effects on butterfly species richness, abundance, and community composition (specifically in terms of the presence/absence of specialist species). This allowed us to identify the factors that 
are most strongly linked with butterfly diversity and abundance, with the aim of improving gardens as resource patches for butterflies.

\section{Methods}

\section{Site and survey methods}

We conducted this study at 26 gardens (Fig. 9) in three adjacent counties in Kentucky, USA: Jefferson, Bullitt, and Hardin. Jefferson County includes the entire city of Louisville $\left(38^{\circ} 15^{\prime} \mathrm{N}, 85^{\circ} 46^{\prime} \mathrm{W}\right)$, which had a population just above 760,000 in 2019 (U.S. Census Bureau, 2019). Jefferson, Bullitt and Hardin counties are located in northcentral Kentucky and are a part of the Interior Low Plateau, Bluegrass Section in the Eastern Broadleaf Forest (Continental) Province biome (USDA Forest Service 2018). Annual mean temperature for Louisville is $14.6^{\circ} \mathrm{C}$ with a mean minimum in January of $2.8^{\circ} \mathrm{C}$ and a mean maximum in July of $31.7^{\circ} \mathrm{C}$. Annual precipitation averages $114 \mathrm{~cm}$ and ranges from 7.6 to $13.4 \mathrm{~cm}$ monthly (US Climate Data 2018).

We conducted butterfly surveys at 26 garden sites from May-October 2018. These sites included eight residential gardens, eight gardens at schools, nine gardens in public parks, and one corporate garden (Table 2). The term "garden" will be used to refer to all of the sites, although 6 of the park sites are restored meadow patches. To test the effects of garden size on butterfly diversity and abundance, we selected gardens that ranged widely in size $\left(18-2,165 \mathrm{~m}^{2}\right)$, and because the amount of available sunlight can influence butterfly diversity (Matteson and Langellotto 2010), we included only gardens with little to no tree cover. To evaluate the potential of native plant gardens to attract 
butterflies, we used sites with a majority of native plants, as small numbers of native plants may have little effect on the presence of butterflies and other pollinators when the overwhelming majority of garden flora is exotic (Matteson and Langellotto 2011).

Surveys began at 10:00 AM and ended no later than 1.5 hours before sunset. The minimum temperature for beginning a survey was $17^{\circ} \mathrm{C}$ (Cussans et al. 2010, Konvicka and Kadlec 2011, Shackleton and Ratnieks 2015), and surveys were conducted only when there was no precipitation and Beaufort wind speed was less than 5 (Cussans et al. 2010). Gardens were surveyed on a rotating basis, so that all 26 gardens were visited before repeating any sites. We used a rule-based stopping method for the surveys (Prescott and Eason 2018). Each survey had a base length of 20 minutes (Shackleton and Ratnieks 2015); if a new butterfly species appeared in the final five minutes of the survey then the survey was extended for an additional 10 minutes. This process was repeated until no new species appeared in the final five minutes. The Pollard (1977) method of surveying was not used because transect surveys were not appropriate for the sites that were small, formal gardens (Wang et al. 2017). We conducted each survey by actively searching the garden for butterflies, walking slowly throughout the site and recording each butterfly seen. Butterflies were identified to species using Eagle Optics ${ }^{\odot} 10 \times 42$ binoculars and a field guide (Kaufman and Brock 2006). We paused the survey timer while identifying any individuals that were not immediately recognizable to species, and if needed we photographed such individuals with a digital camera for later verification.

\section{Determination of generalists and specialists}


Butterflies were defined as host-plant specialists or host-plant generalists based on an established definition by Kitahara and Fujii (1994). Butterflies known to feed on 10 or fewer host plant species in the same taxonomic family were classified as host-plant specialists, and butterflies known to feed either on more than 10 host plant species in the same taxonomic family or on host plants in two or more taxonomic families were classified as host-plant generalists.

\section{Garden variables}

We recorded the following variables at each site: percent impervious surface surrounding the garden, garden area $\left(\mathrm{m}^{2}\right)$, plant species richness, and plant biovolume density $\left(\mathrm{m}^{3} / \mathrm{m}^{2}\right)$. We used ArcGIS ${ }^{\circledast}$ to calculate the percentage of impervious surface surrounding each site for radii of $0.5 \mathrm{~km}, 1.0 \mathrm{~km}$, and $1.5 \mathrm{~km}$. We included all herbaceous plants and shrubs in calculating plant species richness, which ranged from 8 65 species. We calculated plant biovolume density using two different methods depending on plant density. At high-density sites, we recorded plant height every $2 \mathrm{~m}$ along a transect; transects were $3 \mathrm{~m}$ apart for small sites (those with area less than 500 $\mathrm{m}^{2}$ ) and $5 \mathrm{~m}$ apart for three large meadows that were over $1000 \mathrm{~m}^{2}$ in area. Length of each transect varied proportionately by meadow or garden area sampled. At high-density sites, where plants were immediately adjacent to one another, plant biovolume density was equivalent to mean plant height ((garden area x plant height)/garden area). At lowdensity sites, where individual plants were spaced apart, we calculated each plant's volume individually, and we divided the sum of all plant volumes by garden area to 
calculate plant biovolume density. Plant biovolume density ranged from $0.02-0.65$ $\mathrm{m}^{3} / \mathrm{m}^{2}$

\section{Statistical Methods}

We analyzed butterfly species richness and butterfly abundance using linear regression models with glm in $\mathrm{R}$ ( $\mathrm{R}$ Core Team 2016.) Both species richness and abundance data were cube-root transformed so that a histogram of the residuals fit a normal distribution. The abundance of cabbage whites (Pieris rapae) was removed prior to our analyses due to over-representation at several urban sites, some of which contained several cabbage white larval host-plants. We analyzed the probability of recording the proportion of host-plant specialists using logistic regression models with glm in R. We used AIC model comparison to determine which measure of percent impervious surface surrounding each site best explained variation in the data; we selected among circles with radii of $0.5 \mathrm{~km}, 1.0 \mathrm{~km}$, and $1.5 \mathrm{~km}$. For each model, the percent impervious surface within $0.5 \mathrm{~km}$ of the sites best explained the variation in the data and was used for further analyses. At $0.5 \mathrm{~km}$, percentage impervious surface ranged from 3-87\%.

\section{Results}

Each of the 26 sites was surveyed 21 times. In total, we recorded 53 butterfly species and 5,121 individual butterflies. Of the 53 species recorded, 30 were classified as host-plant generalists and 23 were classified as host-plant specialists (Table 3). Excluding woodland and marsh butterflies, the species we recorded represent $67 \%$ of the regional species pool (Covell 1974). Over all 21 survey periods combined, cumulative butterfly 
species richness per site ranged from $7-37$, and cumulative butterfly abundance per site ranged from 9-750.

Total butterfly species richness was not significantly affected by plant biovolume density, but each of the other explanatory variables (percent impervious surface $(0.5 \mathrm{~km})$, garden area, and plant species richness) had significant effects in the final linear regression model. Garden area had a significant main effect $(\mathrm{p}=0.037)$, with the number of butterfly species recorded increasing as garden area increased. Butterfly species richness increased steeply as garden area increased up to approximately $300 \mathrm{~m}^{2}$ and increased more gradually across larger gardens (Figure 10). There was a significant interaction between percent impervious surface and plant species richness $(\mathrm{p}=0.027)$. When plant species richness was low, increasing percent impervious surface had a strong negative effect on butterfly species richness. However, higher values of plant species richness lessened the negative effect of impervious surface. In areas with a high percentage of impervious surface, butterfly species richness increased with increasing plant species richness, but as percent impervious surface decreased, the positive effect of plant species richness on the number of butterfly species also decreased (Figure 11).

All four explanatory variables influenced total butterfly abundance through significant interactions in the final linear regression model. Percentage impervious surface interacted significantly with both garden area $(\mathrm{p}<0.001)$ and plant biovolume density $(\mathrm{p}=0.001)$. There was also a significant interaction between plant biovolume density and plant species richness $(\mathrm{p}=0.026)$. When gardens were small, high levels of percent impervious surface had a large negative impact on butterfly abundance, but this effect was reduced as gardens increased in size, such that large urban gardens supported 
much higher butterfly abundances than small urban gardens (Figure 12). This same pattern was observed in the interaction between percent impervious surface and plant biovolume density. Increasing plant biovolume density was most effective in increasing butterfly abundance when percent impervious surface was high, and the negative effect of percent impervious surface was strongest when plant biovolume density was very low (Figure 13). The interaction between plant biovolume density and plant species richness followed a different pattern. Increasing either variable had a positive effect on butterfly abundance when the other variable was low, but the effect of either variable on butterfly abundance was greatly diminished when both variables were average-to-high (Figure 14).

In the logistic regression on the proportion of host-plant specialists, percent impervious surface had a significant main effect (Figure 15, $\mathrm{p}<0.001$ ), and there was a significant interaction between garden area and plant species richness (Figure 16, $\mathrm{p}<0.0001)$. Plant biovolume density did not have a significant effect. As percent impervious surface increased, the likelihood of seeing a host-plant specialist decreased. The likelihood of seeing a host-plant specialist increased when garden area and plant species richness both increased.

\section{Discussion}

Although our study found that increasing urbanization had negative effects on butterfly species richness and abundance, we did not find the main-effect declines that are characteristic of many previous studies (Blair 1999, Ramírez-Restrepo and MacGregorFors 2016, Merckx and Van Dyck 2019, Tzortzakaki et al. 2019, Kurylo et al. 2020, Kuussaari et al. 2020). Instead, we found that complex interactions between a garden's 
features (size, plant species richness, plant biovolume density) and the amount of impervious surface surrounding it significantly affected both butterfly species richness and abundance.

Garden area was the strongest driver of butterfly species richness and abundance in our study. As garden area increased, sites had significantly higher butterfly species richness regardless of their level of urbanization. Garden area significantly affected butterfly abundance via an interaction with percent impervious surface. At all levels of percent impervious surface, increasing garden area increased butterfly abundance, and this effect was magnified at high levels of percent impervious surface (see also Fontaine et al. 2016). Large urban gardens thus had much higher butterfly abundances than small urban gardens. Several urban butterfly studies in Europe have also found positive effects of increasing patch size on butterfly species richness (Knapp et al. 2008, Fontaine et al. 2016, Shwartz et al. 2013), and patch area is an important driver of urban arthropod diversity and abundance in general (Bolger et al. 2000, Quistberg et al. 2016, Burks and Philpott 2017, Egerer et al. 2020). This pattern is also found in other taxa; for example, urban bird diversity (Jokimäki 1999, Crooks et al. 2004, Dale 2018, Mayorga et al. 2020) and abundance (Crooks et al. 2004, Mayorga et al. 2020) is higher in larger habitat patches.

Butterfly species richness was also significantly affected by an interaction between percent impervious surface and plant species richness. Increasing percent impervious surface resulted in significant declines in butterfly species richness only when garden plant species richness was low. Plant diversity has been tied to butterfly species richness in both urban rights-of-way (Leston and Koper 2016) and natural systems like 
forests (Simonson et al. 2001, Kitahara et al. 2008) and shrubland (Grill et al. 2005). This may be attributable in part to butterfly species' divergence and specificity in foraging preferences (Bergerot et al. 2010, Pohl et al. 2011), requiring the availability of a wide variety of nectar plants to satisfy the full community (Shackleton and Ratnieks 2015). Similarly, Theodorou et al. (2020) found that bee species richness and abundance was strongly tied to plant species richness and indirectly influenced by the negative effect of increasing urbanization on the species richness of flowering plants. Accordingly, enhancing the species richness of nectar and host plants in urban gardens and other green spaces may help recapture some of the butterfly diversity that is typically lost in urban areas.

Plant biovolume density did not significantly influence butterfly species richness but did significantly affect butterfly abundance. Butterfly abundance significantly declined with increasing percent impervious surface only when plant biovolume density was low, i.e. where garden plant cover was relatively sparse. Although there have not been many studies addressing the effect of plant biovolume density on butterflies, the abundance of some few species, including the pearl crescent (Phyciodes tharos) and the European skipper (Thymelicus lineola), increased with greater plant density (Leston and Koper 2016). Greater herbaceous plant and shrub cover has also been associated with beneficial effects for other animal taxa in urban systems, including increased diversity of birds (Beissinger and Osborne 1982, MacGregor-Fors and Schondube 2011) and wasps (Lassau and Hochuli 2005). Similarly, in other human-managed landscapes, such as vineyards (Sáenz-Romo et al. 2019) and orchards (Silva et al. 2010), more ground cover significantly increases arthropod abundances. We also found some compensatory effects 
of plant biovolume density and plant species richness on butterfly abundance: increasing either variable helped increase butterfly abundance to a certain point, after which additional increases in either factor did not result in increases in butterfly abundance. The effects of these two variables on butterfly abundance are much weaker than the effects of garden size and percent impervious surface.

Although the impact of percent impervious surface was tempered by garden characteristics for butterfly species richness and abundance, it had a negative main effect on the proportion of specialist species, which declined slightly but significantly $(\sim 23 \%-$ $12 \%$ ) as percent impervious surface increased. This supports previous evidence that urban habitats filter out most butterfly specialist species (Kitahara and Fujii 1994, Blair and Launer 1995, Koh and Sodhi 2004, Bergerot et al. 2010). However, increasing plant species richness and garden area had positive effects on the proportion of host-plant specialists, so it is possible that some of specialist species can be recovered in urban gardens if those gardens are fairly large and plant-diverse. Some research has shown that host-plant specialists (Steffan-Dewenter and Tscharntke 2000) and habitat specialists (Krauss et al. 2003a, Krauss et al. 2003b) are more sensitive to changes in habitat size and thus exhibit a steeper species-area curve than generalists. Therefore, there may be a minimum garden size that is required to support host-specialists, a threshold that likely increases for urban gardens. Increasing plant species richness could be critical for attracting specialist species; more information is needed, but there is some evidence that the presence of host-plant specialists is tied to plant diversity (Aviron et al. 2011). It may be possible to aid specialists in urban environments by planting gardens on the outskirts of large parks and urban forest fragments. Gardens in close proximity to potential sources 
of more specialized pollinators, such as reserves and forest fragments, often have more diverse communities (Majewska and Altizer 2020). In our study, the 10 most infrequently recorded species (occurring at only one or two sites) were found (with one exception) at sites with relatively large nearby forest fragments. This result may be in part due to habitat and/or host plant requirements, as 6 of the 10 species were woodland butterflies like Satyrium calanus, the banded hairstreak, and Satyrodes appalachia, the Appalachian brown. Even parks that are relatively isolated may serve as important refuges for butterflies; in our study, park gardens that were relatively close to the city center had a high degree of community similarity to park gardens that were very distant from the city center (Sørensen similarity index: 0.82). Furthermore, parks and other large urban greenspaces should be improved to expand specialist habitat, as the presence of grassland (Krauss et al. 2003a, Krauss et al. 2003b) and woodland (Yamaura et al. 2008) butterflies in fragmented landscapes is strongly tied to the patch area of these specific habitat types.

Plant communities in urban areas are often dominated by exotic and invasive species (Pickett et al. 2011, Concepción et al. 2015), and accordingly previous butterfly and pollinator studies in urban systems often focused on gardens with a high percentage of exotic or invasive plants. While exotic plants are frequently used by pollinators as nectar sources (Lowenstein et al. 2019, Staab et al. 2020), there is little evidence that they are more beneficial than native plants (Bergerot et al. 2010, Harrison and Winfree 2015). In fact, the presence of exotic species consistently causes negative effects on butterfly communities and decreases in caterpillar survival (reviewed by Yoon et al. 2016). The gardens we tested in this study were composed predominantly of native plants, and therefore our measure of plant species richness was nearly identical to a measure of 
native plant species richness. Given the general importance of native plants to butterflies (Simonson et al. 2001, Collinge et al. 2003, Kurylo et al. 2020) bees (McIntyre and Hostetler 2001, Pardee and Philpott 2014, Threlfall et al. 2015, Threlfall et al. 2017, Egerer et al. 2020), and other insects (Smith et al. 2015, Fukase and Simons 2016) it is possible that the relatively strong effects of plant species richness in our study (it was associated with increased butterfly species richness, abundance, and host-specialist presence) were magnified because the plant species were native rather than exotic. While native plant gardens may not represent the majority of current gardens, they may represent best practices for butterfly conservation.

In conclusion, our results show that urban native plant gardens can be improved to help ameliorate the deleterious impacts of urbanization on butterflies. The primary focus for conservation efforts should be increasing garden size. This can be accomplished easily in suburban areas by expanding gardens into space currently taken up by lawns, as traditional lawns support comparatively little biodiversity (Smith et al. 2015). For more tightly packed urban lots, it may be possible to capture a similar effect at the neighborhood or community level by turning small adjacent gardens into a much larger “collective" garden. (Vergnes et al. 2012, Braaker et al. 2014) Urban gardens can also be improved by adding plant species and planting gardens more densely. The use of predominantly native plants could substantially improve garden quality, especially considering that almost all native butterflies require native host-plant species. Where possible, native trees should also be added within or adjacent to gardens, as trees are important hosts for many butterfly species. Promoting the widespread use of native plants in urban gardens may thus be vital to maximizing gardens as conservation spaces for 
butterflies. Convincing the public to "go native" is likely to be difficult, as many gardeners prefer exotic plant species (Anderson et al. 2014) due to their presumed aesthetic superiority. Encouraging native plant use will also require facilitating the procurement of native species, as they can be difficult to source and exotics are far more readily available for purchase in nurseries and garden centers (Hoff and Rydgren 2011, Altrichter et al. 2017, Torres-Camacho et al. 2017).

However, it is important to note that improving urban gardens cannot replace the full benefits provided by rural and natural habitats. In many ways rural gardens are inherently more likely to have higher butterfly biodiversity and abundance due to the more natural surrounding matrix, so tweaking characteristics like plant species richness and plant biovolume density didn't change their attractiveness to butterflies nearly as much as they did in urban environments, where the matrix is not generally habitable (Dennis and Hardy 2007) and gardens acted more as oases. It is likely that rural and natural areas provide the source populations for many butterfly species found in the city (Majewska and Altizer 2020). If too much of this habitat is lost to further urban expansion, many butterfly species may face such drastic declines that urban conservation spaces will lose their value. 
Table 2

\begin{tabular}{|c|c|c|c|c|c|}
\hline Site & Site Type & $\begin{array}{c}\text { \% Impervious } \\
\text { Surface }(0.5 \\
\text { km radius) }\end{array}$ & $\begin{array}{l}\text { Garden Area } \\
\qquad\left(\mathrm{m}^{2}\right)\end{array}$ & $\begin{array}{l}\text { Plant Species } \\
\text { Richness }\end{array}$ & $\begin{array}{c}\text { Plant } \\
\text { Biovolume } \\
\text { Density } \\
\left(\mathrm{m}^{3} / \mathrm{m}^{2}\right) \\
\end{array}$ \\
\hline Bernheim I & Park & 3.5 & 2574 & 12 & 0.05 \\
\hline Iroquois I & Park & 4.0 & 1238 & 29 & 0.61 \\
\hline Iroquois II & Park & 4.0 & 200 & 21 & 0.49 \\
\hline Bernheim II & Park & 5.6 & 42.5 & 13 & 0.02 \\
\hline Broad Run & Park & 8.0 & 120 & 18 & 0.04 \\
\hline Beckley I & Park & 8.6 & 80 & 8 & 0.15 \\
\hline Beckley II & Park & 9.6 & 2165 & 31 & 0.44 \\
\hline Private Garden I & Residential & 9.6 & 18 & 19 & 0.04 \\
\hline Cherokee I & Park & 10.9 & 426 & 9 & 0.60 \\
\hline Cherokee II & Park & 13.1 & 1024 & 34 & 0.38 \\
\hline Moore & School & 23.7 & 384.1 & 22 & 0.55 \\
\hline St. Agnes & School & 27.8 & 82.3 & 26 & 0.05 \\
\hline $\begin{array}{c}\text { Louisville Nature } \\
\text { Center }\end{array}$ & Park & 29.2 & 448.7 & 34 & 0.24 \\
\hline Chenoweth & School & 38.0 & 125.8 & 39 & 0.03 \\
\hline John Paul II & School & 40.8 & 82.3 & 24 & 0.65 \\
\hline Private Garden II & Residential & 44.0 & 96.8 & 49 & 0.30 \\
\hline Private Garden III & Residential & 44.6 & 102.1 & 46 & 0.43 \\
\hline Private Garden IV & Residential & 46.2 & 91.6 & 59 & 0.41 \\
\hline Portland & School & 48.6 & 44.4 & 33 & 0.04 \\
\hline Holy Spirit & School & 49.3 & 59.5 & 20 & 0.05 \\
\hline Private Garden V & Residential & 50.5 & 35.4 & 40 & 0.12 \\
\hline $\begin{array}{c}\text { Old Louisville } \\
\text { Community Garden }\end{array}$ & Residential & 59.0 & 34.2 & 29 & 0.47 \\
\hline Private Garden VI & Residential & 61.4 & 20.9 & 17 & 0.38 \\
\hline $\begin{array}{l}\text { U of L Korfhage } \\
\text { Garden }\end{array}$ & School & 67.5 & 372.4 & 65 & 0.02 \\
\hline Copper and Kings & Business & 74.6 & 341.9 & 38 & 0.41 \\
\hline St. Francis & School & 87.4 & 184.5 & 13 & 0.24 \\
\hline
\end{tabular}


Table 3

\begin{tabular}{|c|c|c|c|c|c|}
\hline Family & Genus & Species & $\begin{array}{l}\text { Common } \\
\text { Name }\end{array}$ & Abundance & $\begin{array}{c}\text { Host } \\
\text { specificity }\end{array}$ \\
\hline \multirow[t]{5}{*}{ Papillionidae } & Battus & Battus philenor & $\begin{array}{l}\text { Pipevine } \\
\text { swallowtail }\end{array}$ & 4 & Specialist \\
\hline & Papilio & Papilio glaucus & $\begin{array}{l}\text { Eastern tiger } \\
\text { swallowtail }\end{array}$ & 108 & Generalist \\
\hline & & $\begin{array}{c}\text { Papilio } \\
\text { polyxenes }\end{array}$ & $\begin{array}{c}\text { Black } \\
\text { swallowtail }\end{array}$ & 13 & Generalist \\
\hline & & Papilio troilus & $\begin{array}{l}\text { Spicebush } \\
\text { swallowtail }\end{array}$ & 53 & Specialist \\
\hline & - & NIS & - & 43 & - \\
\hline \multirow[t]{7}{*}{ Lycaenidae } & Calycopis & $\begin{array}{l}\text { Calycopis } \\
\text { cecrops }\end{array}$ & $\begin{array}{l}\text { Red-banded } \\
\text { hairstreak }\end{array}$ & 10 & Generalist \\
\hline & Celastrina & $\begin{array}{l}\text { Celastrina } \\
\text { neglecta }\end{array}$ & Summer azure & 36 & Generalist \\
\hline & Everes & Everes comyntas & $\begin{array}{l}\text { Eastern tailed- } \\
\text { blue }\end{array}$ & 434 & Generalist \\
\hline & Satyrium & Satyrium calanus & $\begin{array}{c}\text { Banded } \\
\text { hairstreak }\end{array}$ & 30 & Generalist \\
\hline & & Satyrium titus & $\begin{array}{c}\text { Coral } \\
\text { hairstreak }\end{array}$ & 1 & Specialist \\
\hline & Strymon & Strymon melinus & $\begin{array}{c}\text { Gray } \\
\text { hairstreak }\end{array}$ & 57 & Generalist \\
\hline & - & NIS & - & 3 & - \\
\hline \multirow[t]{14}{*}{ Nymphalidae } & Agraulis & Agraulis vanillae & Gulf fritillary & 2 & Specialist \\
\hline & Asterocampa & $\begin{array}{c}\text { Asterocampa } \\
\text { celtis }\end{array}$ & $\begin{array}{l}\text { Hackberry } \\
\text { emperor }\end{array}$ & 14 & Specialist \\
\hline & Cercyonis & Cercyonis pegala & $\begin{array}{c}\text { Common } \\
\text { wood-nymph }\end{array}$ & 6 & Specialist \\
\hline & Chlosyne & Chlosyne nycteis & $\begin{array}{c}\text { Silvery } \\
\text { checkerspot }\end{array}$ & 133 & Generalist \\
\hline & Danaus & $\begin{array}{l}\text { Danaus } \\
\text { plexippus }\end{array}$ & Monarch & 298 & Specialist \\
\hline & Euptoieta & Euptoieta claudia & $\begin{array}{l}\text { Variegated } \\
\text { fritillary }\end{array}$ & 44 & Generalist \\
\hline & Junonia & Junonia coenia & $\begin{array}{l}\text { Common } \\
\text { buckeye }\end{array}$ & 204 & Generalist \\
\hline & Libytheana & $\begin{array}{l}\text { Libytheana } \\
\text { carinenta }\end{array}$ & $\begin{array}{l}\text { American } \\
\text { snout }\end{array}$ & 23 & Specialist \\
\hline & Limenitis & $\begin{array}{l}\text { Limenitis } \\
\text { archippus }\end{array}$ & Viceroy & 25 & Specialist \\
\hline & & $\begin{array}{l}\text { Limenitis } \\
\text { arthemis }\end{array}$ & $\begin{array}{l}\text { Red-spotted } \\
\text { purple }\end{array}$ & 26 & Generalist \\
\hline & Megisto & Megisto cymela & $\begin{array}{l}\text { Little wood- } \\
\text { satyr }\end{array}$ & 25 & Specialist \\
\hline & Phyciodes & Phyciodes tharos & Pearl crescent & 510 & Generalist \\
\hline & Polygonia & - & - & 6 & Generalist \\
\hline & & $\begin{array}{l}\text { Polygonia } \\
\text { comma }\end{array}$ & $\begin{array}{l}\text { Eastern } \\
\text { comma }\end{array}$ & 2 & Generalist \\
\hline
\end{tabular}




\begin{tabular}{|c|c|c|c|c|c|}
\hline & & Polygonia & Question mark & 12 & Generalist \\
\hline & Satyrodes & $\begin{array}{l}\text { Satyrodes } \\
\text { appalachia }\end{array}$ & $\begin{array}{l}\text { Appalachian } \\
\text { brown }\end{array}$ & 2 & Specialist \\
\hline & Speyeria & Speyeria cybele & $\begin{array}{l}\text { Great spangled } \\
\text { fritillary }\end{array}$ & 21 & Specialist \\
\hline & Vanessa & - & - & 2 & - \\
\hline & & Vanessa atalanta & Red admiral & 23 & Generalist \\
\hline & & Vanessa cardui & Painted lady & 5 & Generalist \\
\hline & & $\begin{array}{c}\text { Vanessa } \\
\text { virginiensis }\end{array}$ & American lady & 7 & Specialist \\
\hline & - & NIS & - & 2 & - \\
\hline Pieridae & Colias & - & - & 51 & Generalist \\
\hline & & Colias eurytheme & $\begin{array}{l}\text { Orange } \\
\text { sulphur }\end{array}$ & 263 & Generalist \\
\hline & & Colias philodice & $\begin{array}{l}\text { Clouded } \\
\text { sulphur }\end{array}$ & 207 & Generalist \\
\hline & Eurema & Eurema lisa & Little yellow & 33 & Specialist \\
\hline & & Eurema nicippe & Sleepy orange & 22 & Specialist \\
\hline & Phoebis & Phoebis sennae & $\begin{array}{l}\text { Cloudless } \\
\text { sulphur }\end{array}$ & 139 & Specialist \\
\hline & Pieris & Pieris rapae & Cabbage white & $354 *$ & Generalist \\
\hline & Pontia & Pontia protodice & $\begin{array}{c}\text { Checkered } \\
\text { white }\end{array}$ & 2 & Generalist \\
\hline Hesperiidae & Achalarus & $\begin{array}{c}\text { Achalarus } \\
\text { lyciades }\end{array}$ & Hoary edge & 1 & Generalist \\
\hline & Anatrytone & Anatrytone logan & $\begin{array}{l}\text { Delaware } \\
\text { skipper }\end{array}$ & 5 & Specialist \\
\hline & Ancyloxypha & $\begin{array}{l}\text { Ancyloxypha } \\
\text { numitor }\end{array}$ & Least skipper & 24 & Generalist \\
\hline & Atalopedes & $\begin{array}{l}\text { Atalopedes } \\
\text { campestris }\end{array}$ & $\begin{array}{l}\text { Sachem } \\
\text { skipper }\end{array}$ & 645 & Generalist \\
\hline & Epargyreus & $\begin{array}{l}\text { Epargyreus } \\
\text { clarus }\end{array}$ & $\begin{array}{l}\text { Silver-spotted } \\
\text { skipper }\end{array}$ & 298 & Generalist \\
\hline & Erynnis & Erynnis baptisiae & $\begin{array}{l}\text { Wild indigo } \\
\text { duskywing }\end{array}$ & 161 & Specialist \\
\hline & & Erynnis horatius & $\begin{array}{l}\text { Horace's } \\
\text { duskywing }\end{array}$ & 1 & Specialist \\
\hline & Euphyes & Euphyes vestris & Dun skipper & 55 & Generalist \\
\hline & Hylephila & $\begin{array}{l}\text { Hylephila } \\
\text { phyleus }\end{array}$ & Fiery skipper & 92 & Generalist \\
\hline & Nastra & $\begin{array}{c}\text { Nastra } \\
\text { lherminier }\end{array}$ & $\begin{array}{l}\text { Swarthy } \\
\text { skipper }\end{array}$ & 11 & Specialist \\
\hline & Poanes & Poanes zabulon & $\begin{array}{l}\text { Zabulon } \\
\text { skipper }\end{array}$ & 36 & Generalist \\
\hline & Pholisora & $\begin{array}{l}\text { Pholisora } \\
\text { catullus }\end{array}$ & $\begin{array}{l}\text { Common } \\
\text { sootywing }\end{array}$ & 2 & Generalist \\
\hline & Polites & Polites origenes & $\begin{array}{l}\text { Crossline } \\
\text { skipper }\end{array}$ & 28 & Specialist \\
\hline & & Polites peckius & Peck's skipper & 201 & Specialist \\
\hline
\end{tabular}




\begin{tabular}{|c|c|c|c|c|}
\hline & $\begin{array}{c}\text { Polites } \\
\text { themistocles }\end{array}$ & $\begin{array}{l}\text { Tawny-edge } \\
\text { skipper }\end{array}$ & 247 & Generalist \\
\hline Pompeius & Pompeius verna & $\begin{array}{c}\text { Little } \\
\text { glassywing }\end{array}$ & 39 & Specialist \\
\hline Pyrgus & $\begin{array}{l}\text { Pyrgus } \\
\text { communis }\end{array}$ & $\begin{array}{l}\text { Common } \\
\text { checkered- } \\
\text { skipper }\end{array}$ & 3 & Generalist \\
\hline- & NIS & - & 17 & - \\
\hline
\end{tabular}


Figure 9

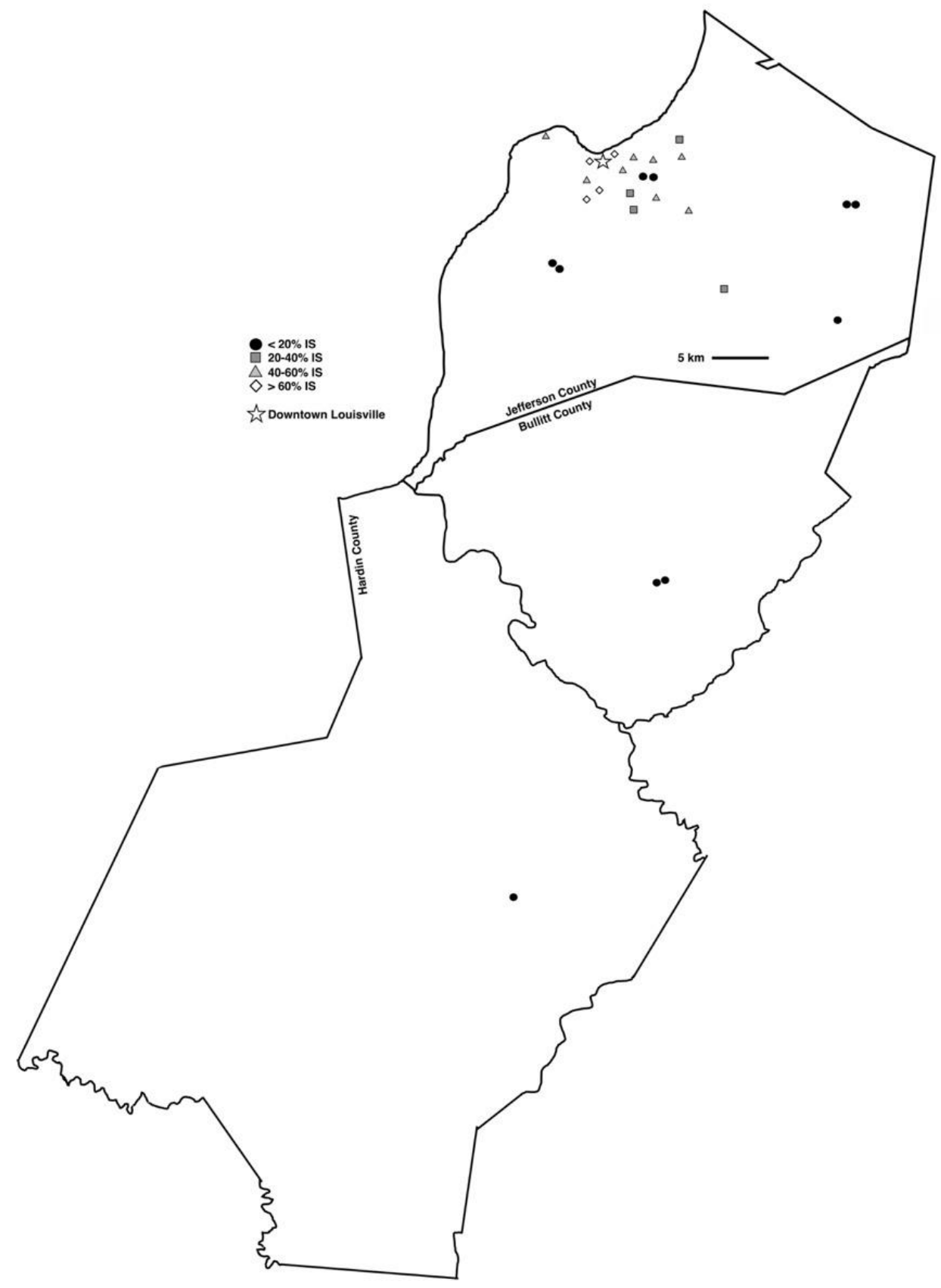


Figure 10

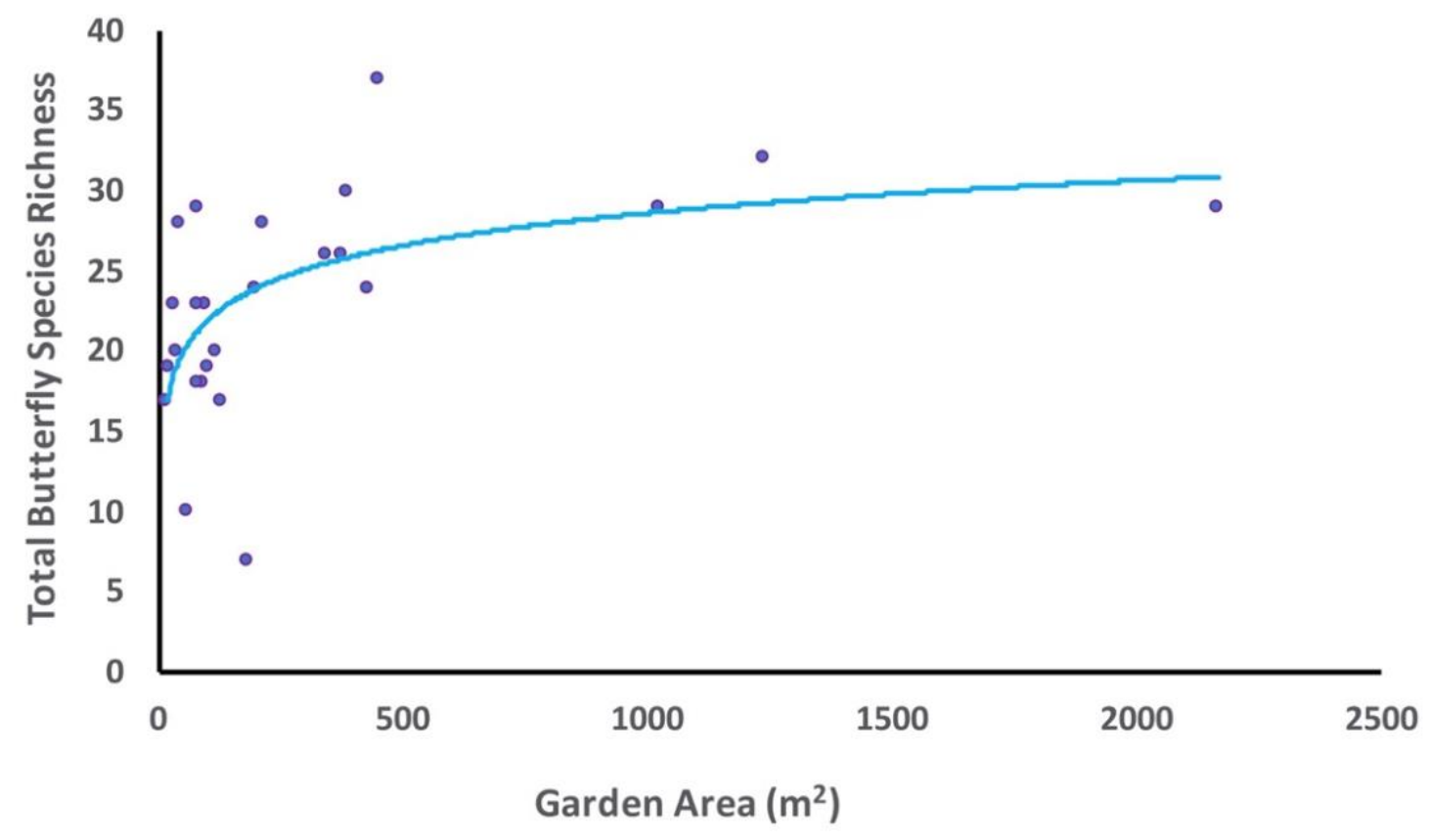


Figure 11

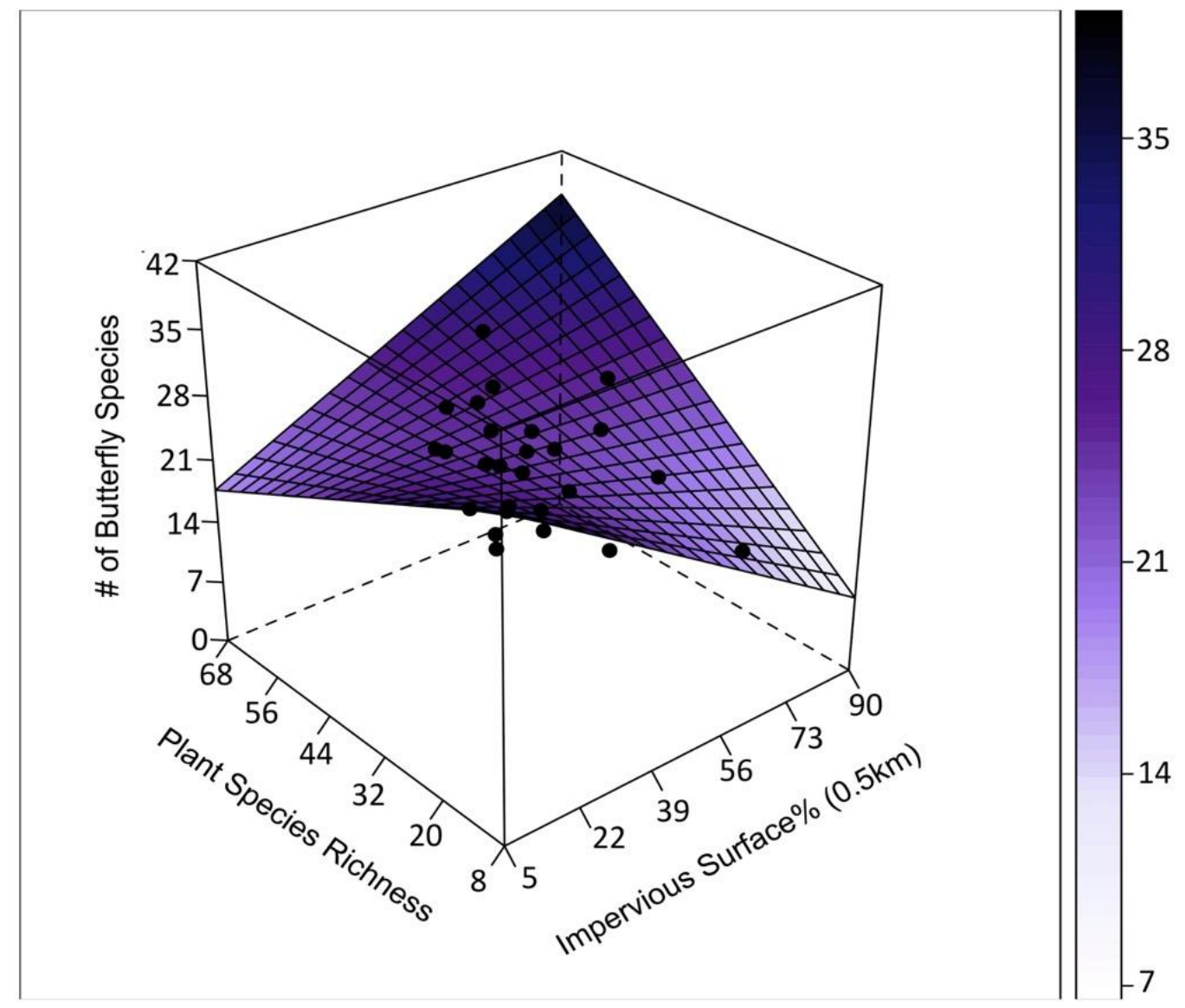


Figure 12

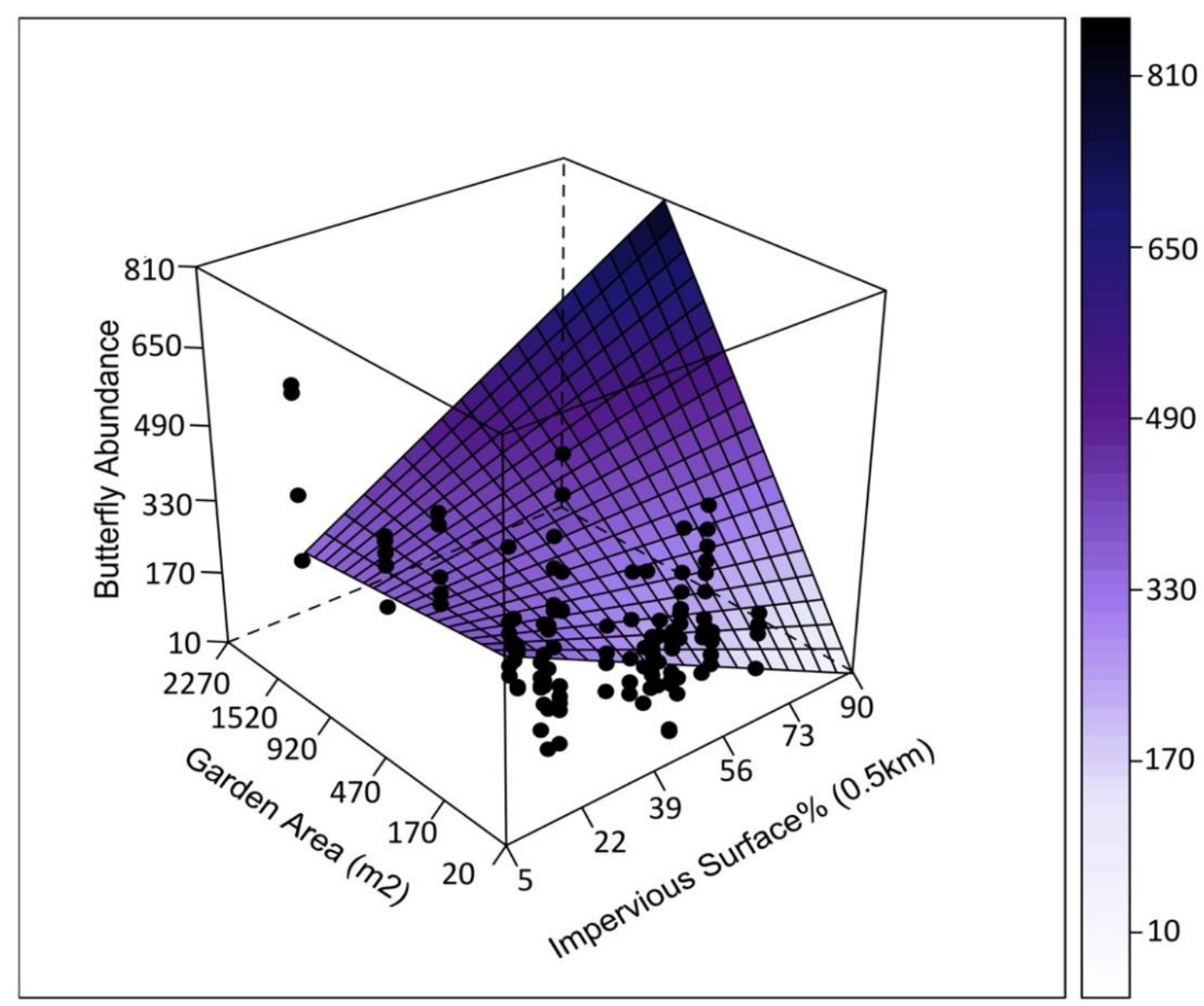


Figure 13

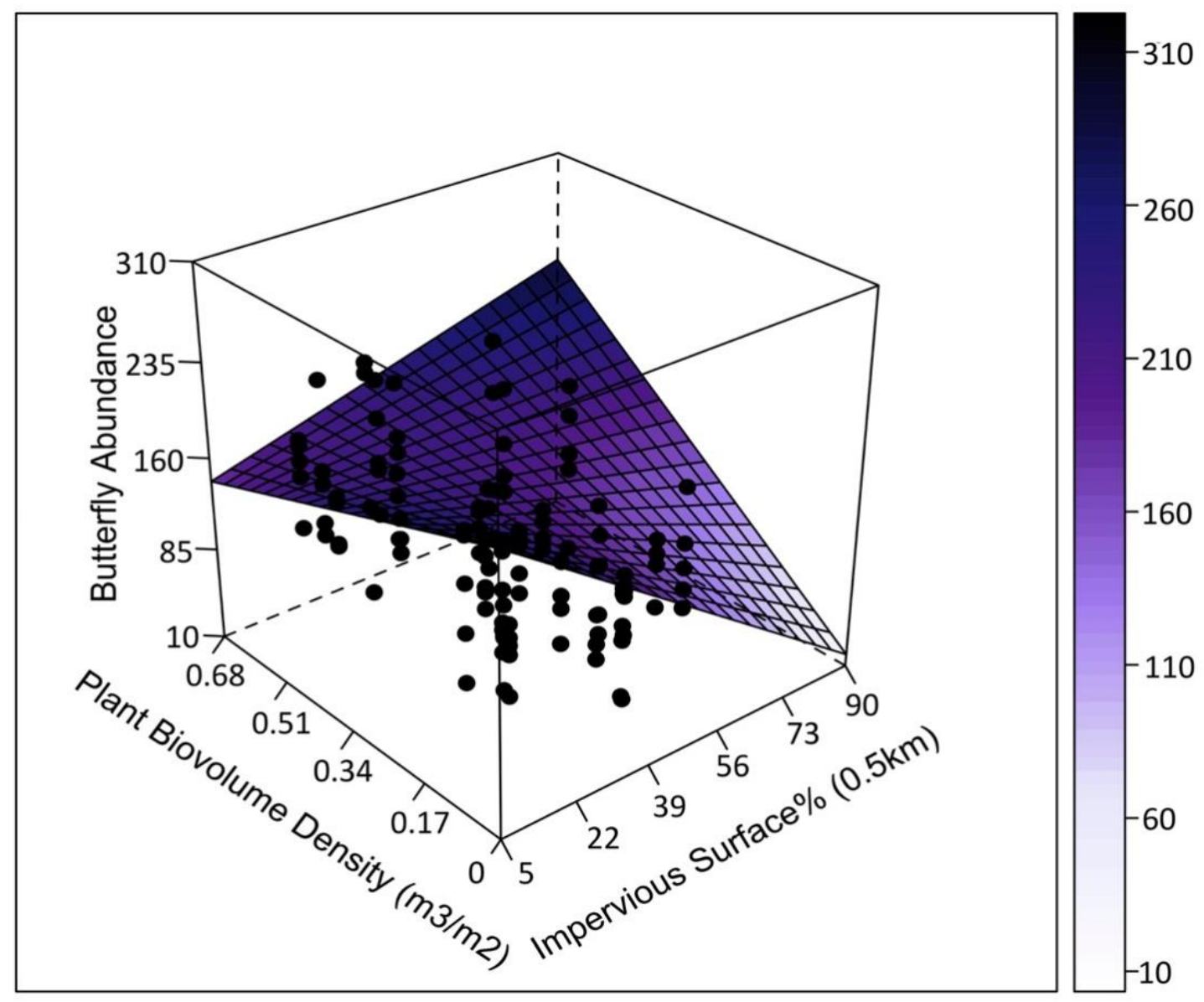


Figure 14

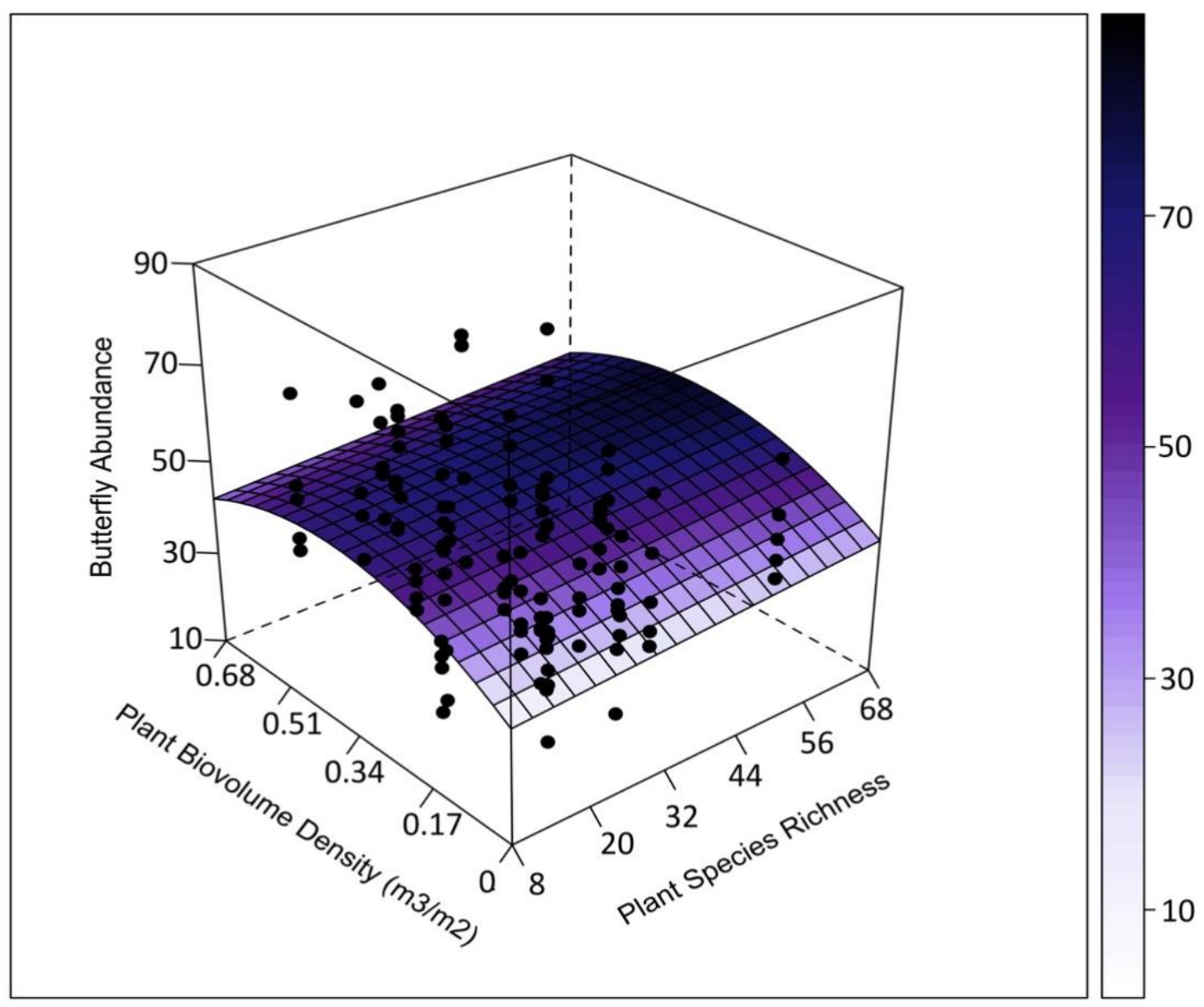


Figure 15

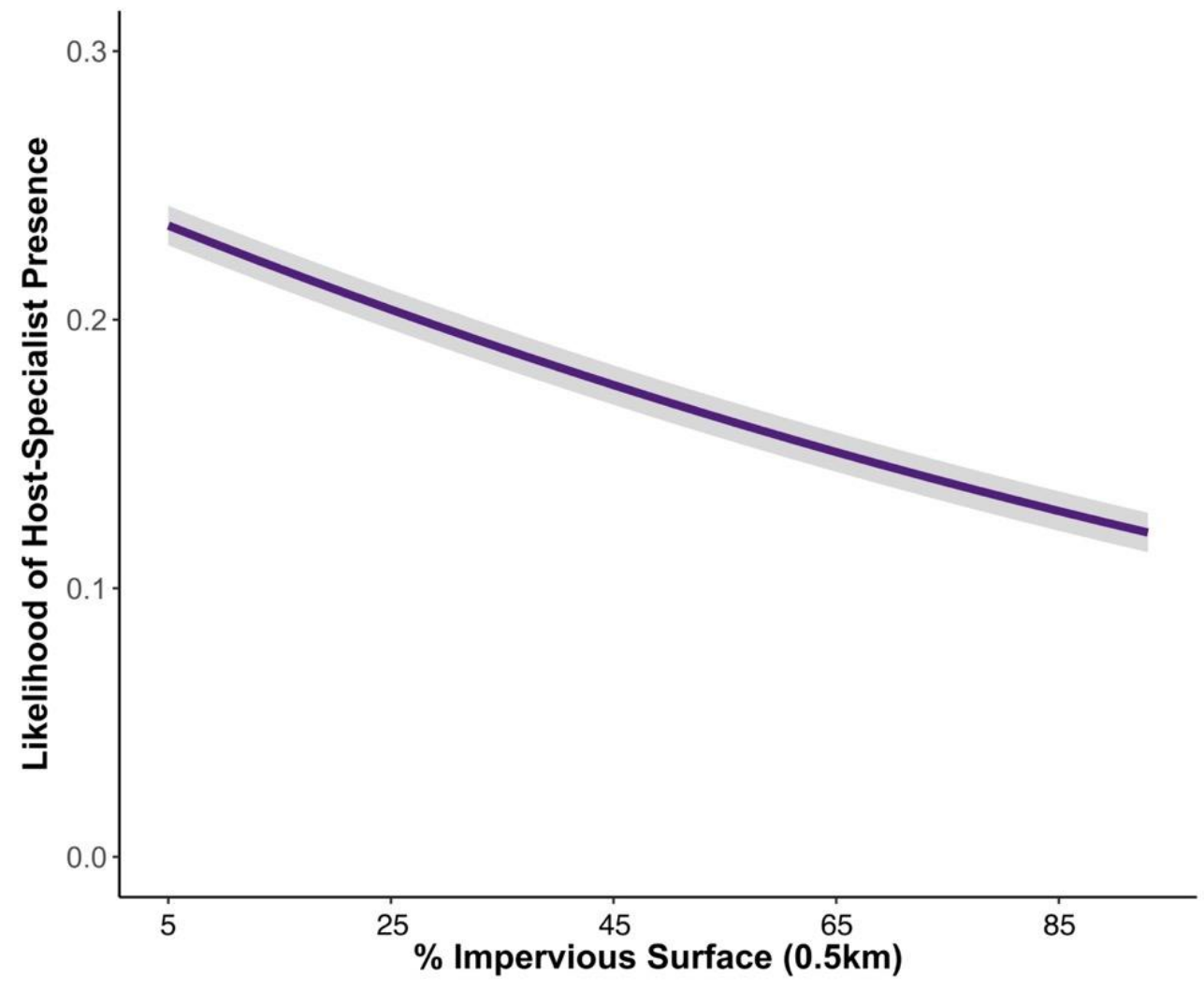


Figure 16

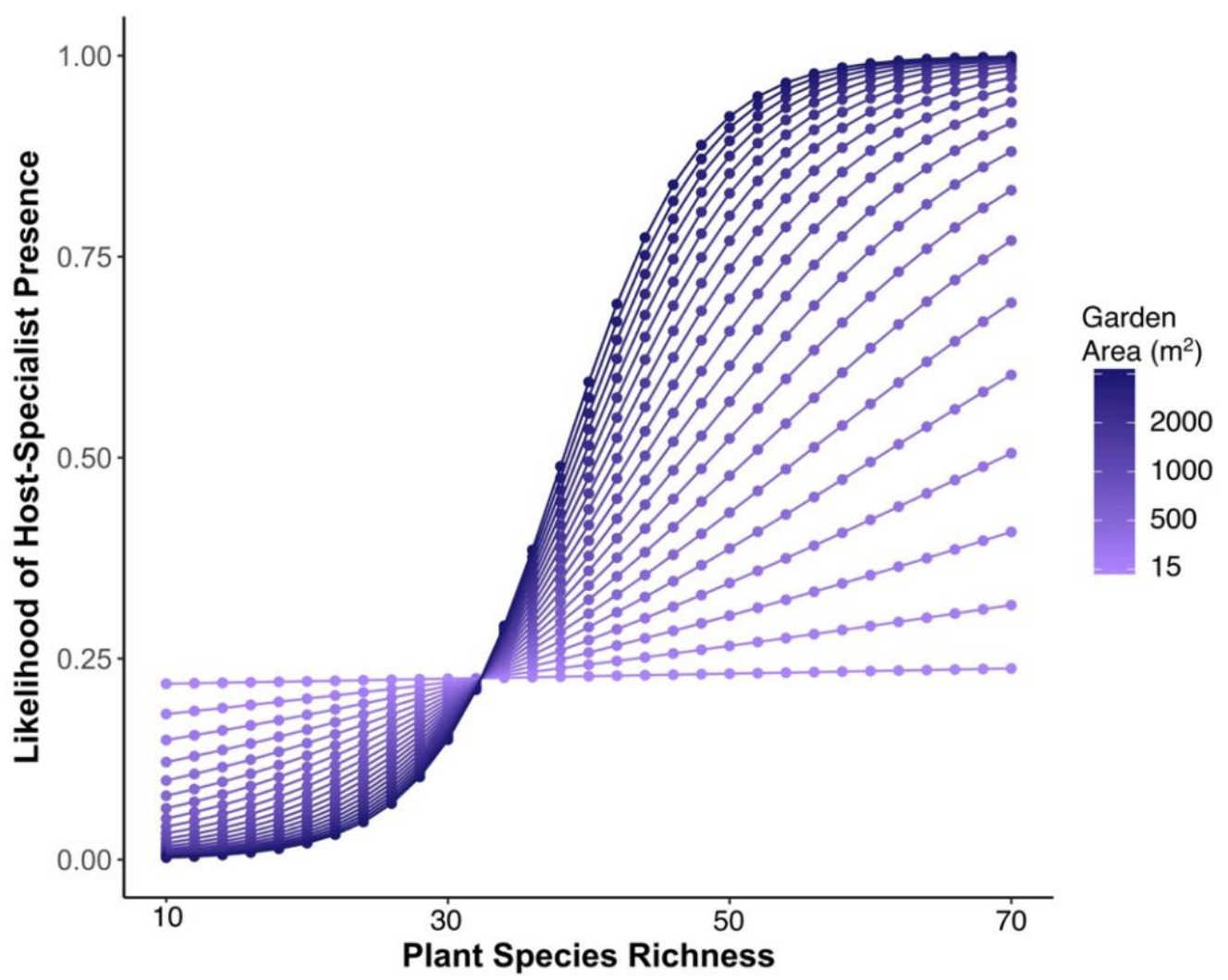




\section{Captions}

Table 2 A table showing each garden site and its characteristics. U of $\mathrm{L}$ refers to the University of Louisville.

Table 3 A table listing each recorded butterfly species by taxonomic Family, along with its abundance and status as a larval host plant specialist or generalist. Abundances are cumulative across all sites and surveys. Some individuals were identified only to Genus; abundances marked "NIS" were identified at the Family level. Cabbage white (Pieris rapae) abundance is marked with an* because it was excluded from our analysis of cumulative butterfly abundance.

Fig. 9 A map showing the relative locations of the 26 garden sites, with the symbol for each site indicating the level of impervious surface (IS) surrounding each site.

Fig. 10 A graph showing the relationship between butterfly species richness and garden area. Butterfly species richness increased asymptotically with garden area $(\mathrm{p}=0.037)$.

Fig. 11 A graph showing the interaction between percent impervious surface and plant species richness, and its effect on butterfly species richness. Where percent impervious surface is high, adding plant species richness increased butterfly species richness $(\mathrm{p}=0.027)$. The color scale indicates increases in butterfly species richness from light to dark.

Fig. 12 A graph showing the interaction between percent impervious surface and garden area, and its effect on butterfly abundance. Butterfly abundance increased with garden area; this effect is particularly strong when percent impervious surface is high $(\mathrm{p}<0.001)$. The color scale indicates increases in butterfly abundance from light to dark. 
Fig. 13 A graph showing the interaction between percent impervious surface and plant biovolume density, and its effect on butterfly abundance. In areas with high percent impervious surface, increasing plant density increased butterfly abundance $(p=0.001)$. The color scale indicates increases in butterfly abundance from light to dark.

Fig. 14 A graph showing the interaction between plant species richness and plant biovolume density, and its effect on butterfly abundance. Butterfly abundance is highest when both plant density and plant species richness are intermediate $(\mathrm{p}=0.026)$.

Fig. 15 A graph showing the effect of percent impervious surface on the proportion of larval host-plant specialists in a garden. The proportion of larval host-plant specialists declined as percent impervious surface increased $(\mathrm{p}<0.001)$.

Fig. 16 A graph showing the interaction between garden area and plant species richness, and its effect on the proportion of larval host-plant specialists in a garden. The proportion of larval host-plant specialists increased with plant species richness; the strength of this increase was magnified in larger gardens $(\mathrm{p}<0.0001)$. 


\section{CHAPTER THREE}

\section{Introduction}

Urban environments affect a wide suite of behaviors across many animal taxa, including anti-predator behavior (Møller et al. 2015, Uchida et al. 2016, AvilésRodríguez and Kolbe 2019), signaling (Halfwerk et al. 2019, Akçay et al. 2020, Lailvaux 2020), movement patterns (Taylor and Paszkowski 2018, Ritzel and Gallo 2020, Rycken et al. 2021), and foraging (Sol et al. 2013, Chejanovski et al. 2017, Ritzel and Gallo 2020). However, most of this research has focused on vertebrates, primarily birds and mammals, and much less is known about the effect of the urban environment on the behavior of insects and other invertebrates. Some studies on invertebrates have examined the effects of an individual component of the urban environment on behavior; for example, Johnson et al.(2020) found that elevated temperatures associated with the urban heat island effect altered the foraging and web-building behaviors of black widow spiders, and Altermatt et al. (2016) found that moths from urban populations exposed to high levels of light pollution were not as attracted to light sources as were rural moths. There is also some evidence that urban environments affect the foraging behavior of bees, as urban bees have been found to alter both distance traveled when foraging (Garbuzov et al. 2015) and the amount of time spent foraging in a patch (Andrieu et al. 2009, Harrison and Winfree 2015) in comparison with rural bees. 
There is very little evidence to indicate whether butterfly foraging and/or movement behaviors are also affected by urban environments; urban butterfly studies have primarily focused on diversity and abundance, and butterfly foraging studies often focus on floral preference in terms of flower color, flower morphology, or plants' native/non-native status. However, some few studies that have characterized butterfly flight behaviors have found that butterflies fly very differently depending on the habitat context. Butterflies recognize habitat patches as distinct from the matrix surrounding those patches (Conradt and Roper 2006), and slower, more looping flight is associated with foraging behavior (Cant et al. 2005). Butterflies generally fly more slowly and more sinuously within habitat patches than in the matrix (Schultz and Crone 2001, Schtickzelle et al. 2007, Skórka et al. 2013) and as the combined abundance of host and nectar plants increases (Fernández et al. 2016). As these different flight patterns are easily recognizable and are associated with both habitat quality and foraging behavior, they provide good metrics for evaluating any differences in butterfly behavior between urban and rural environments.

In this study, we analyzed the flight and foraging behaviors of cabbage white butterflies (Pieris rapae) in urban and rural gardens. The goals of this research were to a) determine whether butterfly flight and foraging behaviors differ between urban and rural gardens and b) examine whether distinctive flight patterns are associated with foraging activity and floral resources alone, in the absence of significant host-plant presence.

\section{Methods}




\section{Site and survey methods}

This study took place in three adjacent counties in Kentucky, USA: Jefferson, Bullitt, and Hardin. Jefferson County includes the entire city of Louisville $\left(38^{\circ} 15^{\prime} \mathrm{N}, 85^{\circ}\right.$ 46’ W), which had a population just above 760,000 in 2019 (U.S. Census Bureau, 2019). Jefferson, Bullitt and Hardin counties are located in north-central Kentucky and are a part of the Interior Low Plateau, Bluegrass Section and in the Eastern Broadleaf Forest (Continental) Province biome (USDA Forest Service 2018). Annual mean temperature for Louisville is $14.6{ }^{\circ} \mathrm{C}$ with a mean minimum in January of $-2.8^{\circ} \mathrm{C}$ and a mean maximum in July of $31.7^{\circ} \mathrm{C}$. Annual precipitation averages $114 \mathrm{~cm}$ and ranges from 7.6 to $13.4 \mathrm{~cm}$ monthly (US Climate Data 2018).

We conducted butterfly behavior trials at 12 garden sites from July-September 2019. These sites included five residential gardens, four gardens in parks, two gardens at schools, and one corporate garden (Table 4). Half of the gardens were located in urban areas (44-75\% impervious surface within $0.5 \mathrm{~km}$ radius), and the other half were located in rural areas (4-22\% impervious surface within $0.5 \mathrm{~km}$ radius). The gardens were sizematched, with four sites (two urban and two rural) in each size category: small $\left(<45 \mathrm{~m}^{2}\right)$, medium (80-120 $\left.\mathrm{m}^{2}\right)$, and large (300-400 $\left.\mathrm{m}^{2}\right)$. All gardens had little to no tree cover and thus generally received full sun. Butterfly trials began at 11:00 AM and ended no later than 1.5 hours before sunset. Across trials, temperatures ranged from $27-40^{\circ} \mathrm{C}$, and windspeeds ranged from 3-19 kph. General weather conditions were also recorded as sunny, part sun, or overcast. We estimated floral abundance at the site for each trial; flowers inside inflorescences were counted as individual flowers regardless of size (Cohen et al. 2020). 
In all of the trials, butterflies were captured at one site and released in another that was at least $1.5 \mathrm{~km}$ away from the capture point. The majority of the individuals $(\mathrm{N}=125)$ used in this study were captured from locations that were not used as trial sites. On the few occasions $(\mathrm{N}=17)$ when butterflies were captured at a trial site, they were released at a different trial site. Equal numbers of butterflies were captured in urban and rural source locations, and the trials at each site used butterflies from urban and rural sources evenly. Therefore, trials included all four possible combinations of urban versus rural origin and destination. Prior to conducting a trial, we caught cabbage white butterflies (Pieris rapae) from a source location by netting them and transferring them into mesh cages. We chose to focus on this species because it is abundant in both urban and rural areas, thus removing a potential confound of releasing butterflies in small urban gardens that are predominantly found only in rural areas and large parks. Upon capture, butterflies were identified as male or female, but we could not analyze sex differences because over $95 \%$ of the captured individuals were female.

Before releasing a butterfly, we recorded how many minutes it had been held in the cage before release (range: 12-293 min, average: $53 \mathrm{~min}$.); butterflies were not fed while being held, so wait time may reflect some measure of hunger level. We marked each butterfly on both sides of the thorax with a colored Sharpie ${ }^{\circledR}$ to allow identification if an individual re-entered the site after leaving it. We then released the butterfly in the center of the site, and recorded its behavior until it either a) exited the site and did not reenter for 20 minutes or b) sat unmoving in the same location for a full hour. If the released butterfly immediately flew high and fast away from the site and showed no exploratory behavior, we waited 45 minutes instead of 20 for the butterfly to return; if it 
did not return, the trial was eliminated from consideration in data analyses. During a trial, the focal butterfly's behavior was recorded in two ways. First, we narrated its actions (flying, feeding, resting, fighting, etc.) into a digital recorder as they occurred in real time. Second, we recorded its flight path on a sheet of tracing paper placed over a scale map of the site (Figure 17). We later photographed the maps and analyzed them in ImageJ. When necessary, we used the audio transcripts to add repeated small-scale flight patterns, e.g. loops around a particular plant, to the ImageJ files that would have caused the original map to be unreadable if drawn in real time. From the audio transcripts, we recorded 1) the total amount of time each butterfly spent directly feeding from flowers, and 2) the amount of total active time (feeding and flying, but not resting) the butterfly spent at the site. From the drawn maps we recorded several measures of flight behavior, including flight path length $(\mathrm{m})$, the number of turns (deviations of $\geq 20^{\circ}$ from a straight path), the percentage of turns that were tight $\left(\leq 125^{\circ}\right)$, mean turn angle, and the number of loops per $\mathrm{m}$ of flight. We defined loops as full circles made by the butterfly in a single continuous motion. We calculated average flight speed by dividing the total time a butterfly spent flying by its flight path length.

\section{Statistical Methods}

We use linear regression models with glm in R ( $\mathrm{R}$ Core Team, 2016) to analyze the factors affecting feeding time, activity time, flight path length, average flight speed, percentage of tight turns, mean turn angle, and the number of loops per meter of flight. Feeding time, activity time, and path length were cube-root transformed, the number of loops per meter of flight was square-root transformed, and average flight speed was 
natural-log transformed, so that a histogram of the residuals for each model fit a normal distribution. Models examining tight turn percentage and mean turn angle met the assumptions of normality without transformation. We also determined the significance of correlations between foraging time, activity time and the flight variables using Pearson's correlation tests. We used AIC model comparison to determine which measure of floral abundance best explained variation in foraging and activity time; the best measure was the number of flowers of preferred plant species (species that cabbage whites foraged on for $>1,000$ seconds over all trials combined, Table 5). However, there was a much stronger association between a logarithmic increase in the number of flowers and feeding/activity time than a linear increase, so we used the log of preferred floral abundance in our analyses.

\section{Results}

In total, we completed 142 butterfly behavior trials (71 urban, 71 rural). The behaviors we observed in our trials were highly variable; many individuals did not feed from flowers at all and spent very little time active (min: 7 seconds). Other individuals were highly active and spent extensive time feeding from flowers (max: 129 minutes active, 115 minutes foraging). Butterfly flight path lengths ranged from 5.5-1,101.5 meters, and there was a grade of sinuosity from very straight flight to highly curved, looping flight (Figure 18). Across trials, butterflies fed on an average of 2 plant species; a maximum of 9 plant species was fed on by one individual. On average, 7 blooming plant species were available in a trial, with 3 of these being preferred plant species. All but six butterflies allocated over $90 \%$ of their foraging time to one or two plant species. 
We found significant correlations between how long cabbage white butterflies were active in a garden and measures of their flight behavior. (These correlations were also significant for foraging time alone, but the correlations were stronger for total activity time). Greater activity in gardens was associated with longer flight paths ( $\mathrm{r}=$ $0.69, \mathrm{p}<0.0001$, Figure 19a), more loops per meter of flight $(r=0.52, p<0.0001), a$ greater percentage of tight turns $(r=0.62, p<0.0001$, Figure 19b), tighter average turn angles $(r=-0.53, p<0.0001$, Figure 19c), and slower average flight speeds $(r=-0.41$, $\mathrm{p}<0.0001$, Figure 19d). Butterflies that were highly active in a garden (and generally spent a lot of time foraging) thus flew slowly along extensive, curvy flight paths, and butterflies that left gardens quickly flew relatively fast along short, straight flight paths.

Despite the correlations, there were differences in how these variables responded to the explanatory factors we tested. Site location (urban vs rural) significantly affected every variable except flight speed. Butterflies released in urban gardens fed from flowers longer $(p=0.003)$, were active longer $(p=0.001$, Figure 20a), flew longer paths $(p<0.0001$, Figure 20b), flew tighter turns on average ( $p<0.001$ Figure 20c), flew more loops per meter of flight $(\mathrm{p}<0.0001)$, and flew paths with a greater percentage of tight turns ( $p=0.002$, Figure 20d). Therefore, urbanization had a significant impact on butterfly behavior that led to longer stays with more feeding and long, sinuous flight paths.

Preferred floral abundance significantly (or near-significantly) affected feeding time $(p=0.06)$, activity time $(p=0.035$, Figure $21 a)$, percentage of tight turns $(p=0.035$, Figure 21b), loops per meter ( $\mathrm{p}=0.057)$, and flight speed $(\mathrm{p}<0.0001$, Figure $21 \mathrm{c})$, but not path length or average turn angle. As the number of preferred flowers increased, butterflies fed longer, were active longer, flew paths with a higher percentage of tight 
turns, flew more loops, and flew more slowly. The effect of temperature was similar, although it did not significantly affect the number of loops flown per meter. As temperature increased, butterflies fed longer $(p=0.02)$, were active longer $(p=0.01)$, flew paths with a higher percentage of tight turns $(\mathrm{p}=0.04)$ and flew more slowly $(\mathrm{p}=0.004)$.

Site size significantly affected both path length $(\mathrm{p}<0.001)$ and average flight speed ( $\mathrm{p}=0.002)$, but nothing else. Butterflies flew longer paths in large gardens, but similar path lengths in small and medium gardens. They also flew slightly slower on average as site size increased. The time a butterfly spent caged before being released significantly affected only feeding time: butterflies that waited longer in the cage fed from flowers for a longer period of time $(\mathrm{p}=0.03)$. On average, butterflies released in rural locations waited 60 minutes in the cage and butterflies released in urban locations waited 45 minutes in the cage, so it is unlikely that increased hunger levels due to waiting time explain the longer activity times we observed in urban gardens. We also tested for any effect of butterfly source location (urban vs. rural), but it did not significantly affect any of our behavioral variables either as a main effect or as part of an interaction.

We also analyzed the factors that affected flight behavior in individuals that did not feed from flowers. We found that these butterflies still flew significantly more slowly as the number of preferred flowers increased $(\mathrm{p}<0.0001$, Figure $22 \mathrm{a})$, and flew more slowly in large sites $(\mathrm{p}<0.001)$. These butterflies also flew a significantly greater percentage of tight turns $(p=0.035$, Figure $22 b)$ and more loops per meter $(p=0.003)$ in urban gardens. 


\section{Discussion}

Cabbage white behavior was significantly different in urban versus rural gardens, and those differences did not depend on previous experience, as butterflies captured in urban and rural gardens did not differ from one another in foraging behavior. Individuals fed from flowers longer and spent more time active in urban gardens than in rural gardens, and they were also more likely to fly distinct patterns associated with foraging behavior (Cant et al. 2005) and high-quality habitat (Fernández et al. 2016). In urban gardens, butterflies flew longer, more sinuous flight paths with many more loops and tight turning angles. Even when butterflies did not feed from flowers, they flew more loops and tight turns in the urban gardens, which suggests that they were performing more localized searches in these gardens than in the rural ones.

Urban gardens are generally more isolated from nearby resource patches compared to rural gardens (Davis and Glick 1978, Fattorini et al. 2017), which could increase travel time between patches and encourage longer stay times at urban sites (Charnov 1976). The urban matrix may also be particularly inhospitable to traverse; it has been shown to restrict the free movement of animals across the landscape for taxa including insects (Peralta et al. 2011, Le Gall et al. 2017, Buchholz et al. 2020), mammals (Robinson and Marks 2001, Braaker et al. 2014, Hämäläinen et al. 2019), and birds (Tremblay and St. Clair 2011, Shimazaki et al. 2014, Evans et al. 2017). Butterfly dispersal is affected by boundary permeability (Schtickzelle and Baguette 2003, Fernández et al. 2019), as well as the presence of natural barriers such as dense forest (Kuussaari et al. 1996, Schultz et al. 2012, Kallionemi et al. 2014) and windbreaks (Dover and Fry 2001). Urban areas are riddled with boundaries and barriers (e.g. 
buildings, tall fences, etc.) with low permeability that likely affect butterflies' ability to navigate through the matrix and locate resource patches. Jain et al. (2020) found that butterflies in urban parks were less likely to move between habitat patches than butterflies in forested sites, and woodland butterflies consistently refuse to cross into urban habitat (Kuefler et al. 2010). The butterflies in our study were able to quickly enter and exit the urban gardens, but they were notably impeded by the presence of houses and other large, solid structures (pilot data from a concurrent study on butterfly boundarycrossing behavior). A study by Dennis and Hardy (2007) found that cabbage white butterflies had limited access to resources (specifically host plants) in an urban matrix (defined as roads, parking lots, etc.) and performed far fewer resource-use activities and exploratory flights in the urban matrix than in more rural matrices (including mown grass and crop fields).

Butterflies in urban gardens may thus have greater incentive to remain longer and utilize the resources that are immediately available to them, whereas butterflies in rural gardens may be quicker to leave and seek better resources nearby. Due to the fact that we transported the butterflies and released them far from their capture points, it is unlikely that these individuals used memory of the landscape to make these decisions. Instead, they likely relied upon visual cues like landscape openness and scent detection of nearby resources (Ikeura et al. 2010, Schäpers et al. 2015). Some of the behavioral changes we observed are also likely explained by differences in floral availability between our urban and rural sites. Combined across all trials, the average preferred floral abundance at the urban gardens was $2 \mathrm{x}$ greater than the average preferred floral abundance at rural gardens. However, while preferred floral abundance significantly affected most of the 
behaviors we measured, the effect of urbanization was still stronger for every variable except flight speed.

The behavior of cabbage whites was also significantly affected by patch quality; in our study quality is primarily attributable to floral abundance, as we found only limited effects of site size. Cabbage whites are known to have strong preferences when foraging (Lazri and Barrows 1984, Lewis 1986, Lewis 1989), and this matches what we observed in the field. During our trials, focal butterflies usually fed on only one or two plant species, and showed strong preferences for plant species that on average represented less than half of the available species pool of blooming plants. Therefore, it is not surprising that the behaviors we recorded were better explained by the floral abundance of a small number of preferred plant species than broader measures of floral abundance. When in gardens of higher quality (as measured by preferred floral abundance), butterflies were more active and flew paths with more loops and tight turns. They also flew much more slowly; in fact, butterfly flight speed was so strongly associated with floral abundance that it was the only behavioral variable unaffected by site location. Even butterflies that did not ultimately forage flew significantly more slowly in gardens with higher floral abundance. Flight speed may thus be a highly reliable indicator of general habitat quality for butterflies; Schultz et al. (2017) found that butterfly flight speed was negatively correlated with population density, such that butterfly densities were higher in land cover types through which they moved more slowly. Our results confirm that butterflies fly distinct search patterns based on foraging resources alone, and that the presence of host plants is not needed to change their flight behavior. Higher temperatures also increased butterfly activity levels; as urban areas are frequently hotter than rural areas, butterflies in 
urban environments may face increased caloric demands that could reduce their fitness if sufficient nectar resources are not readily available. The behavioral patterns we observed were highly variable, and are not fully explained by the variables we were able to measure. It is likely that other factors had significant effects on an individual's behavior, including: nectar availability, floral age, patch configuration, butterfly age, and mating status.

In conclusion, we found that the flight and foraging behaviors of cabbage whites were strongly affected by urbanization and garden quality. Individuals increased their activity levels and intensive search behaviors in urban gardens, and in gardens with a higher abundance of preferred flowers. Of these two factors, urbanization had the largest effect on cabbage white behavior. It is likely that features of the urban landscape alter butterflies' foraging decisions. This may be due to the presence of vertical structures that make traversing the urban matrix difficult or energetically expensive, or even hinder butterflies' ability to perceive resource patches, as many butterflies rely strongly on visual cues (Goulson and Cory 1993, Kandori and Ohsaki 1996, Omura and Honda 2005). Given resource deficiencies in the urban matrix compared to many rural matrices, urban gardens may also function more as isolated "habitat islands" than rural gardens, and therefore lead butterflies to increase their residence time. The potentially high energetic costs of life in an urban habitat due to patch isolation, urban structure, and urban temperature could reduce the fitness of urban butterflies and lower their reproductive success, even if host plants are made widely available. Detailed knowledge of butterfly movement behavior (Schultz et al. 2019), as well as determining landscape connectivity for butterflies in urban habitats may be key to implementing effective 
conservation efforts. Future studies should directly examine how features of the urban landscape affect butterflies' dispersal and inter-patch movement, butterflies' ability to perceive resource patches, and butterflies' energy expenditure. There should also be additional research examining the conservation implications of improving the urban matrix, as there could be trade-offs between facilitating connectivity and maximizing persistence at high-quality sites, as conservation projects often have limited funds for habitat improvement and maintenance (Crone et al. 2019). 
Table 4

\begin{tabular}{cccc}
\hline Site & Site Type & Site Location & Site Size \\
\hline Beckley Creek & Park & Rural & Medium \\
Bernheim I & Park & Rural & Large \\
Bernheim II & Park & Rural & Small \\
Broad Run & Park & Rural & Medium \\
Moore & School & Rural & Large \\
Private Garden I & Residential & Rural & Small \\
Copper and Kings & Business & Urban & Large \\
Private Garden II & Residential & Urban & Small \\
Private Garden III & Residential & Urban & Medium \\
Private Garden IV & Residential & Urban & Medium \\
Private Garden V & Residential & Urban & Small \\
U of L Korfhage Garden & School & Urban & Large \\
\hline
\end{tabular}


Table 5

\begin{tabular}{ccc}
\hline Plant Species & Common Name & Cumulative Feeding Time (s) \\
\hline Symphyotrichum novae-angliae & New-England aster & 11,597 \\
Verbena hastata & Blue vervain & 10,970 \\
Buddleja davidii & Butterfly bush & 4,380 \\
Vernonia noveboracensis & New-York ironweed & 3,634 \\
Thymus vulgaris & Common thyme & 3,190 \\
Conoclinium coelestinum & Blue mistflower & 3,024 \\
Agastache foeniculum & Anise hyssop & 2,989 \\
Pycnanthemum incanum & Hoary mountain mint & 2,851 \\
Nepeta racemose & Catmint & 2,770 \\
Echinacea purpurea & Purple coneflower & 2,478 \\
Apocynum cannabinum & Dogbane & 2,073 \\
Liatris spicata & Blazing star & 1,322 \\
\hline
\end{tabular}




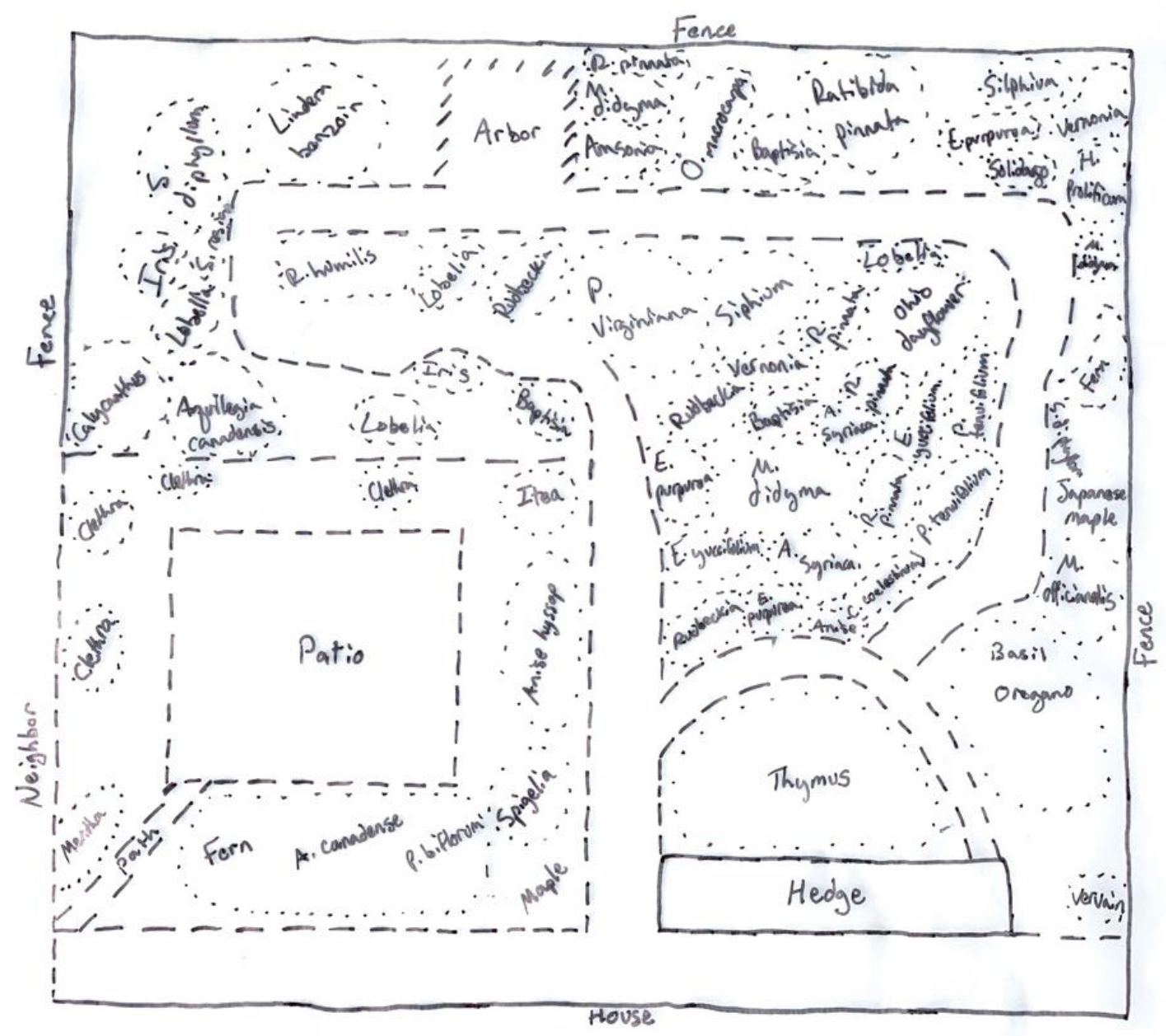


Figure 18

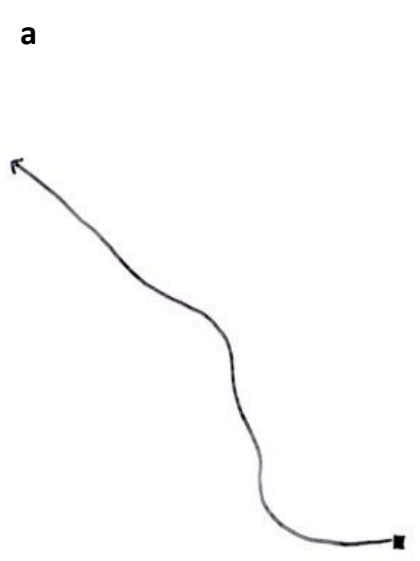

b

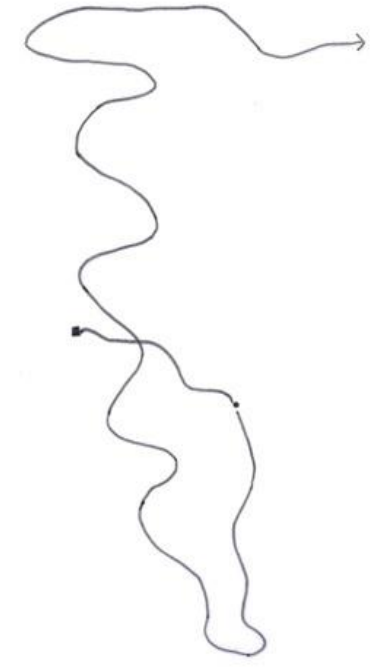

c

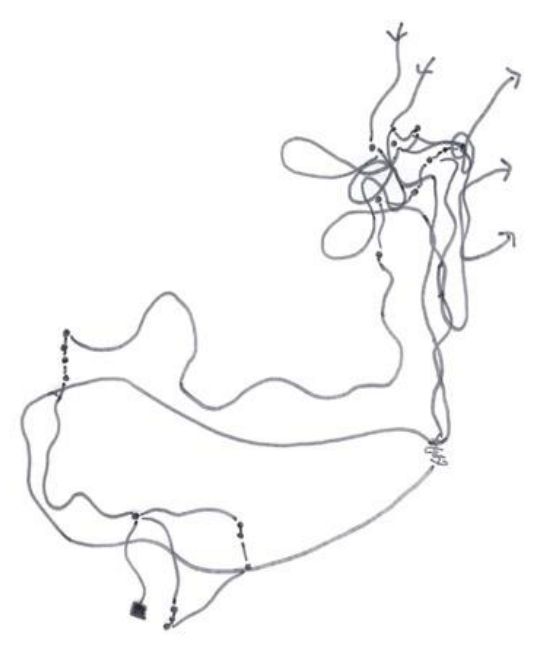




\section{Figure 19}
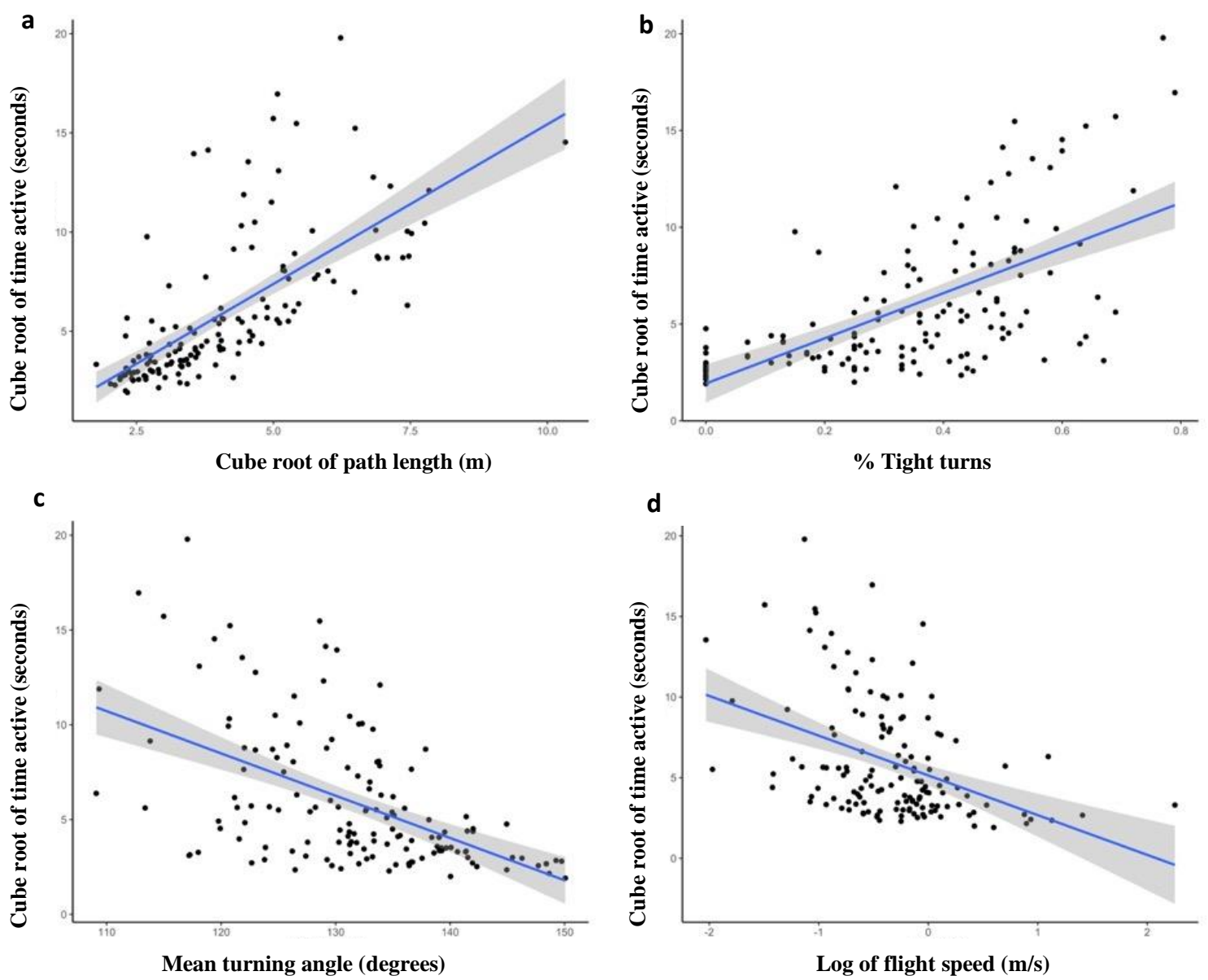
Figure 20
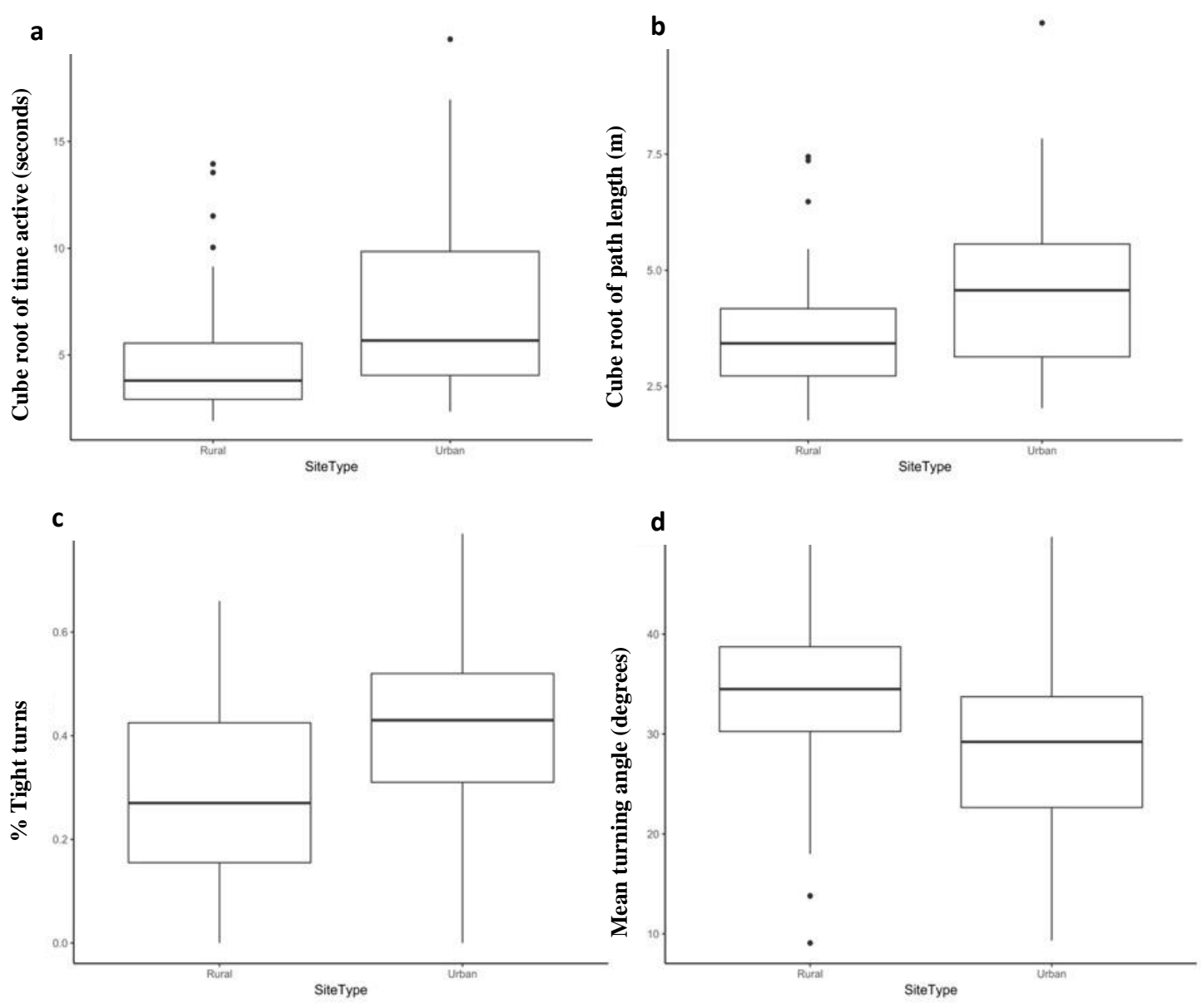
Figure 21
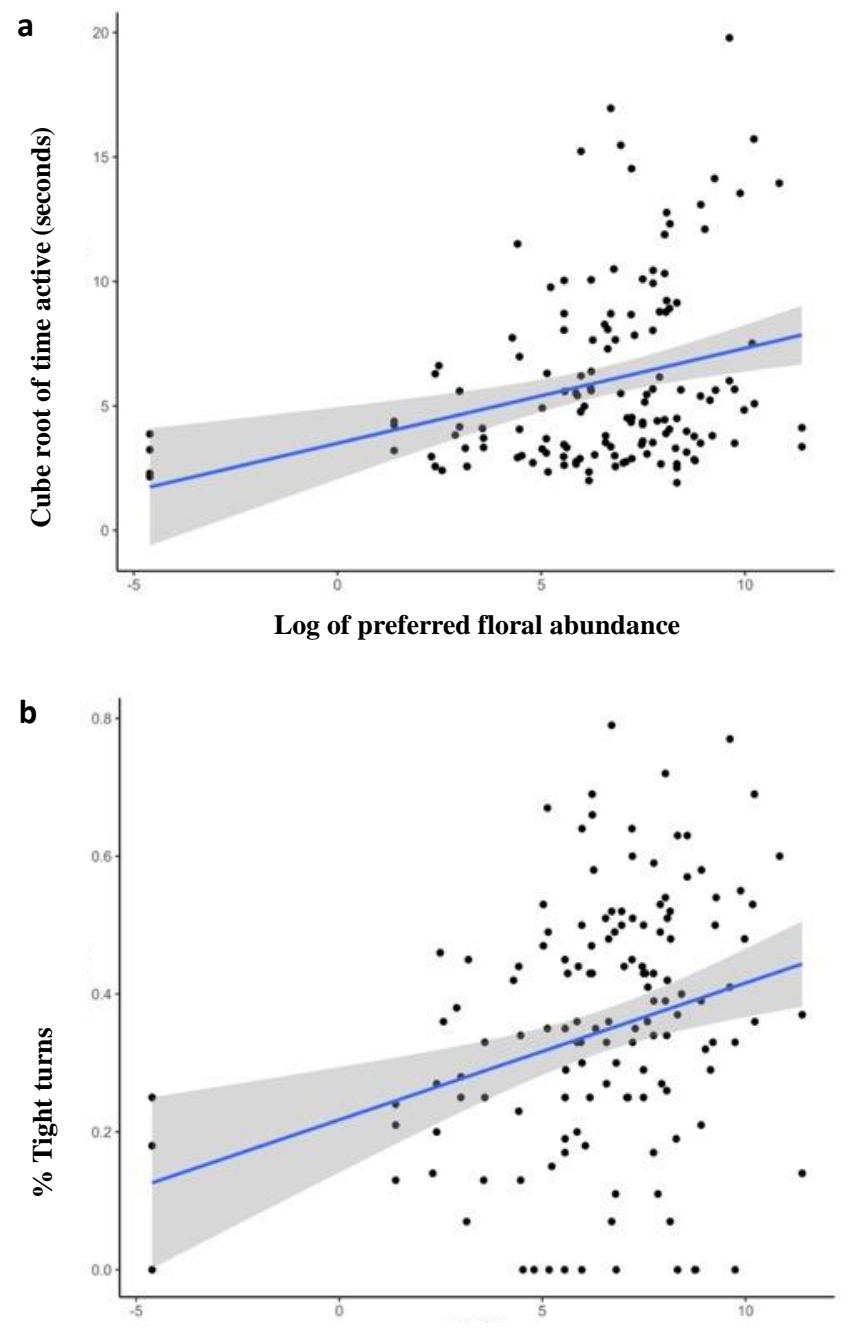

Log of preferred floral abundance

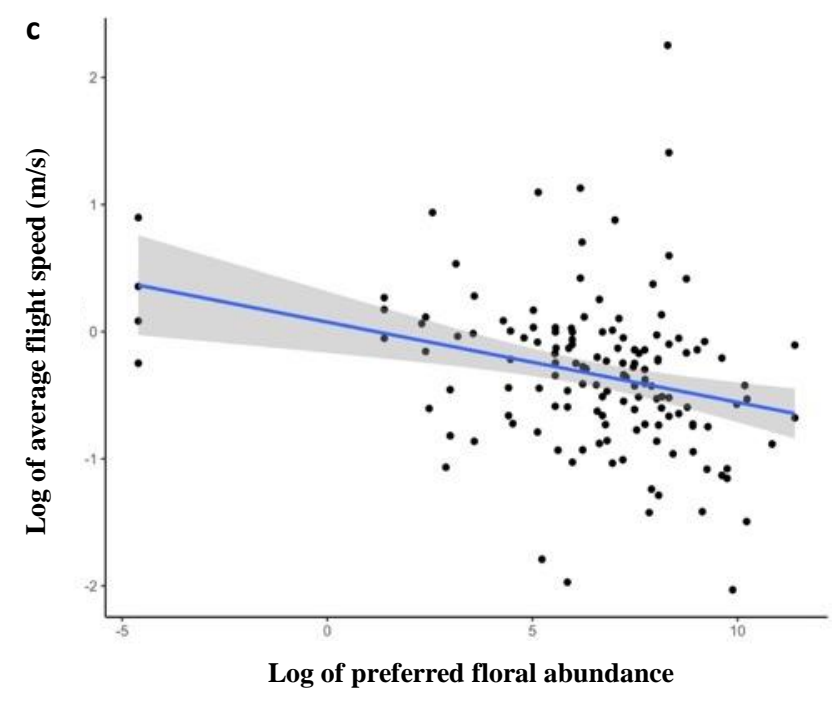


Figure 22
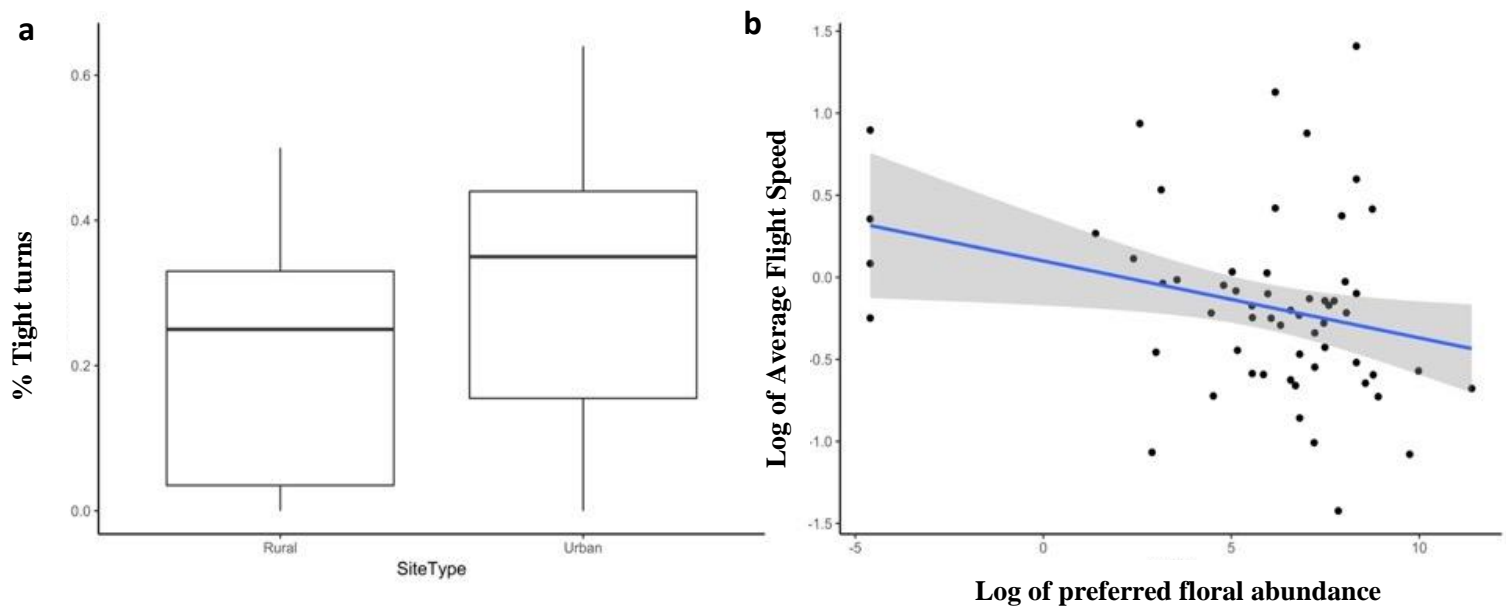


\section{Captions}

Table 4 A table showing each garden site and its characteristics. U of L refers to the University of Louisville.

Table 5 A table showing the 12 preferred plant species used for floral abundance calculations, and the total amount of time they were foraged on across all trials.

Fig. 17 An example of a scale map of a garden used to draw butterfly flight paths. Solid lines represent solid borders, dashed lines represent open borders to paths or neighboring lawn, and dotted lines represent the approximate borders of plant patches.

Fig. 18 Examples of butterfly flight paths on a gradient of sinuosity. a) straight flight b) broadly curved flight c) tightly curved flight. Squares represent the start location where the butterfly was released, dots represent landing points, outward-facing arrows represent exit points, and inward-facing arrows represent re-entry points.

Fig. 19a A graph showing the correlation between time active and flight path length. Butterflies that spent more time active flew longer paths $(\mathrm{r}=0.69, \mathrm{p}<0.0001)$.

Fig. 19b A graph showing the correlation between time active and proportion of tight turns. Butterflies that spent more time active flew a greater percentage of tight turns (less than $\left.125^{\circ}\right)(\mathrm{r}=0.62, \mathrm{p}<0.0001)$.

Fig. 19c A graph showing the correlation between time active and mean turning angle. Butterflies that spent more time active flew tighter average turn angles $(\mathrm{r}=-0.53, \mathrm{p}<0.0001)$.

Fig. 19d A graph showing the correlation between time active and average flight speed. Butterflies that spent more time active flew more slowly $(\mathrm{r}=-0.41, \mathrm{p}<0.0001)$.

Fig. 20a A boxplot showing the effect of site location on time active. Butterflies in urban gardens were active longer than butterflies in rural gardens $(\mathrm{p}=0.001)$. 
Fig. 20b A boxplot showing the effect of site location on time flight path length. Butterflies in urban gardens flew longer paths than butterflies in rural gardens $(\mathrm{p}<0.0001)$.

Fig. 20c A boxplot showing the effect of site location on mean turning angle. Butterflies in urban gardens flew tighter turns on average than butterflies in rural gardens $(\mathrm{p}<0.001)$

Fig. 20d A boxplot showing the effect of site location on proportion of tight turns. Butterflies in urban gardens flew paths with a greater percentage of tight turns (less than $125^{\circ}$ ) than butterflies in rural gardens $(\mathrm{p}=0.002)$.

Fig. 21a A graph showing the effect of preferred floral abundance on time active. Butterflies were active longer when there was greater preferred floral abundance $(\mathrm{p}=0.035)$

Fig. 21b A graph showing the effect of preferred floral abundance on proportion of tight turns. Butterflies flew a higher percentage of tight turns (less than $125^{\circ}$ ) when there was greater preferred floral abundance $(\mathrm{p}=0.035)$.

Fig. 21c A graph showing the effect of preferred floral abundance on average flight speed. Butterflies flew more slowly when there was greater preferred floral abundance $(\mathrm{p}<0.0001)$.

Fig. 6a Butterflies that did not forage flew more slowly when there was greater preferred floral abundance $(\mathrm{p}<0.0001)$.

Fig. 6b Butterflies that did not forage flew a greater percentage of tight turns (less than $125^{\circ}$ ) in urban gardens $(\mathrm{p}=0.035)$. 


\section{CONCLUSION}

My research shows that urban gardens have strong potential to act as conservation spaces for butterflies, and possibly other taxa as well. Local garden characteristics, like garden size, native plant species richness, and plant biovolume density, had strong positive effects on butterfly diversity and abundance that helped compensate for the negative impact of increased impervious surface. I found more diverse communities of butterflies and higher numbers of individuals when gardens were large, plant-diverse, and densely planted. I also found that attacks on model caterpillars by vertebrates, spiders, and predatory wasps increased with greater plant biovolume density; this suggests that these taxa may also be present in higher numbers in densely planted gardens. Additionally, the results of my clay caterpillar study show that caterpillars are attacked less frequently in urban gardens compared to rural gardens. Therefore, adding host plants is likely to be a beneficial strategy, rather than one that creates and ecological trap (due to predation).

In my cabbage white behavioral study, I found that butterfly behavior can be significantly affected by urbanization. Butterflies were more likely to spend a long time active (flying and foraging) in urban gardens. They also performed more intensive search

flights in urban gardens than rural gardens. Urbanization had a stronger effect on butterfly behavior than floral abundance, suggesting that the urban landscape induces 
butterflies to utilize the resources in front of them rather than seeking alternative resource patches. Urban gardens may thus have a low degree of connectivity for butterflies due to patch isolation and/or barriers to movement caused by vertical structure (e.g. buildings, fencing).

Based on my findings, I would recommend to gardeners that they plant diverse communities of native species, including both host plants and nectar plants. They should also fill in their garden space as much as possible (i.e. densely without large gaps between plants). Most importantly, they should increase the size of their gardens (if possible), and encourage friends and neighbors to do so as well. Clusters of gardens would not only create large neighborhood-scale resource patches, but could also help improve the connectivity of gardens across a city.

Future studies should examine caterpillar survival in urban gardens, and determine if factors other than predation (e.g. plant nutrition, competition, urban heat island effects, microclimates, etc.) might limit butterfly reproduction in urban areas. There should also be more research evaluating whether adding both host and nectar plants to a garden attracts a greater diversity of butterfly species (particularly hostspecialist species) than just adding one resource type alone. Finally, there should by additional studies on butterfly movement through the urban matrix, and direct assessment of the connectivity of habitat patches in urban systems. 


\section{REFERENCES}

Abrahamczyk S., Wohlgemuth T., Nobis M., Nyffeler R., and Kessler M. (2020) Shifts in food plant abundance for flower-visiting insects between 1900 and 2017 in the canton of Zurich, Switzerland. Ecological Applications 30.

Ahrné K., Bengtsson J., and Elmqvist T. (2009) Bumble bees (Bombus spp) along a gradient of increasing urbanization. Plos One 4:9.

Akçay C., Beck M.L., and Sewall K.B. (2020) Are signals of aggressive intent less honest in urban habitats? Behavioral Ecology 31:213-221.

Altrichter E.A., Thompson J.R., and Mabry C.M. (2017) Stakeholders' perceptions of native plants and local ecotypes in ecological restoration. Ecological Restoration 35:218-227.

Anderson P.M.L., Avlonitis G., and Ernstson H. (2014) Ecological outcomes of civic and expertled urban greening projects using indigenous plant species in Cape Town, South Africa. Landscape and Urban Planning 127:104-113.

Andrieu E., Dornier A., Rouifed S., Schatz B., and Cheptou P-O. (2009) The town Crepis and the country Crepis: How does fragmentation affect a plant-pollinator interaction? Acta Oecologica 35:1-7.

ArcGIS Desktop Version 10.6. (2018) Redlands, CA: Environmental Systems Research Institute, Inc. 
Aronson M.F.J., et al. (2014) A global analysis of the impacts of urbanization on bird and plant diversity reveals key anthropogenic drivers. Proceedings of the Royal Society BBiological Sciences 281.

Avilés-Rodríguez K.J., and Kolbe J.J. (2019) Escape in the city: urbanization alters the escape behavior of Anolis lizards. Urban Ecosystems 22:733-742.

Aviron S., Herzog F., Klaus I., Schüpbach B., and Jeanneret P. (2011) Effects of wildflower strip quality, quantity, and connectivity on butterfly diversity in a Swiss arable landscape. Restoration Ecology 19:500-508.

Baldock K.C.R., et al. (2019) A systems approach reveals urban pollinator hotspots and conservation opportunities. Nature Ecology \& Evolution 3:363-+.

Baldock K.C.R., et al. (2015) Where is the UK's pollinator biodiversity? The importance of urban areas for flower-visiting insects. Proceedings of the Royal Society B-Biological Sciences 282:10.

Banaszak-Cibicka W., and Żmihorski M. (2020) Are cities hotspots for bees? Local and regional diversity patterns lead to different conclusions. Urban Ecosystems 23:713-722.

Bates A.J., et al. (2014) Garden and landscape-scale correlates of moths of differing conservation status: Significant effects of urbanization and habitat diversity. Plos One 9:11.

Beissinger S.R., and Osborne D.R. (1982) Effects of urbanization on avian community organization. Condor 84:75-83.

Bergerot B., Fontaine B., Renard M., Cadi A., and Julliard R. (2010) Preferences for exotic flowers do not promote urban life in butterflies. Landscape and Urban Planning 96:98107. 
Bigelow, D.P., and Borchers A. (2012) Major uses of land in the United States. U.S. Department of Agriculture Economic Research Service EIB-178.

Blair R.B. (1996) Land use and avian species diversity along an urban gradient. Ecological Applications 6:506-519.

Blair R.B. (1999) Birds and butterflies along an urban gradient: Surrogate taxa for assessing biodiversity? Ecological Applications 9:164-170.

Blair R.B., and Launer A.E. (1995) Butterfly diversity and human land use: Species assemblages along an urban gradient. Biological Conservation 80:113-125.

Bolger D.T., Suarez A.V., Crooks K.R., Morrison S.A., and Case T.J. (2000) Arthropods in urban habitat fragments in southern California: Area, age, and edge effects. Ecological Applications 10:1230-1248.

Bonebrake T.C., and Cooper D.S. (2014) A Hollywood drama of butterfly extirpation and persistence over a century of urbanization. Journal of Insect Conservation 18:683-692.

Braaker S., Ghazoul J., Obrist M.K., and Moretti M. (2014) Habitat connectivity shapes urban arthropod communities: the key role of green roofs. Ecology 95:1010-1021.

Braaker S., Moretti M., Boesch R., Ghazoul J., Obrist M.K., and Bontadina F. (2014) Assessing habitat connectivity for ground-dwelling animals in an urban environment. Ecological Applications 24:1583-1595.

Brown D.G., Johnson K.M., Loveland T.R., and Theobald D.M. (2005) Rural land-use trends in the conterminous United States, 1950-2000. Ecological Applications 15:1851-1863.

Buchholz S., Gathof A.K., Grossmann A.J., Kowarik I., and Fischer L.K. (2020) Wild bees in urban grasslands: Urbanisation, functional diversity and species traits. Landscape and Urban Planning 196. 
Burghardt K.T., Tallamy D.W., and Shriver W.G. (2009) Impact of native plants on bird and butterfly biodiversity in suburban landscapes. Conservation Biology 23:219-224.

Burks J.M., and Philpott S.M. (2017) Local and landscape drivers of parasitoid abundance, richness, and composition in urban gardens. Environmental Entomology 46:201-209.

Callaghan C.T., Bino G., Major R.E., Martin J.M., Lyons M.B., and Kingsford R.T. (2019) Heterogeneous urban green areas are bird diversity hotspots: insights using continentalscale citizen science data. Landscape Ecology 34:1231-1246.

Cant E.T., Smith A.D., Reynolds D.R., and Osborne J.L. (2005) Tracking butterfly flight paths across the landscape with harmonic radar. Proceedings of the Royal Society B-Biological Sciences 272:785-790.

Casner K.L., Forister M.L., O'Brien J.M., Thorne J., Waetjen D., and Shapiro A.M. (2014) Contribution of urban expansion and a changing climate to decline of a butterfly fauna. Conservation Biology 28:773-782.

Chace J.F., and Walsh J.J. (2006) Urban effects on native avifauna: a review. Landscape and Urban Planning 74:46-69.

Charnov E.L. (1976) Optimal foraging, marginal value theorem. Theoretical Population Biology 9:129-136.

Chejanovski Z.A., Avilés-Rodríguez K.J., Lapiedra O., Preisser E.L., and Kolbe J.J. (2017) An experimental evaluation of foraging decisions in urban and natural forest populations of Anolis lizards. Urban Ecosystems 20:1011-1018.

Christie F., and Hochuli D. (2009) Responses of wasp communities to urbanization: effects on community resilience and species diversity. Journal of Insect Conservation 13:213-221. 
Clark P.J., Reed J.M., and Chew F.S. (2007) Effects of urbanization on butterfly species richness, guild structure, and rarity. Urban Ecosystems 10:321-337.

Cohen H., Philpott S.M., Liere H., Lin B.B., and Jha S. (2020) The relationship between pollinator community and pollination services is mediated by floral abundance in urban landscapes. Urban Ecosystems.

Collinge S.K., Prudic K.L., and Oliver J.C. (2003) Effects of local habitat characteristics and landscape context on grassland butterfly diversity. Conservation Biology 17:178-187.

Concepción E.D., Obrist M.K., Moretti M., Altermatt F., Baur B., and Nobis M.P. (2016)

Impacts of urban sprawl on species richness of plants, butterflies, gastropods and birds: not only built-up area matters. Urban Ecosystems 19:225-242.

Conradt L., and Roper T.J. (2006) Nonrandom movement behavior at habitat boundaries in two butterfly species: Implications for dispersal. Ecology 87:125-132.

Corcos D., Cerretti P., Caruso V., Mei M., Falco M., and Marini L. (2019) Impact of urbanization on predator and parasitoid insects at multiple spatial scales. Plos One 14.

Costello M.J., and Daane K.M. (1998) Influence of ground cover on spider populations in a table grape vineyard. Ecological Entomology 23:33-40.

Crone E.E., Brown L.M., Hodgson J.A., Lutscher F., and Schultz C.B. (2019) Faster movement in nonhabitat matrix promotes range shifts in heterogeneous landscapes. Ecology 100.

Crooks K.R., Suarez A.V., and Bolger D.T. (2004) Avian assemblages along a gradient of urbanization in a highly fragmented landscape. Biological Conservation 115:451-462.

Curtis R.J., Brereton T.M., Dennis R.L.H., Carbone C., and Isaac N.J.B. (2015) Butterfly abundance is determined by food availability and is mediated by species traits. Journal of Applied Ecology 52:1676-1684. 
Cussans J., Goulson D., Sanderson R., Goffe L., Darvill B., and Osborne J.L. (2010) Two beepollinated plant species show higher seed production when grown in gardens compared to arable farmland. Plos One 5.

Cutting B.T., and Tallamy D.W. (2015) An evaluation of butterfly gardens for restoring habitat for the monarch butterfly (Lepidoptera: Danaidae). Environmental Entomology 44:13281335.

Dale S. (2018) Urban bird community composition influenced by size of urban green spaces, presence of native forest, and urbanization. Urban Ecosystems 21:1-14.

Davis A.M., and Glick T.F. (1978) Urban ecosystems and island biogeography. Environmental Conservation 5:299-304.

Dennis R.L.H., and Hardy P.B. (2007) Support for mending the matrix: resource seeking by butterflies in apparent non-resource zones. Journal of Insect Conservation 11:157-168.

Dover J.W., and Fry G.L.A. (2001) Experimental simulation of some visual and physical components of a hedge and the effects on butterfly behaviour in an agricultural landscape. Entomologia Experimentalis Et Applicata 100:221-233.

Egerer M., Cecala J.M., and Cohen H. (2020) Wild bee conservation within urban gardens and nurseries: Effects of local and landscape management. Sustainability 12.

Evans B.S., Kilpatrick A.M., Hurlbert A.H., and Marra P.P. (2017) Dispersal in the urban matrix: Assessing the influence of landscape permeability on the settlement patterns of breeding songbirds. Frontiers in Ecology and Evolution 5.

Fabian Y., Sandau N., Bruggisser O.T., Aebi A., Kehrli P., Rohr R.P., Naisbit R.E., Bersier L.F. (2014) Plant diversity in a nutshell: Testing for small-scale effects on trap nesting wild bees and wasps. Ecosphere 5. 
Fattorini S., Mantoni C., De Simoni L., Galassi D.M.P. (2018) Island biogeography of insect conservation in urban green spaces. Environmental Conservation 45:1-10.

Fernández P., Rodríguez A., Gutiérrez D., Jordano D., and Fernández-Haeger J. (2019) Firebreaks as a barrier to movement: The case of a butterfly in a Mediterranean landscape. Journal of Insect Conservation 23:843-856.

Fernández P., Rodríguez A., Obregón R., de Haro S., Jordano D., and Fernández-Haeger J. (2016) Fine scale movements of the butterfly Plebejus argus in a heterogeneous natural landscape as revealed by GPS tracking. Journal of Insect Behavior 29:80-98.

Ferrante M., Lo Cacciato A., Lovei G.L. (2014) Quantifying predation pressure along an urbanisation gradient in Denmark using artificial caterpillars. European Journal of Entomology 111:649-654.

Fontaine B., Bergerot B., Le Viol I., and Julliard R. (2016) Impact of urbanization and gardening practices on common butterfly communities in France. Ecology and Evolution 6:81748180.

Franzén M., Betzholtz P-E., Pettersson L., and Forsman A. (2020) Urban moth communities suggest that life in the city favours thermophilic multi-dimensional generalists. Proceedings of the Royal Society B 287: 20193014.

Fukase J., and Simons A.M. (2016) Increased pollinator activity in urban gardens with more native flora. Applied Ecology and Environmental Research 14:297-310.

Garbuzov M., Schürch R., and Ratnieks F.L.W. (2015) Eating locally: dance decoding demonstrates that urban honey bees in Brighton, UK, forage mainly in the surrounding urban area. Urban Ecosystems 18:411-418. 
Geest E.A., Wolfenbarger L.L., and McCarty J.P. (2019) Recruitment, survival, and parasitism of monarch butterflies (Danaus plexippus) in milkweed gardens and conservation areas. Journal of Insect Conservation 23:211-224.

Goddard M.A., Dougill A.J., and Benton T.G. (2010). Scaling up from gardens: Biodiversity conservation in urban environments. Trends in Ecology \& Evolution 25:90-98.

Goulson D., and Cory J.S. (1993) Flower constancy and learning in foraging preferences of the green-veined white butterfly Pieris napi. Ecological Entomology 18:315-320.

Grenis K., Tjossem B., and Murphy S.M. (2015) Predation of larval Lepidoptera in habitat fragments varies spatially and temporally but is not affected by light pollution. Journal of Insect Conservation 19:559-566.

Grill A., Knoflach B., Cleary D.F.R., and Kati V. (2005) Butterfly, spider, and plant communities in different land-use types in Sardinia, Italy. Biodiversity \& Conservation 14:1281-1300.

Güneralp B., Reba M., Hales B.U., Wentz E.A., and Seto K.C. (2020) Trends in urban land expansion, density, and land transitions from 1970 to 2010: a global synthesis. Environmental Research Letters 15:13.

Gunnarsson B., and Federsel L.M. (2014) Bumblebees in the city: abundance, species richness and diversity in two urban habitats. Journal of Insect Conservation 18:1185-1191.

Halfwerk W., Blaas M., Kramer L., Hijner N., Trillo P.A., Bernal X.E., Page R.A., Goutte S., Ryan M.J., and Ellers J. (2019) Adaptive changes in sexual signalling in response to urbanization. Nature Ecology \& Evolution 3:374-+.

Hämäläinen S., Fey K., and Selonen V. (2019) The effect of landscape structure on dispersal distances of the Eurasian red squirrel. Ecology and Evolution 9:1173-1181. 
Harrison T., and Winfree R. (2015) Urban drivers of plant-pollinator interactions. Functional Ecology 29:879-888.

Hausmann S.L., Petermann J.S., and Rolff J. (2016) Wild bees as pollinators of city trees. Insect Conservation and Diversity 9:97-107.

Hertzog L.R., Ebeling A., Weisser W.W., and Meyer S.T. (2017) Plant diversity increases predation by ground-dwelling invertebrate predators. Ecosphere $\mathbf{8}$.

Hill M.J., and Wood P.J. (2014) The macroinvertebrate biodiversity and conservation value of garden and field ponds along a rural-urban gradient. Fundamental and Applied Limnology 185:107-119.

Hoff R., and Rydgren K. (2011) Garden-centres are an important source for the dispersal of alien plant species. Blyttia 69:245-252.

Hooks C.R.R., Pandey R.R., and Johnson M.W. (2003) Impact of avian and arthropod predation on lepidopteran caterpillar densities and plant productivity in an ephemeral agroecosystem. Ecological Entomology 28:522-532.

Hülsmann M., von Wehrden H., Klein A.M., and Leonhardt S.D. (2015) Plant diversity and composition compensate for negative effects of urbanization on foraging bumble bees. Apidologie 46:760-770.

Ikeura H., Kobayashi F., and Hayata Y. (2010) How do Pieris rapae search for Brassicaceae host plants? Biochemical Systematics and Ecology 38:1199-1203.

Isaksson C., and Andersson S. (2007) Carotenoid diet and nestling provisioning in urban and rural great tits Parus major. Journal of Avian Biology 38:564-572. 
Jain A., Chan S.K.M, Vlasanek P., and Webb E.L. (2020) Impacts of habitat on butterfly dispersal in tropical forests, parks and grassland patches embedded in an urban landscape. Biotropica 52:404-409.

Johnston M.K., Hasle E.M., Klinger K.R., Lambruschi M.P., Lewis A.D., Stolz D.F., Winter A.M., Bouman M.J., and Redlinski I. (2019) Estimating milkweed abundance in metropolitan areas under existing and user-defined scenarios. Frontiers in Ecology and Evolution 7.

Jokimäki J. (1999) Occurrence of breeding bird species in urban parks: Effects of park structure and broad-scale variables. Urban Ecosystems 3:21-34.

Kallioniemi E., Zannese A., Tinker J.E., and Franco A.M.A. (2014) Inter-and intra-specific differences in butterfly behaviour at boundaries. Insect Conservation and Diversity 7:232-240.

Kandori I., and Ohsaki N. (1996) The learning abilities of the white cabbage butterfly, Pieris rapae, foraging for flowers. Researches on Population Ecology 38:111-117.

Kitahara M., and Fujii K. (1994) Biodiversity and community structure of temperate butterfly species within a gradient of human disturbance - An analysis based on the concept of generalist vs specialist strategies. Researches on Population Ecology 36:187-199.

Kitahara M., Yumoto M., and Kobayashi T. (2008) Relationship of butterfly diversity with nectar plant species richness in and around the Aokigahara primary woodland of Mount Fuji, central Japan. Biodiversity and Conservation 17:2713-2734.

Knapp S., Kühn I., Mosbrugger V., and Klotz S. (2008) Do protected areas in urban and rural landscapes differ in species diversity? Biodiversity and Conservation 17:1595-1612. 
Koh L.P., and Menge D.N.L. (2006) Rapid assessment of lepidoptera predation rates in neotropical forest fragments. Biotropica 38:132-134.

Koh L.P., and Sodhi N.S. (2004) Importance of reserves, fragments, and parks for butterfly conservation in a tropical urban landscape. Ecological Applications 14:1695-1708.

Konvicka M., and Kadlec T. (2011) How to increase the value of urban areas for butterfly conservation? A lesson from Prague nature reserves and parks. European Journal of Entomology 108:219-229.

Krauss J., Steffan-Dewenter I., and Tscharntke T. (2003a) Local species immigration, extinction, and turnover of butterflies in relation to habitat area and habitat isolation. Oecologia 137:591-602.

Krauss J., Steffan-Dewenter I., Tscharntke T. (2003b) How does landscape context contribute to effects of habitat fragmentation on diversity and population density of butterflies? Journal of Biogeography 30:889-900.

Kuefler D., Hudgens B., Haddad N.M., Morris W.F., and Thurgate N. (2010) The conflicting role of matrix habitats as conduits and barriers for dispersal. Ecology 91:944-950.

Kurylo J.S., Threlfall C.G., Parris K.M., Ossola A., Williams N.S.G., and Evans K.L. (2020) Butterfly richness and abundance along a gradient of imperviousness and the importance of matrix quality. Ecological Applications 30.

Kuussaari M., Nieminen M., and Hanski I. (1996) An experimental study of migration in the Glanville fritillary butterfly Melitaea cinxia. Journal of Animal Ecology 65:791-801. Kuussaari M., Toivonen M., Heliölä J., Poyry J., Mellado J., Ekroos J., Hyyryläinen V., VähäPiikkiö I., and Tiainen J. (2020) Butterfly species' responses to urbanization: Differing effects of human population density and built-up area. Urban Ecosystems. 
Lailvaux S.P. (2020) It's not easy being green: Behavior, morphology, and population structure in urban and natural populations of green anole (Anolis carolinensis) lizards. Frontiers in Ecology and Evolution $\mathbf{8}$.

Lancaster R.K., and Rees W.E. (1979) Bird communities and the structure of urban habitats. Canadian Journal of Zoology 57:2358-2368. https://doi.org/10.1139/z79-307

Lassau S.A., and Hochuli D.F. (2005) Wasp community responses to habitat complexity in Sydney sandstone forests. Austral Ecology 30:179-187.

Lazri B., and Barrows E.M. (1984) Flower visiting and pollen transport by the imported cabbage butterfly (Lepidoptera, Pieridae) in a highly disturbed urban habitat. Environmental Entomology 13:574-578.

Le Gall M., Chaput-Bardy A., and Husté A. (2017) Context-dependent local movements of the blue-tailed damselfly, Ischnura elegans: Effects of pond characteristics and the landscape matrix. Journal of Insect Conservation 21:243-256.

Leles B., Xiao X., Pasion B.O., Nakamura A., and Tomlinson K.W. (2017) Does plant diversity increase top-down control of herbivorous insects in tropical forest? Oikos 126:11421149.

Leston L., and Koper N. (2017) Urban rights-of-way as extensive butterfly habitats: A case study from Winnipeg, Canada. Landscape and Urban Planning 157:56-62.

Levy J.M., and Connor E.F. (2004) Are gardens effective in butterfly conservation? A case study with the pipevine swallowtail, Battus philenor. Journal of Insect Conservation 8:323330.

Lewis A.C. (1986) Memory constraints and flower choice in Pieris rapae. Science 232:863-865. 
Lewis A.C. (1989) Flower visit consistency in Pieris rapae, the cabbage butterfly. Journal of Animal Ecology 58:1-13.

Low P.A., Sam K., McArthur C., Posa M.R.C., and Hochuli D.F. (2014) Determining predator identity from attack marks left in model caterpillars: Guidelines for best practice. Entomologia Experimentalis Et Applicata 152:120-126.

Lowenstein D.M., Matteson K.C., and Minor E.S. (2019) Evaluating the dependence of urban pollinators on ornamental, non-native, and 'weedy' floral resources. Urban Ecosystems 22:293-302.

MacGregor-Fors I., and Schondube J.E. (2011) Gray vs. green urbanization: Relative importance of urban features for urban bird communities. Basic and Applied Ecology 12:372-381.

Majewska A.A., and Altizer S. (2020) Planting gardens to support insect pollinators. Conservation Biology 34:15-25.

Marciniak B., Nadolski J., Nowakowska M., Loga B., and Bańbura J. (2007) Habitat and annual variation in arthropod abundance affects Blue Tit Cyanistes caeruleus reproduction. Acta Ornithologica 42:53-62.

Marshall A.J., Grose M.J., and Williams N.S.G. (2019) From little things: More than a third of public green space is road verge. Urban Forestry \& Urban Greening 44.

Matteson K.C., and Langellotto G.A. (2010) Determinates of inner city butterfly and bee species richness. Urban Ecosystems 13:333-347.

Mayorga I., Bichier P., and Philpott S.M. (2020) Local and landscape drivers of bird abundance, species richness, and trait composition in urban agroecosystems. Urban Ecosystems 23:495-505. 
McIntyre N.E., and Hostetler M.E. (2001) Effects of urban land use on pollinator (Hymenoptera: Apoidea) communities in a desert metropolis. Basic and Applied Ecology 2:209-218.

McKinney M.L. (2002) Urbanization, biodiversity, and conservation. Bioscience 52:883-890.

Melin M., Hinsley S.A., Broughton R.K., Bellamy P., and Hill R.A. (2018) Living on the edge: utilising lidar data to assess the importance of vegetation structure for avian diversity in fragmented woodlands and their edges. Landscape Ecology 33:895-910.

Merckx T., and Van Dyck H. (2019) Urbanization-driven homogenization is more pronounced and happens at wider spatial scales in nocturnal and mobile flying insects. Global Ecology and Biogeography 28:1440-1455.

Møller A.P., Tryjanowski P., Díaz M., Kwieciński Z., Indykiewicz P., Mitrus C., Goławski A., and Polakowski M. (2015) Urban habitats and feeders both contribute to flight initiation distance reduction in birds. Behavioral Ecology 26:861-865.

New T.R., and Sands D.P.A. (2002) Conservation concerns for butterflies in urban areas of Australia. Journal of Insect Conservation 6:207-215.

Oder, T. (2015) Redefining curb appeal: homeowners are recognizing the value of replacing front lawns with native plants. National Wildlife ${ }^{\circledR}$ Magazine April-May. https://www.nwf.org/Magazines/ NationalWildlife/2015/AprilMay/Gardening/Redefining-Curb- Appeal

Olivier T., Schmucki R., Fontaine B., Villemey A., and Archaux F. (2016) Butterfly assemblages in residential gardens are driven by species' habitat preference and mobility. Landscape Ecology 31:865-876.

Omura H., and Honda K. (2005) Priority of color over scent during flower visitation by adult Vanessa indica butterflies. Oecologia 142:588-596. 
Otoshi M.D., Bichier P., and Philpott S.M. (2015) Local and landscape correlates of spider activity density and species richness in urban gardens. Environmental Entomology 44:1043-1051.

Pardee G.L., and Philpott S.M. (2014) Native plants are the bee's knees: Local and landscape predictors of bee richness and abundance in backyard gardens. Urban Ecosystems 17:641-659.

Peralta G., Silvina Fenoglio M., and Salvo A. (2011) Physical barriers and corridors in urban habitats affect colonisation and parasitism rates of a specialist leaf miner. Ecological Entomology 36:673-679.

Pereira-Peixoto M.H., Pufal G., Martins C.F., and Klein A-M. (2014) Spillover of trap-nesting bees and wasps in an urban-rural interface. Journal of Insect Conservation 18:815-826.

Philpott S.M., Cotton J., Bichier P., Friedrich R.L., Moorhead L.C., Uno S., and Valdez M. (2014) Local and landscape drivers of arthropod abundance, richness, and trophic composition in urban habitats. Urban Ecosystems 17:513-532.

Pickett S.T.A., et al. (2011) Urban ecological systems: Scientific foundations and a decade of progress. Journal of Environmental Management 92:331-362.

Pohl N.B., Van Wyk J., and Campbell D.R. (2011) Butterflies show flower colour preferences but not constancy in foraging at four plant species. Ecological Entomology 36:290-300.

Pollard E. (1977) Method for assessing changes in abundance of butterflies. Biological Conservation 12:115-134.

Posa M.R.C., Sodhi N.S., and Koh L.P. (2007) Predation on artificial nests and caterpillar models across a disturbance gradient in Subic Bay, Philippines. Journal of Tropical Ecology 23:27-33. 
Potts S.G., et al. (2016) Safeguarding pollinators and their values to human well-being. Nature 540:220-229.

Prescott V.A., Eason P.K. (2018) Lentic and lotic odonate communities and the factors that influence them in urban versus rural landscapes. Urban Ecosystems 21:737-750.

Quistberg R.D., Bichier P., and Philpott S.M. (2016) Landscape and local correlates of bee abundance and species richness in urban gardens. Environmental Entomology 45:592601.

R Core Team. (2016) R: A language and environment for statistical computing. R Foundation for Statistical Computing, Vienna, Austria. URL https://www.R-project.org/.

Ramírez-Restrepo L., and MacGregor-Fors I. (2017) Butterflies in the city: a review of urban diurnal Lepidoptera. Urban Ecosystems 20:171-182.

Ritzel K., and Gallo T. (2020) Behavior change in urban mammals: A systematic review. Frontiers in Ecology and Evolution $\mathbf{8}$.

Robinson N.A., and Marks C.A. (2001) Genetic structure and dispersal of red foxes (Vulpes vulpes) in urban Melbourne. Australian Journal of Zoology 49:589-601.

Rosenzweig M.L. (2003) Reconciliation ecology and the future of species diversity. Oryx 37:194-205.

Roslin T., et al. (2017) Higher predation risk for insect prey at low latitudes and elevations. Science 356:742-744.

Ruszczyk A. (1996) Spatial patterns in pupal mortality in urban palm caterpillars. Oecologia 107:356-363.

Rycken S., Shephard J.M., Yeap L., Vaughan-Higgins R., Page M., Dawson R., Smith K., Mawson P.R., and Warren K.S. (2021) Regional variation in habitat matrix determines 
movement metrics in Baudin's cockatoos in southwest Western Australia. Wildlife Research 48:18-29.

Sáenz-Romo M.G., Veas-Bernal A., Martínez-García H., Campos-Herrera R, Ibáñez-Pascual S., Martínez-Villar E., Pérez-Moreno I., Marco-Mancebón V.S. (2019) Ground cover management in a Mediterranean vineyard: Impact on insect abundance and diversity. Agriculture Ecosystems \& Environment 283.

Samnegård U., Persson A.S., and Smith H.G. (2011) Gardens benefit bees and enhance pollination in intensively managed farmland. Biological Conservation 144:2602-2606.

Schäpers A., Carlsson M.A., Gamberale-Stille G., and Janz N. (2015) The role of olfactory cues for the search behavior of a specialist and generalist butterfly. Journal of Insect Behavior 28:77-87.

Schtickzelle N., and Baguette M. (2003) Behavioural responses to habitat patch boundaries restrict dispersal and generate emigration-patch area relationships in fragmented landscapes. Journal of Animal Ecology 72:533-545.

Schtickzelle N., Joiris A., Van Dyck H., and Baguette M. (2007) Quantitative analysis of changes in movement behaviour within and outside habitat in a specialist butterfly. $B M C$ Evolutionary Biology 7.

Schultz C.B., and Crone E.E. (2001) Edge-mediated dispersal behavior in a prairie butterfly. Ecology 82:1879-1892.

Schultz C.B., Franco A.M.A., and Crone E.E. (2012) Response of butterflies to structural and resource boundaries. Journal of Animal Ecology 81:724-734. 
Schultz C.B., Haddad N.M., Henry E.H., and Crone EE. (2019) Movement and demography of at-risk butterflies: Building blocks for conservation. Annual Review of Entomology 64: 167-184.

Schultz C.B., Pe'er B.G., Damiani C., Brown L., and Crone E.E. (2017) Does movement behaviour predict population densities? A test with 25 butterfly species. Journal of Animal Ecology 86:384-393.

Seifert C.L., Lehner L., Adams M.O., and Fiedler K. (2015) Predation on artificial caterpillars is higher in countryside than near-natural forest habitat in lowland south-western Costa Rica. Journal of Tropical Ecology 31:281-284.

Seress G., Hammer T., Bókony V., Vincze E., Preiszner B., Pipoly I., Sinkovics C., Evans K.L., and Liker A. (2018) Impact of urbanization on abundance and phenology of caterpillars and consequences for breeding in an insectivorous bird. Ecological Applications 28:1143-1156.

Seto K.C., Güneralp B., and Hutyra L.R. (2012) Global forecasts of urban expansion to 2030 and direct impacts on biodiversity and carbon pools. Proceedings of the National Academy of Sciences of the United States of America 109:16083-16088.

Shackleton K., Ratnieks F.L.W. (2016) Garden varieties: How attractive are recommended garden plants to butterflies? Journal of Insect Conservation 20:141-148.

Shimazaki A., Yamaura Y., Senzaki M., Yabuhara Y., Akasaka T., and Nakamura F. (2016) Urban permeability for birds: An approach combining mobbing-call experiments and circuit theory. Urban Forestry \& Urban Greening 19:167-175. 
Shwartz A., Muratet A., Simon L., and Julliard R. (2013) Local and management variables outweigh landscape effects in enhancing the diversity of different taxa in a big metropolis. Biological Conservation 157:285-292.

Silva E.B., Franco J.C., Vasconcelos T., and Branco M. (2010) Effect of ground cover vegetation on the abundance and diversity of beneficial arthropods in citrus orchards. Bulletin of Entomological Research 100:489-499.

Simonson S.E., Opler P.A., Stohlgren T.J., and Chong G.W. (2001) Rapid assessment of butterfly diversity in a montane landscape. Biodiversity and Conservation 10:1369-1386.

Skórka P., Nowicki P., Lenda M., Witek M., Śliwińska E.B., Settele J., and Woyciechowski M. (2013) Different flight behaviour of the endangered scarce large blue butterfly Phengaris teleius (Lepidoptera: Lycaenidae) within and outside its habitat patches. Landscape Ecology 28:533-546.

Smith L.S., Broyles M.E.J., Larzleer H.K., and Fellowes M.D.E. (2015) Adding ecological value to the urban lawnscape. Insect abundance and diversity in grass-free lawns. Biodiversity and Conservation 24:47-62.

Smith L.S., and Fellowes M.D.E. (2014) The grass-free lawn: Management and species choice for optimum ground cover and plant diversity. Urban Forestry \& Urban Greening 13:433-442.

Sobek S., Tscharntke T., Scherber C., Schiele S., and Steffan-Dewenter I. (2009) Canopy vs. understory: Does tree diversity affect bee and wasp communities and their natural enemies across forest strata? Forest Ecology and Management 258:609-615.

Sol D., Lapiedra O., and González-Lagos C. (2013) Behavioural adjustments for a life in the city. Animal Behaviour 85:1101-1112. 
Solonen T. (2001) Breeding of the Great Tit and Blue Tit in urban and rural habitats in southern Finland. Ornis Fennica 78:49-60.

Sperber C.F., Nakayama K., Valverde M.J., and Neves F.D. (2004) Tree species richness and density affect parasitoid diversity in cacao agroforestry. Basic and Applied Ecology $\mathbf{5}: 241-251$

Staab M., Pereira-Peixoto M.H., and Klein A-M. (2020) Exotic garden plants partly substitute for native plants as resources for pollinators when native plants become seasonally scarce. Oecologia 194:465-480.

Stamp N.E., and Bowers M.D. (1988) Direct and indirect effects of predatory wasps (Polistes spp., Vespidae) on gregarious caterpillars (Hemileuca lucina, Saturniidae). Oecologia 75:619-624.

Steffan-Dewenter I., and Tscharntke T. (2000) Butterfly community structure in fragmented habitats. Ecology Letters 3:449-456.

Suárez-Rodríguez M., Montero-Montoya R., and Garcia C.M. (2017) Anthropogenic nest materials may increase breeding costs for urban birds. Frontiers in Ecology and Evolution 5.

Sumasgutner P., Nemeth E., Tebb G., Krenn H.W., and Gamauf A. (2014) Hard times in the city_attractive nest sites but insufficient food supply lead to low reproduction rates in a bird of prey. Frontiers in Zoology 11.

Swengel S.R., Schlicht D., Olsen F., and Swengel A.B. (2011) Declines of prairie butterflies in the midwestern USA. Journal of Insect Conservation 15:327-339.

Tallamy D.W., Narango D.L., and Mitchell A.B. (2020) Do non-native plants contribute to insect declines? Ecological Entomology. 
Tam K.C., and Bonebrake T.C. (2016) Butterfly diversity, habitat and vegetation usage in Hong Kong urban parks. Urban Ecosystems 19:721-733.

Taylor M.E.D., Paszkowski C.A. (2018) Postbreeding movement patterns and habitat use of adult Wood Frogs (Lithobates sylvaticus) at urban wetlands. Canadian Journal of Zoology 96:521-532.

Theodorou P., Herbst S-C., Kahnt B., Landaverde-González P., Baltz L.M., Osterman J., and Paxton R.J. (2020) Urban fragmentation leads to lower floral diversity, with knock-on impacts on bee biodiversity. Scientific Reports $\mathbf{1 0}$.

Threlfall C.G., Mata L., Mackie J.A., Hahs A.K., Stork N.E., Williams N.S.G., and Livesley S.J. (2017) Increasing biodiversity in urban green spaces through simple vegetation interventions. Journal of Applied Ecology 54:1874-1883.

Threlfall C.G., Walker K., Williams N.S.G.., Hahs A.K., Mata L., Stork N., and Livesley S.J. (2015) The conservation value of urban green space habitats for Australian native bee communities. Biological Conservation 187:240-248.

Torres-Camacho K.A., Meléndez-Ackerman E.J., Díaz E., Correa N., Vila-Ruiz C., Olivero-Lora S., Erazo A., Fontánez J., Santiago L., Seguinot J. (2017) Intrinsic and extrinsic drivers of yard vegetation in urban residential areas: Implications for conservation planning. Urban Ecosystems 20:403-413.

Tremblay M.A., and St Clair C.C. (2011) Permeability of a heterogeneous urban landscape to the movements of forest songbirds. Journal of Applied Ecology 48:679-688.

Tvardikova K., and Novotny V. (2012) Predation on exposed and leaf-rolling artificial caterpillars in tropical forests of Papua New Guinea. Journal of Tropical Ecology 28:331341. 
Tzortzakaki O., Kati V., Panitsa M., Tzanatos E., and Giokas S. (2019) Butterfly diversity along the urbanization gradient in a densely-built Mediterranean city: Land cover is more decisive than resources in structuring communities. Landscape and Urban Planning 183:79-87.

Uchida K., Suzuki K., Shimamoto T., Yanagawa H., and Koizumi I. (2016) Seasonal variation of flight initiation distance in Eurasian red squirrels in urban versus rural habitat. Journal of Zoology 298:225-231.

US Census Data. (2019) Online database. Accessed 9 September 2020 from https://www.census.gov/quickfacts/jeffersoncountykentucky

US Climate Data. (2018) Online database. Accessed 10 September 2018 from https://www.usclimatedata.com/climate/louisville/kentucky/unitedstates/usky1846.

USDA Forest Service. (2018) Ecoregions of the United States. Online database. Accessed 10 September 2018 from https://www.fs.fed.us/rm/ecoregions/products/map-ecoregionsunited-states/\#.

U.S. Department of Agriculture. (2020) Summary Report: 2017 National Resources Inventory. Natural Resources Conservation Service, Washington, DC, and Center for Survey Statistics and Methodology, Iowa State University, Ames, Iowa. https://www.nrcs.usda.gov/wps/portal/nrcs/main/national/technical/nra/nri/results/

Vanbergen A.J., et al. (2013) Threats to an ecosystem service: Pressures on pollinators. Frontiers in Ecology and the Environment 11:251-259.

van Langevelde F., et al. (2018) Declines in moth populations stress the need for conserving dark nights. Global Change Biology 24:925-932. 
Verboven H.A.F., Uyttenbroeck R., Brys R., and Hermy M. (2014) Different responses of bees and hoverflies to land use in an urban-rural gradient show the importance of the nature of the rural land use. Landscape and Urban Planning 126:31-41.

Vergnes A., Le Viol I., and Clergeau P. (2012) Green corridors in urban landscapes affect the arthropod communities of domestic gardens. Biological Conservation 145:171-178.

Wang J.W., Poh C.H., Tan C.Y.T., Lee V.N., Jain A., and Webb E.L. (2017) Building biodiversity: Drivers of bird and butterfly diversity on tropical urban roof gardens. Ecosphere $\mathbf{8}$.

Wenzel A., Grass I., Belavadi V.V., and Tscharntke T. (2020) How urbanization is driving pollinator diversity and pollination—A systematic review. Biological Conservation 241.

Wilson C.J., and Jamieson M.A. (2019) The effects of urbanization on bee communities depends on floral resource availability and bee functional traits. Plos One $\mathbf{1 4 .}$

Yamaura Y., Kawahara T., Iida S., and Ozaki K. (2008) Relative importance of the area and shape of patches to the diversity of multiple taxa. Conservation Biology 22:1513-1522.

Yang B., Li B., He Y.X., Zhang L.P., Bruelheide H., and Schuldt A. (2018) Tree diversity has contrasting effects on predation rates by birds and arthropods on three broadleaved, subtropical tree species. Ecological Research 33:205-212.

Yoon S., and Read Q. (2016) Consequences of exotic host use: Impacts on Lepidoptera and a test of the ecological trap hypothesis. Oecologia 181:985-996.

Young A.M., Kohl P.L., Rutschmann B., Steffan-Dewenter I., Brockmann A., and Dyer F.C. (2021) Temporal and spatial foraging patterns of three Asian honey bee species in Bangalore, India. Apidologie. 


\title{
CURRICULUM VITA
}

\author{
Lindsay Nason \\ University of Louisville \\ Department of Biology
}

$2301 \mathrm{~S} 3^{\text {rd }} \mathrm{St}$

Louisville, Ky 40292

\section{$\underline{\text { Education }}$}

2021

Ph.D., Ecology, Evolution, \& Behavior, University of Louisville.

"Saving butterflies in the city: Gardens as conservation spaces in urban landscapes."

2015 B.S. in Biology, University of Louisville, summa cum laude

Honors Thesis: "The effect of predator positioning and related angles on the flight-initiation distance and refuge choice of the eastern gray squirrel.”

\section{$\underline{\text { Primary Research Interests }}$}

- Best practices for wildlife conservation 
- Effects of urbanization on species abundance, diversity and behavior

- Improving human-dominated landscapes to support increased biodiversity

\section{$\underline{\text { Awards }}$}

Dissertation Completion award (2021)

University Fellowship (2015-2020)

Earth Stewardship Initiative Fellow (2019)

\section{Publications}

Nason, L.D., Eason, P.K., Carreiro, M.M. et al. 2021. "Caterpillar survival in the city: attack rates on model lepidopteran larvae along an urban-rural gradient show no increase in predation with increasing urban intensity." Urban Ecosystems.

Eason, Perri K; Nason, Lindsay D.; Alexander, James E. Jr. 2019. "Squirrels Do the Math: Flight Trajectories in Eastern Gray Squirrels (Sciurus carolinensis).” Frontiers in Ecology and Evolution. 7:66

Fuselier, Linda; Carreiro, Margaret M.; Nason, Lindsay. 2018. "Invasive Species Management Impacts on Native and Nonnative Ferns in an Urban Forest Spore Bank.” Castanea. 83:28-37.

\section{$\underline{\text { Presentations }}$}


Munn, W, Nason, L, and Eason, P. (2020). The cityscape as a barrier to butterfly movement: butterflies avoid flying over buildings and tall fences when navigating urban areas. Abstract accepted for IU Animal Behavior Conference, Bloomington, Indiana. (Meeting canceled due to COVID)

Nalley, A, Costlow, M, Nason, L, and Eason, P. (2020). Flight behavior of the cabbage white butterfly (Pieris rapae) changes with habitat quality. Abstract accepted for IU Animal Behavior Conference, Bloomington, Indiana. (Meeting canceled due to COVID)

Nason, L and Eason, P. (2020). City slickers? The behavior of cabbage white butterflies (Pieris rapae) differs between urban and rural gardens. Abstract accepted for the International Society for Behavioral Ecology meeting, Melbourne, Australia. (Meeting canceled due to COVID)

Nason, L; Eason, P. (2019). The Importance of Gardens For Urban Butterfly Conservation. Poster. Entomological Society of America annual meeting, St. Louis, MO.

Nason, L; Eason, P. (2019). The Importance of Gardens For Urban Butterfly Conservation. Talk. Ecological Society of America annual meeting, Louisville, KY. Nason, L; Eason, P; Cherry, A; Lawson, J; Carreiro, M. (November 2018). Caterpillar Survival in Urban Gardens: Assessing Predation Rates on Models of Lepidopteran Larvae Along an Urban-Rural Gradient. Poster. Entomological Society of America annual meeting, Vancouver, BC, Canada. 
Eason, P; Nason, L; and Alexander, J. (April 2018). Squirrels Do the Math: Flight Trajectories in Eastern Grey Squirrels. Poster. IU Animal Behavior Conference, Bloomington, IN.

Nason, L. Urban Garden Butterfly Diversity (2017) Talk. Kentucky Society of Natural History, Louisville, KY.

\section{$\underline{\text { Grants }}$}

(2018) U of L Graduate Student Council travel grant (intramural) (2017) BGSA research grant (2017) Woody Boebinger Memorial Scholarship (Kentucky Society of Natural History).

\section{Teaching Experience}

Graduate Teaching Assistant, University of Louisville (2016-2020)

- Biol 240 honors recitation (Fall, 2020; 2 sections)

- Biol 244 2-credit majors lab (8 semesters; Spring, 2016-Fall, 2020; 11 total sections)

- Biol 102, 1-credit nonmajors lab (2 semester, Spring, 2019-Fall, 2019; 4 total sections)

Guest Lecturer, University of Louisville (2017-2020) 
- Presentation on writing talks for specific audiences for Biol 203 (Scientific Literacy and Communication); 2020

- Lecture on transforming data/histograms/introduction to using R for Biol 350 (Biostatistics); 2018

- Lecture on rules of probability/binomial distribution for Biol 350; 2018

- Lecture on biodiversity for Biology 102 (non-majors biology); 2017

Mentor to Undergraduate Researchers, University of Louisville (2017-2020)

- Ashley Nalley and Madeline Costlow (Spring 2020). "Differences in flight and forgaing behavior in cabbage white butterflies."

- Whena Munn (Summer and Fall 2019). "How urban barriers affect butterfly flight behavior."

- Amy Cherry and Jessica Raley (Summer 2018). "Effects of Volatiles on Predation of Model Caterpillars.”

- Amy Cherry, Jacob Lawson, Olivia Rumble, and Lauren Kappel (Summer 2017). "Predation of Model Caterpillars in Urban and Rural Gardens" and "Insect Pollinator Diversity in Gardens Across an Urban-Suburban Gradient."

STEM GTA mini-academy (Summer 2016)

- Learned and practiced techniques for more effective teaching

Tutor for the REACH program, University of Louisville (2014-2015) 
- Conducted small-group tutoring sessions at the Learning Resource Center (Intro biology for majors, genetics, animal behavior, comparative vertebrate anatomy)

\section{$\underline{\text { Service }}$}

- Biology Graduate Student Association Secretary (2019-2020)

- Biology Graduate Student Association Fundraising chair (2017-2018)

- Assisted maintenance of the Harriet A. Korfhage Native Plant Garden (20162020)

- Science Fair Judge for Louisville Regional Science and Engineering Fair (20172018)

- Mentored high school student Lucy Biberman for a science fair project on predation-response behavior of shell-dwelling cichlids. Project was presented at Louisville Regional Science \& Engineering Fair. (2017)

\section{Professional Development}

Earth Stewardship Initiative Fellow (August 2019)

- Worked with a team to make connections between city government, citizens, and other stakeholders to plan urban sustainability projects 
Assisted with the UofL/Charles Covell annual butterfly count at the Horner Wildlife Sanctuary (2017-2019), a 30-year project to document change in butterfly diversity.

- Surveyed an extensive natural area to record butterfly species and abundance data

Attended "Managing Pollinators in Natural Areas: A Synthesis of New Research and BMPs Presented at the 2017 NAC AND Resource-based Competition Between Managed and Wild Bees"; Natural Areas Association Webinar (2018)

Attended Saving the Planet - Starting in your Backyard: Workshop for Landowners on Sustainable Landscape Management” (2017) Locust Grove, Kentucky.

Intern, Louisville Nature Center (2014-2015)

- Led educational hikes

- Teaching assistant for educational programs

- Removed invasive plants from the Beargrass Creek State Nature Preserve

- Extracted native flora from an area awaiting development for the purpose of transplanting them onto the preserve

- Hammered live stakes into erosion control area

- Performed office duties, ie. data management, copying, printing, and placing/answering calls

- Opened/closed the bird blind 


\section{$\underline{\text { Research experience/skills }}$}

Dissertation research: How can urban gardens be improved to promote butterfly diversity and conservation? (2017-2020)

- Identified butterfly species using nonlethal techniques (binoculars, photography)

- Captured, marked, and released butterflies

- Estimated butterfly abundance

- Used scale maps to track butterfly flight patterns

- Recorded butterfly behavior observations

- Identified predators from marks left in artificial caterpillars

- Identified plant species

- Estimated plant biovolume density (a measure of plant cover that incorporates height and plant spacing)

- Estimated floral abundance

- Determined species diversity using Shannon's and Simpson's indices

- Performed statistical analyses using $\mathrm{R}$

- $\quad$ Estimated impervious surface cover using ArcGIS ${ }^{\circledR}$ and ArcMap ${ }^{\circledR}$

- Quantified visual data using ImageJ

- Directed undergraduate researchers

- Coordinated with multiple organizations/citizens for research site access and permissions

- Surveyed scientific literature 
- Planned research methods and adapted published protocols to fit urban gardens

Assisted Megan DeWhatley, graduate student, Department of Biology, University of Louisville (2016)

- Collected freshwater snails

Assisted Gavin Bradley, graduate student, Department of Biology, University of Louisville (2015)

- Collected data on the cave salamander (Eurycea lucifuga)

- Traversed cave environments, including narrow squeeze-through/crawling areas

Senior undergraduate honors project: Squirrel refuge choice and escape behavior (2015)

- Recorded squirrel behavior observations

- Reconstructed squirrel escape trajectories

- Transformed compass data into angular data

- Performed statistical analyses using R

Research assistant to William Persons, graduate student, Department of Biology, University of Louisville (2012-2014)

- Placed, monitored, and removed small animal traps 
- Assisted in marking research grid

- Recorded field data

- Prepared materials for field use

- Recorded data on materials collected from the field

\section{$\underline{\text { Honors }}$}

- University of Louisville Fellow (2015-2020)

- University of Louisville Honors Program (2011-2015)

- Biology Department Award (2014)

- Dean's Scholar (Fall 2011, Spring 2012, Fall 2013)

- Dean's List (Fall 2012, Spring 2013)

- Athletic Director's Honor Roll (2011-2015) 